\title{
Voted In, Standing Out: Public Response to Immigrants' Political Accession
}

\author{
Guy Grossman* Stephanie Zonszein ${ }^{\dagger}$
}

April 24, 2023

\begin{abstract}
How do dominant-group natives react to immigrants' political integration? We argue that ethnic minority immigrants winning political office makes natives feel threatened, triggering animosity. We test this dynamic across the 2010-2019 UK general elections, using hate crime police records, public opinion data, and text data from over 500,000 regional and local newspaper articles. While past work has not established a causal relationship between minorities' political power gains and dominant group animosity, we identify natives' hostile reactions with a regression discontinuity design that leverages close election results between immigrant-origin ethnic minority and dominant-group candidates. We find that minority victories increase hate crimes by $68 \%$, exclusionary attitudes by $66 \%$, and negative media coverage of immigrant groups by $110 \%$. Consistent with power threat and social identity theories, these findings demonstrate a strong and widespread negative reaction - encompassing a violence-prone fringe and the mass public - against ethnic minority immigrants' integration into majority settings.
\end{abstract}

Word count: 9,959

*Professor, University of Pennsylvania. Email: ggros@upenn.edu.

${ }^{\dagger}$ Assistant Professor, University of California, Berkeley. Email: szon@berkeley.edu. Corresponding author.

We thank Jacob Denenberg for excellent assistance collecting data on candidates' ethnic backgrounds, and Jennifer van Heerde-Hudson for kindly sharing the Parliamentary Candidates UK project data. We also thank Rafaela Dancygier, Fernanda Márquez-Padilla, Rahsaan Maxwell and Kevin Munger for helpful advice, and participants at the ITAM Alumni Conference 2021, PolMeth XXXVIII, 2021 APSA Annual Meeting, Online Political Economy Seminar Series 2021, the Development Economics Seminar at Hitotsubashi University, the Political Economy Seminar at Hebrew University, Harvard's Working Group in Political Psychology and Behavior, the department seminar at American University, IZA's 18th Annual Migration Meeting, ICRS's seminar at the University of Michigan, the Comparative Politics workshop at Texas AM University, UPenn's 4th Annual Conference on International Borders in a Globalizing World, and at Houston's Hobby School of Public Affairs seminar. 


\section{Introduction}

How do dominant-group natives respond to immigrant-origin ethnic minorities' integration into political institutions? ${ }^{1}$ It has long been argued that the economic and political ascendance of a minority group can trigger hostility from members of the majority group concerned by a real (Bobo, 1983) or perceived (Blumer, 1958) threat to the status quo. Hostility to minority groups can occur in response to structural social changes like population shifts (Blau, 1977) and economic restructuring (Sharma, 2015), or if previously disenfranchised groups increase their political power (Van Dyke and Soule, 2002). Such hostility, expressed as violence or exclusionary attitudes, is partly reactionary and can be a means of reasserting social control (King and Brustein, 2006).

Prior studies suggest that when immigrant-origin ethnic minorities integrate into political institutions, dominant-group natives will perceive this as a challenge to their power and social position (Dancygier, 2010). Using UK election results, we explore majority group members' responses to ethnic minority immigrants winning seats in Parliament.

Our study's theoretical expectations and research design are grounded in threat theory, which encompasses two related strands with similar observable implications for hostility to immigrant minorities. First, power threat theory explains intergroup conflict as a clash over valued scarce goods, including claims to social status and privilege (e.g. Blalock, 1967). Conflict in power threat theory is rooted in social-structural sources of group difference. Elections between ethnic minority and dominant-group candidates, under this theory, are a clash over economic, political and social resources. Losing to an ethnic minority candidate threatens dominant-group natives' control over those valued resources.

The starting point of the second strand of threat theory, social identity theory, is that individuals' sense of self is based on the status of the groups they belong to (Tajfel and Turner, 1979). Because people strive for positive self-worth, when these groups are negatively evaluated, people attempt to make their group more positively distinct. Hostility here, is thus based on threat related to group categorization and social status differentiation. Elections, in this context, inherently entail a social

${ }^{1}$ We use the term immigrant to refer to both first- and later-generation immigrants. We use it interchangeably with the term ethnic minority, as many of the numerically sizable minority groups in rich democracies have immigrant origins. 
comparison. Dominant-group natives consider an electoral loss as a threat to their social identity, and in turn their self-worth.

Both strands of threat theory imply that minority political victories trigger threats against the dominant group, either rooted in concerns about resources or about social status. Both strands also assume that conflict results from dominant-group desires to suppress such threats. The close correspondence we find between hostility against immigrant minorities and minority electoral victories underscores the political role of threat and of dominant-group efforts to counter it.

Our study addresses two limitations of prior studies, which contend that when marginalized groups gain political power, the dominant group responds with greater hostility. In a first limitation, past work has struggled to establish a causal relationship between minorities' political power gains and dominant-group hostile responses. Common proxy measures such as the size of the minority group (Quillian, 1995) do not necessarily capture the group's political power, even though they indirectly measure competition for scarce resources. Studies that capture minorities' political power with direct measures - such as the ratio of minority-to-majority votes in recent elections (D'Alessio, Stolzenberg and Eitle, 2002), the share of legislators that are members of the minority group (Van Dyke and Soule, 2002), and whether a minority holds mayoral office (Jacobs and Wood, 1999) - are vulnerable to identification concerns. Particularly, these studies do not account for unobserved factors determining both minority political power and hostility against minorities. We address these concerns using a regression discontinuity design of close parliamentary elections, comparing constituencies where a minority candidate narrowly wins to constituencies where a minority candidate narrowly loses.

Second, previous work is ambiguous about which members of the majority group respond negatively to gains in minority political power. Much of the existing literature focuses on violent backlash in the form of hate crimes (Dugan and Chenoweth, 2020), lynchings (Hovland and Sears, 1940), and inter-racial killings (D'Alessio, Stolzenberg and Eitle, 2002); it does not evaluate whether such negative behavior is more widely shared among majority group members. Although some studies have established a correlation between minority political power gains and mass public opinion (e.g. Quillian, 1996), it is unclear whether the conditions that trigger a violent backlash also generate less extreme (attitudinal) responses. We address this concern by exploring - within the context of a 
single (electoral) event - outcomes at two different societal levels: hate crimes, a behavior at the tail of the societal distribution, and attitudes toward migrants, which captures mass public opinion. The media possibly profits from these electoral events. As such, we corroborate our results on the mass public by gathering data on newspapers' tone towards migrant groups, which reflects the response of 'fourth estate' elites to the election results, as well as their expectations regarding readers' increased engagement.

Leveraging close results between immigrant-origin ethnic minority and dominant-group candidates in the 2010 to 2019 UK general elections, we find that a minority victory triggered hostility against minority communities. In constituencies where ethnic minority candidates narrowly won a parliamentary seat, compared to where they narrowly lost, the subsequent hate crime rate is significantly higher. Three months after the election we identify an effect of 0.88 standard deviations, which corresponds to a $68 \%$ increase in hate crimes relative to the average hate crime rate in constituencies where minority candidates narrowly lost. We further provide evidence that this effect likely captures an increase in hate crime incidence, and not merely in reporting. As for the mass public, we find that minority victories also shape mass attitudes toward immigrants, significantly increasing the share of those who state that too many immigrants have been let into the UK. The size of the effect corresponds to a $66 \%$ decrease in inclusionary attitudes (or 0.65 standard deviations). The media response is consistent with that of the mass public. We computed a measure of negative speech about a candidate's ethnic group, by analyzing text with Natural Language Processing (NLP) tasks from over 500,000 newspaper articles that we matched to the ethnic background of the candidates and to their constituencies. Three months after the election, we detect a 0.66 standard deviations difference between the proportion of negative mentions of the narrow winners' and narrow losers' ethnic groups.

Our paper contributes to the literature on intergroup conflict that is rooted in Blalock's 1967 original conceptualization of threat theory. While the correlation between minority political power gains and majority-group hostility has been established, we provide causal estimates of such animosity. We also show within a single event that the hostility to minority group's political gains is not limited to a violence-prone fringe; it is also observed among the mass public. Supporting the main mechanism in our argument - threat, we provide empirical evidence consistent with material and 
status threat-triggering concerns: subgroup analyses show that hostile responses are concentrated on candidates who pose a greater threat to the status quo - for example, Muslim and women candidates, and those who belong to left-leaning parties, which are more likely to support redistributive policies that challenge existing social hierarchies. Consistent with the mass public response, increased negative media reporting is most evident in right-wing newspapers, which arguably target a dominant group segment that is most threatened by pluralistic values and redistribution.

We advance the literature on hate crime targeting minority ethnic groups. We enrich work on situational trigger events, which hitherto focused on reactions to unexpected shocks (Dipoppa, Grossman and Zonszein, 2022), and to minorities perpetrating terror attacks (Deloughery, King and Asal, 2012) and serious felonies (Jäckle and König, 2018). We demonstrate that minorities can trigger a similar violent response by winning parliamentary elections, arguably because their political ascendance heightens dominant group members' sense of threat to their dominant position.

A small number of studies has assessed variation in media coverage of immigration based on immigrant-related events (mostly terrorist attacks perpetrated by members of minority groups); these focus on national media coverage (e.g. Bleich, Nisar and Abdelhamid, 2016). We assess instead whether (and how) media coverage of migrants changes in response to ethnic minorities integrating into host country political institutions. Our study contributes to the political communication literature by showing that the electoral success of a migrant group changes the amount and type of national and local media coverage it receives. Media coverage changes possibly to heighten the public's engagement, given the election context and the public's response to the election result.

\section{Minority political accession and intergroup hostility}

We argue that dominant-group natives respond with hostility to ethnic minority electoral victories as they trigger socio-structural threats (discussed in power threat theory) and identity threats (established in social identity theory). 


\section{Power threat theory}

A central tenet of minority-group threat theories is that real or perceived intergroup competition for scarce resources can provoke hostility. Group conflict involves objective competition between members of different groups as well as the subjective perception that outgroup members threaten the dominant group's valued resources, norms, and traditions.

Power threat theory provided the theoretical foundation for a long-standing body of interdisciplinary research on inter-ethnoracial relations. ${ }^{2}$ According to this perspective, minorities who start occupying spaces traditionally dominated by an ethnic majority group are perceived as a threat to the majority's social, political, and economic resources. Empirically, this body of work consistently finds a positive correlation between the relative size of a minority population and hostility toward that group (Green, Strolovitch and Wong, 1998). As the relative size of the minority population increases, the threat increases as well-for example, by heightening interethnic competition for scarce resources like jobs, housing, education, and health care (i.e., an economic and social threat (Jackson, 1989)), or by increasing the potential for minority political mobilization (i.e. a political threat (Leighley, 2001)). As such threats increase, the willingness of (some) dominant group members to allow minorities into 'their' spaces decreases, and denigration of minorities increases.

Evidence of such a dynamic has been provided by linking the relative size (change in size or rank) of a minority population to hate crimes (e.g., Cikara, Fouka and Tabellini, 2021), and negative attitudes toward ethnoracial minorities (e.g. Schlueter and Scheepers, 2010) and immigrants (e.g. Alba, Rumbaut and Marotz, 2005). Prior research has also discussed threat-triggering conditions other than the relative size of a minority group. Blalock (1967)'s central link between intergroup conflict and competition for scarce resources has naturally been extended to economic conditions. Worsening economic circumstances among dominant group members (Sharma, 2015), like job loss (Van Dyke and Soule, 2002) and unemployment (Mayda, 2006), have also been found to trigger hostility against minorities. In addition to minority-group threat theories based on competition for material resources, the hostile response to changing ethnic demographics in rich democracies has also been explained as a reaction to a cultural (Hainmueller and Hopkins, 2014), and

\footnotetext{
${ }^{2}$ See Riek, Mania and Gaertner (2006) for a useful review.
} 
national identity threat (Sniderman, Hagendoorn and Prior, 2004), and to the mere exposure to immigrants (Hangartner et al., 2019).

A handful of studies addresses the political threat aspect of minority-group threat theory. D'Alessio, Stolzenberg and Eitle (2002), for example, use the ratio of Black-to-White votes cast

in South Carolina to measure the threat to the dominant group's political status. Jacobs and Wood (1999) likewise find a significant relationship between the presence of Black US mayors and White killings of Blacks. In discussing ethnic conflict, Hardin (1995) conceptualizes public office as a positional good that is fundamental in the allocation of distributional goods like welfare benefits. Relatedly, Dancygier (2010) explains that immigrant-native conflict in the UK arises from immigrants' costly material demands, to which political parties are responsive. Natives attack immigrant-origin minorities when their presence allegedly reduces natives' material welfare. As such, Dancygier (2010) finds a positive association between the share of minorities in local councils and anti-immigrant hostility, but only under conditions of economic scarcity.

\section{Social identity theory}

According to social identity theory, individuals form their identities and define their interests based on group membership, and evaluate their own group by comparing its attributes to those of other groups (Tajfel and Turner, 1979). Importantly for our context, an outgroup becomes a target of comparison when circumstances, such as elections, make it more salient. When a comparison against an outgroup is unsatisfactory, people attempt to make their group more positively distinct. The goal of such a differentiation is to maintain or achieve social superiority - and by extension, a more positive self-worth. As such, the process of group differentiation is essentially competitive. Insofar as social differentiation rests on comparisons related to status, social competition is expected to be linked to intergroup hostility, as individuals seek to change their group's social position.

\section{Minority electoral victory as a threat}

Power threat and social identity theories both imply that losing an election to an ethnic minority candidate poses threats to the resources and status of the dominant group; majority-group members 
thus react aggressively to suppress such threats. Building on power threat theory, we argue that electoral competitions between ethnic minority and dominant-group candidates establish an arena for intergroup competition for a diverse set of valuable resources. Elections contested by candidates from different ethnic groups are often seen as a way to accommodate coethnic preferences (Dancygier, 2010). Therefore, losing an election to a minority candidate threatens the dominant group's access to such resources. Building on social identity theory, we argue that elections between ethnic minority and dominant-group candidates trigger intergroup competition for social status. An electoral loss may produce negative feelings and hostile behavior because it has direct implications on a dominant-group member's standing and sense of self (Huddy, Mason and Aarøe, 2015).

Political entrepreneurs may capitalize on these socio-structural and identity threats, increasing the election results' salience and the hostile response to minority victories. When elections take place along ethnoracial lines, political elites have incentives to stoke communal grievances to mobilize voters (Horrowitz, 1985). Such mobilization heightens ethnic identification and ethnocentrism (Eifert, Miguel and Posner, 2010), which is frequently expressed as hostility against outgroups. Even when political elites do not exploit elections along ethnoracial lines, we argue that the result of these elections, on its own, may trigger hostility against minorities. Elections contested by ethnic minority candidates may operate as an external stimulus (or informational cue about the size, growth, and mobilization capacity of ethnic minority groups) that connects the dominant group's changing local demographic, economic, and political context with their behavior and attitudes toward minorities. Such a stimulus (or informational cue) reinforces the hostile response to losing an election to an ethnic minority candidate. Indeed, past work demonstrates that providing information to dominant group members about changing ethnic demographics triggers concerns about their status, standing, and potential vulnerabilities, which in turn, promote the denigration of ethnic minorities (Craig, Rucker and Richeson, 2018), and moreover, that dominant group members react more strongly to a changing local demographic context when primed by external stimuli that reinforce that threat (Hopkins, 2010). 


\section{Ethnic minority candidates and Members of Parlia- ment (MPs) in the UK}

We test the above argument using the case of minority candidates in close parliamentary elections in the UK. The number of ethnic minority candidates has been increasing over time, in part due to a 2010 agreement between the three largest parties to set internal targets to increase minorities' representation. In the last four general elections (2010-2019), ethnic minority candidates have run in $58 \%$ of England and Wales's parliamentary constituencies and have won in $28 \%$ of the elections they contested. The number of ethnic minority MPs has thus increased during this period from 26 to 65 (10\% of members of the House of Commons). ${ }^{3}$

MPs in the UK are constituency oriented, and the personal relationships they cultivate with their constituents make them highly visible. About $66 \%$ of British constituents can spontaneously recall the name of their MP; twice the recall level of US Members of Congress (McKay, 2020). The turn towards a focus on constituency services was set in motion by the post-war welfare state, which increased citizens' interactions with the state as they navigated a complex set of rules and eligibility criteria. Recent reforms in Parliament - such as the foundation of the Backbench Business Committee - have further reinforced the centrality of constituency concerns (McKay, 2020). Although parliamentary institutions restrict individual MPs' ability to engage in redistribution, MPs often trade off their time to participate in government-opposition debate (one of their most fundamental resources) for constituency representation, and are frequently involved in local casework, even when matters are legally the responsibility of local government, like housing (Crewe, 2015).

Existing evidence suggests that ethnic minority politicians are more eager than their White counterparts to represent minorities. For example, Minority MPs (especially those who do not belong to the Conservative Party) are more likely to believe that racism has held back British minorities, and that it is their duty to address inequalities by prioritizing minority concerns (Sobolewska, McKee and Campbell, 2018). On the demand side, immigrants believe that coethnic politicians better understand and act on their communities' interests (Bloemraad, 2006).

\footnotetext{
${ }^{3}$ This total is still below the number (93 MPs) that would reflect the ethnic make-up of the UK population (Uberoi and Tunnicliffe, 2021).
} 
In this context, control over political office by a member of an ethnic minority group can be viewed as a threat to the privileged position of the dominant group. Such a threat may be more salient when the increased political presence of ethnic minorities is backed by institutional efforts to increase their representation (King and Brustein, 2006), such as the 2010 multi-party agreement mentioned above. The threat may be based on objective conditions of competition: ethnic minority MPs are more likely to advocate redistributive policies that benefit their fellow group members and may use constituency services to redirect attention to marginalized groups. However, such threats can also be based on the perception that ethnic minority MPs threaten the hierarchical social order: the presence of ethnic minority politicians in Parliament may signal the demise of a 'White political elite' (Clark, 1994). Moreover, minority politicians have been shown to increase minorities' sense of political efficacy and boost their political participation - and thus the prospect of electing more minority-group representatives (Maxwell, 2012). We study a context in which ethnic minority political victories could be thought as jeopardizing the resources and status of dominant group members and may thus lead to hostility towards minorities.

\section{Data and outcome measures}

We measure violent animosity as the number of police-recorded hate crimes each month. Hate crime offenders are not representative of the broader public: in the UK, most are White, male and under 25 years old (Roberts et al., 2013). Thus, hate crimes cannot approximate the mass public's response. We instead measure the mass response with public opinion data on attitudes toward immigrants. Finally, to substantiate the mass response, we assess the media response using the valence of newspaper articles about candidates' ethnic groups. We collect this data for the longest period available covering the general elections from 2010 to 2019.

\subsection{Hate crimes}

Data We use monthly counts of police-recorded hate crimes in England and Wales desegregated by Community Safety Partnership (CSP) and Local Authority District (LAD) from April 2014 to September 2020. We obtained this data from the Home Office via a Freedom of Information request 
by offense sub-code for racially or religiously aggravated offenses (e.g. 'racially or religiously aggravated assault with injury') and equivalent non-aggravated offenses (e.g. 'assault with injury'). ${ }^{4}$ The data contains 327,840 hate crimes, $61 \%$ of which occurred in post-election months and constituencies in which minority candidates ran for Parliament.

Outcomes We measure violence against ethnic minorities as the number of hate crimes per 1,000 residents reported each month in a given constituency. We treat the month of the general election as the first month and focus on crimes committed up to 9 months later, which corresponds to the maximum period of crime data available after the 2019 election as provided by the Home Office. As a placebo outcome, we use the monthly constituency crime rate of equivalent offenses that are not motivated by race or religion. Appendix B describes the process we used to assign hate crimes from LADs to parliamentary constituencies, including a validation exercise.

\subsection{Mass public opinion}

Data Public opinion data are from the 2010, 2015, 2017 and 2019 waves of the British Election Study, which are face-to-face post-election surveys fielded immediately after a general election and are representative of UK eligible voters. We focus on White respondents; for comparability, we subset the data to England and Wales, for which we have hate crime data. ${ }^{5}$ Pooling all survey rounds generates a sample of 2,200 respondents in constituency-elections where minority candidates ran for a seat in Parliament and have at least one respondent in $45 \%$ of these constituency-elections. We analyze the data at the individual level since it is not representative of constituencies.

Outcomes Following the migration literature (e.g. Scheve and Slaughter, 2001; Schwartz et al., 2021), we approximate inclusionary attitudes toward immigrants with attitudes toward immigration entry policy. In particular, we rely on a question included in the last three post-election surveys that asks whether too many immigrants have been let into the UK. To assess the robustness of our

\footnotetext{
${ }^{4}$ We do not have information from 30 CSPs that do not use offense sub-codes to report hate crimes, or information about perpetrators' and victims' ethnicity. We cannot assess whether victims share a candidate's ethnicity.

${ }^{5}$ Appendix I.8 shows that results are robust to including Scotland.
} 
results, we compute two additional outcomes that use all other available survey items on attitudes toward immigration and ethnic minorities. These items were either included in all survey years, but the wording of questions and answers (and their range) changed, or were not included for all four elections. We use an index of left-right views on topics unrelated to immigration as a placebo outcome. Appendix C describes the survey items and how the outcome variables were computed.

\subsection{Media tone toward migrant groups}

Data We use data from over 500,000 articles from 350 national, regional, and local UK newspapers, from 2010-2019. This data is from Common Crawl, which is an open repository of web crawl data. We assume that an article refers to a candidate's ethnic group when three conditions are met: 1) the publication date is within 10 months after each general election (the maximum between the 2019 election and the most recent article), 2) the article mentions terms referring to the candidate's country or nationality of origin (extracted with CoreNLP named entity annotator) and 3) such mentions co-occur in the article with a reference to the candidate's constituency (extracted by tokenizing the article and finding tokens that match place names in the Index of Place Names in Great Britain, and mapping to the corresponding constituency). This data includes almost 150,000 mentions from 156 newspapers that meet these three conditions.

Outcomes Using CoreNLP's five-category sentiment annotator, we compute a measure of media tone about the candidate's ethnic group. From the relevant articles, we extract the sentiment of the sentences that mention the candidate's country and nationality. Our main outcome is the ratio between negative valence mentions and total mentions about the candidate's ethnic group each month. We focus on such a ratio rather than on the number of negative mentions, because the result of the election may increase the salience of the winning candidate's ethnic group. We also compute the proportion of positive- and neutral-valence mentions, which we use to assess the general increase in salience.

To increase confidence in our main measure of tone, we compute a placebo measure-mentions of countries and nationalities in North America, Western Europe, and Oceania in the candidate's constituency, which should not be affected by the identity of the winning candidate. Appendix D 
describes the process we used to gather newspaper data and compute the outcome measures. It also discusses the validity of the named entity and sentiment annotators, and their advantages compared to other methods of measuring the tone of the text.

\subsection{Election results and candidates' ethnic backgrounds}

Data General election results data from 2010 to 2019 are from the Electoral Commission. We construct a binary variable of a parliamentary candidate's ethnicity as either White or Black, Asian, and minority ethnic (BAME). We identify the ethnic origin of candidates based on their country of birth, and their parents and grandparents' countries of birth. Appendix E provides details.

In the last four general elections, 923 ethnic minority candidates from 334 constituencies stood for Parliament in England and Wales, with increasing numbers over time (Figure E.1a). Because our estimation strategy is based on the strongest minority candidate in each constituency, our sample is of 662 candidates with $28 \%$ winners. These candidates are fairly split between the two main parties and across geographical areas (Figure E.1b and E.1c).

\subsection{Constituency characteristics}

We use data from the 2001 and 2011 Census to compute characteristics of a constituency that may determine both an ethnic minority win and an outcome of interest: the constituency population share that is foreign born, ethnic or religious minority, or unemployed; the share of households with high levels of deprivation; population density and vote share for the right-wing UK Independence Party or British National Party in the previous election. Table A.1 presents the summary statistics for our main outcome, treatment and control variables.

\section{Estimation method}

We test whether the accession of members of immigrant-origin ethnic minority groups to political office triggers hostility to immigrant communities using a sharp regression discontinuity (RD) design. Thus, we compare our outcome measures between constituencies in which minority candidates narrowly win vs. narrowly lose (or equivalently, where dominant-group candidates narrowly win). 
This design allows us to causally identify hostility effects because constituencies where a minority candidate narrowly wins or loses to a dominant-group candidate are, on average, otherwise identical.

In our RD design the score is the constituency's ethnic minority margin of victory defined as the vote share of the strongest ethnic minority candidate minus the vote share of his or her strongest dominant-group opponent. Therefore, an ethnic minority candidate must be on the ballot to include a constituency in our estimation sample. This is the case for $58 \%$ of the constituencies in England and Wales across the four last elections. The RD strategy estimates a local average treatment effect that is representative of these constituencies (Table F.1 characterizes them).

For our estimation, we use local polynomial methods to fit two separate regression functions above and below the victory cutoff. The estimated RD effect is thus computed as the difference between the two estimated intercepts. Formally, we estimate the following weighted linear regression:

$$
\begin{aligned}
& Y_{i t m}=\alpha+\beta_{1} \text { VictoryMargin } \\
& i t \\
& \quad \beta_{2}\left(\text { EthnicMinorityVictory } y_{i t} \cdot \text { VictoryMargin }_{i t}\right)+X_{i}+\epsilon_{i t m},
\end{aligned}
$$

where $Y_{i t m}$ is one of our outcome variables measured for constituency $i$ in election year $t$, and month $m$ after the election. ${ }^{6}$ VictoryMargin $i t$ is the score, which controls for the minority's voteshare winning margin and EthnicMinorityVictory $y_{i t}$ is a dummy variable indicating that a minority candidate won the election $\left(\mathbf{I}\left(\right.\right.$ VictoryMargin $\left.\left._{i t}>0\right)=1\right)$. The weights are computed with a triangular kernel of the distance between each observation's score and the cutoff. These kernel-based estimators require a bandwidth for implementation (observations outside the bandwidth receive zero weight). Following common practice, we select an optimal bandwidth that minimizes the mean squared error (MSE) of the RD estimate (Calonico, Cattaneo and Titiunik, 2014). For implementation, we use rdrobust software.

The quantity of interest is $\tau$ which, under the assumption of continuity of the expected potential outcomes at the cutoff, captures the local average treatment effect at the cutoff of an ethnic

\footnotetext{
${ }^{6}$ Media tone is measured for ethnic group e, constituency $i$, election year $t$, and month $m$, and the public opinion outcomes are measured for individual $j$, in constituency $i$ in election year $t$; therefore the outcome and error term are indexed as eitm, jit, respectively.
} 
minority victory on our outcomes. ${ }^{7}$ Because we are pooling observations across elections, $\tau$ does not necessarily recover the average of all the single-election minority victory effects, as the number of close elections changes over time. Instead, $\tau$ reflects the pooled effect (Sekhon and Titiunik, 2012). For efficiency gains, we control for predetermined characteristics of candidates (e.g. incumbency), constituencies (listed in Section 4.5), and survey respondents (for public opinion outcomes). $X_{i}$ captures a vector of such characteristics. ${ }^{8}$

We cluster the standard errors $\epsilon_{i t m}$ by constituency-election to account for the dependence of hate crimes and media tone within a constituency over time after an election, and for the dependence of respondents' attitudes within a constituency and election year. Below we report conventional point estimates and robust bias-corrected inferences. ${ }^{9}$

\section{$6 \quad$ Results}

\subsection{Hate crimes}

Figure 1a presents the effect of minority candidates' victory on the incidence of hate crimes 3 months after the election. To the right of the victory cutoff, the line (with $95 \%$ confidence intervals) depicts the average monthly hate crime rate in constituencies where minority candidates win, for different values of the victory margin. To the left of the cutoff, the line shows the average monthly hate crime rate in constituencies where minority candidates lose. These lines show that there is a jump at the victory cutoff: when a minority candidate goes from narrowly losing to narrowly winning a seat in Parliament, hate crimes in the candidate's constituency increase by 7 per 100,000 residents.

\footnotetext{
${ }^{7}$ Below we report empirical tests supporting this assumption.

${ }^{8}$ For public opinion outcomes we have $X_{j i t}$. Our covariate-adjusted estimator estimates the same quantity as the unadjusted estimator when covariates are continuous at the cutoff, and are included linearly, additive-separably, and without interacting them with the treatment (Cattaneo, Idrobo and Titiunik, 2019). Our estimation complies with these conditions.

${ }^{9}$ Marshall (2022) argues that RD effect estimates of elected politician characteristics suffer from potential bias from compensating differentials. This concern is most relevant to studies assessing politicians' actions. We assess instead constituents' actions. If candidate characteristics affect hostility, our estimates are then a compound treatment effect of candidates' ethnicity and other factors like competence.
} 
This means that a minority win results in an additional 4.9 hate crimes in the average constituency (which contains about 70,000 eligible voters) in the 3 months after an election. Such an effect is equivalent to 0.88 standard deviations and corresponds to a $68 \%$ increase in hate crimes relative to the average hate crime rate in constituencies where minority candidates barely lose. Table 1 reports the point estimate from Figure 1a with robust bias-corrected inference, as well as point estimates using half the MSE-optimal bandwidth, and a fixed bandwidth of 10 percentage points.

Figure 1: Ethnic minority victory effects on hate crime

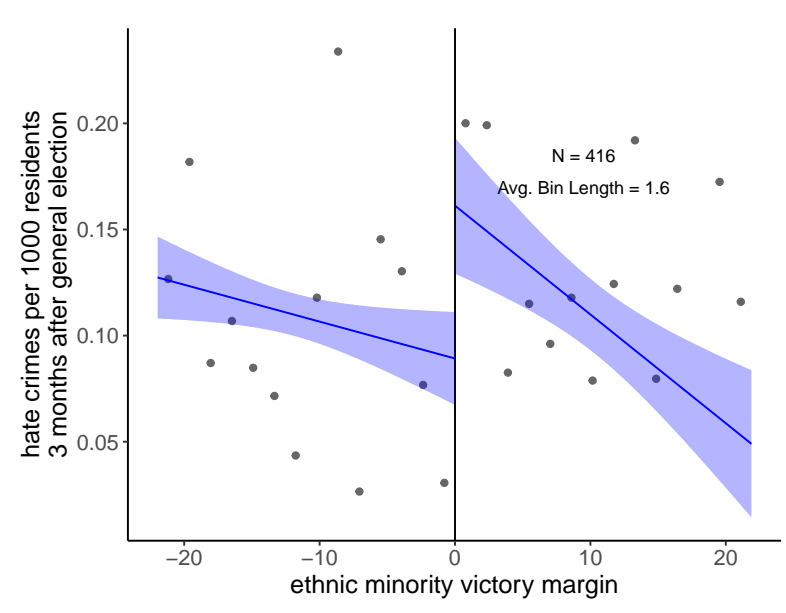

(a) 3 months after general election

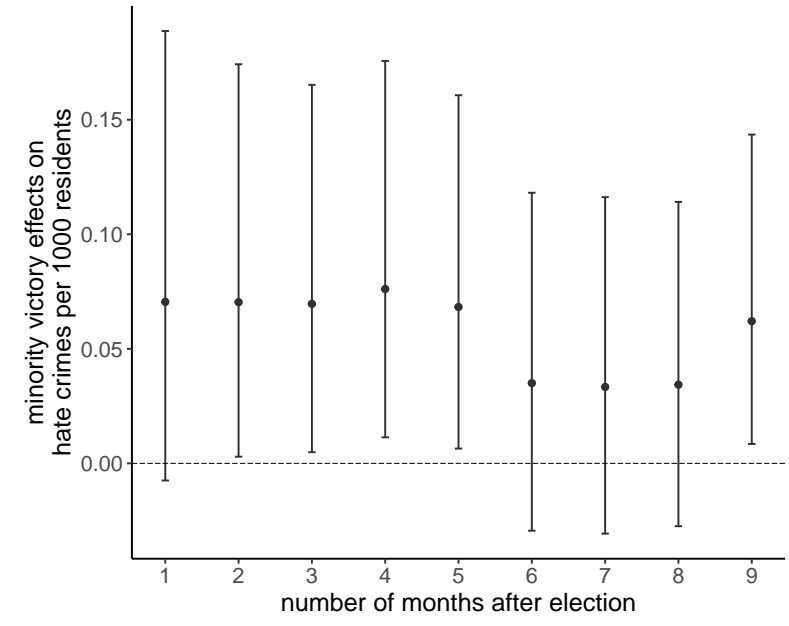

(b) 1-9 months after general election

Notes: In (a) lines are average monthly hate crime rates (with $95 \%$ confidence intervals) from local linear regression with covariate adjustment fitted to the sample of units within the MSE-optimal bandwidth of $+/-22$ percentage points around the victory cutoff. Points are average monthly hate crime rates for equally spaced mimicking-variance bins. In (b) points are conventional RD estimates of minority victory effects and lines depict $95 \%$ robust bias-corrected confidence intervals. These confidence intervals are centered around the robust bias-corrected estimate rather than the conventional RD estimate.

Figure 1b displays estimates of the victory effects on hate crime by the number of months since the general election. While it provides suggestive evidence that these effects decay over time, the effects are not statistically distinguishable from each other across months. Table G.1 presents these effect estimates, estimates of their inference, the size of the MSE-optimal bandwidth, and the effective sample size (i.e., number of observations within the bandwidth). It also reports estimates from a specification that does not include predetermined covariates. Across specifications, the effects are in the same direction and of a similar magnitude and are statistically significant when we control 
Table 1: Ethnic minority victory effects on hate crime

\begin{tabular}{lccc}
\hline & \multicolumn{3}{c}{ Outcome: } \\
& Hate crimes per & 1000 residents \\
\cline { 2 - 4 } & $(1)$ & $(2)$ & $(3)$ \\
\hline I(VictoryMargin $>0)=1$ & 0.070 & 0.102 & 0.105 \\
& $(0.041)$ & $(0.038)$ & $(0.038)$ \\
\hline Mean DV control & 0.103 & 0.065 & 0.062 \\
\hline $\mathrm{R}^{2}$ & 0.317 & 0.536 & 0.553 \\
Num. eff. obs. & 416 & 200 & 184 \\
Num. obs. & 2080 & 2080 & 2080 \\
N Clusters & 520 & 520 & 520 \\
Using bandwidth & 22.285 & 11.143 & 10.000 \\
MSE-optimal bandwidth & 22.285 & 22.285 & 22.285 \\
\hline
\end{tabular}

Notes: The dependent variable is monthly hate crimes per 1000 residents in a constituency 3 months after election. Average treatment effect at cutoff estimated with local linear regression with triangular kernel and MSE-optimal bandwidth in (1), half MSEoptimal in (2) and fixed at 10pp in (3). In parenthesis standard errors robust bias-corrected and clustered by constituency-election. Models control for predetermined covariates.

for predetermined covariates.

Validity tests and robustness checks The RD estimates would be invalid if candidates sort around the winning threshold, in which case observations on either side of the cutoff might not be comparable. Following common practice to validate our design, we conduct density tests, which show that the approximate number of observations just above the cutoff is not significantly different from the number of observations just below it, and covariate tests that seek to show null RD effects on relevant predetermined variables. To ensure that there are no other threats to the validity of our results, we conduct a series of tests, which demonstrate that our results are not sensitive to the bandwidth choice or to the order of the fitted polynomials, and a series of robustness checks, including testing placebo outcomes, ruling out possible hate crime reporting biases (by using only violent hate crimes), and estimating effects with a difference-in-differences approach. Appendix $G$ presents these tests, which support the validity of our results. 


\subsubsection{Theoretically-driven Subgroup Analysis}

Grounded on theories of threat, we assess whether ethnic minorities' accession to political office interacts with five conditions that arguably make minority victories more threatening: 1) local conditions, such as migrant influx and economic downturn, are presumed to affect perceptions of relative deprivation, which would heighten the zero-sum nature of electoral competition and therefore the likelihood of a hostile response, 2) whether a candidate is Muslim, as this may raise concerns about 'threats to British life' for dominant group members susceptible to ethnocentric movements, and possibly also for cosmopolitans whose socially liberal inclinations do not square with Islamic values (Dancygier, 2017), 3) candidates' gender, as hate crime perpetrators (mostly

White males) may be concerned about women entering historically men-dominated institutions, and furthering women's interests (e.g. Catalano, 2009), 4) candidates' political affiliation, as Labour-affiliated minorities have a more liberal ideology on racial and social spending issues, and are more likely to address long-standing inequalities by prioritizing minority concerns (Sobolewska, McKee and Campbell, 2018), which may trigger stronger concerns among dominant-group members who favor the status quo, and 5) whether a constituency elects an ethnic minority candidate for the first time, activating new threat perceptions. In Appendix H, we consider whether, rather than threat, the hostile response to a minority victory is driven by the participation of UKIP and the party's mobilization around Brexit. We show that UKIP is not likely to be a central explanation.

Figure G.10a of Appendix G.12 illustrates that the effect of a minority win on hate crimes in constituencies with a high influx of migrants over the decade before the election is larger and statistically distinguishable from the estimate of the effect in constituencies with a low influx of migrants (the test statistic of the difference in coefficients is $t=2.14$ ). However, in contrast to Dancygier (2010)'s finding that immigrants' political power provokes immigrant-native conflict only in poorer areas, we find that, while larger, the effect of a minority win in constituencies with a high increase in unemployment over the decade before the election is indistinguishable from that in constituencies with a low unemployment increase (test-statistic is $t=0.69$ ).

Moreover, we find suggestive evidence that minority victories have a stronger effect on hate crime if the candidate has a Muslim background (Figure G.11a), and if the candidate is a woman (Figure G.11b). We also find that the hate crime response is concentrated in constituencies where 
candidates belong to left-leaning parties (Figure G.12a). Conservative minority candidates and MPs not only do not prioritize minority concerns as their Labour counterparts do, but their political ideology is also appealing to the voters who are more likely to negatively respond to minorities winning office (Karpowitz et al., 2021). A Conservative minority win therefore does not pose a threat to the status quo in the same way that a Labour minority win does, thus muting the hostile response. ${ }^{10}$ This finding suggests an interaction effect between candidates' ethnic minority background and political affiliation. Tellingly, when we focus on constituencies where only White candidates stand for Parliament, we do not find that a White Labour close victory increases hate crimes after the election; the coefficients are close to zero and statistically insignificant (Figure G.12b). That is, a candidate's political affiliation plays a role in hostility only insofar as the candidate has an ethnic minority background.

Finally, if a minority win serves as an information cue that changes threat perceptions, then a violent response should be more likely in constituencies that elect a minority for the first time. While our model specification isolates incumbency effects, ${ }^{11}$ we assess this expectation by controlling for an indicator of whether a constituency has had an ethnic minority MP at least once prior to any of the elections in our sample. We find that the RD estimate shrinks and is not statistically significant when we control for this variable (Figure G.10b), suggesting that the hate crime response to minority wins is concentrated mainly in constituencies that elect minorities for the first time.

\subsection{Mass public opinion}

Figure 2 presents the main effect of minority candidates' victory on mass attitudes toward immigrants. To the right of the victory cutoff, the line (with $95 \%$ confidence intervals) shows the average proportion of White respondents who do not think that "too many immigrants have been let into the country" in constituencies where minority candidates have won. To the left of the threshold, the line depicts the proportion of White respondents with such an opinion in constituencies where

\footnotetext{
${ }^{10} \mathrm{~A}$ complementary explanation is that Conservative minority candidates compete in more White and homogeneous constituencies with fewer intergroup interactions (Byrne et al., 2020).

${ }^{11} 21 \%$ of the constituency-elections in our sample are represented by incumbents, and $44 \%$ of the winning candidates in the optimal bandwidth are incumbents.
} 
minority candidates lost. These lines indicate a drop at the victory threshold: when a minority candidate goes from barely losing to barely winning a seat in Parliament, the proportion of White respondents who hold inclusionary attitudes toward immigrants decreases by 30 percentage points. This effect is equivalent to 0.65 standard deviations and corresponds to a $66 \%$ decrease in inclusionary attitudes relative to the average attitude in constituencies where minority candidates narrowly lose. Table 2 shows the point estimate from Figure 2 with robust bias-corrected inference, as well as point estimates using half the MSE-optimal bandwidth, and a fixed bandwidth of 10 percentage points. Because public opinion data is sparse, we refrain from assessing subgroup effects in this section, given power constraints.

Figure 2: Ethnic minority victory effects on attitudes toward immigrants

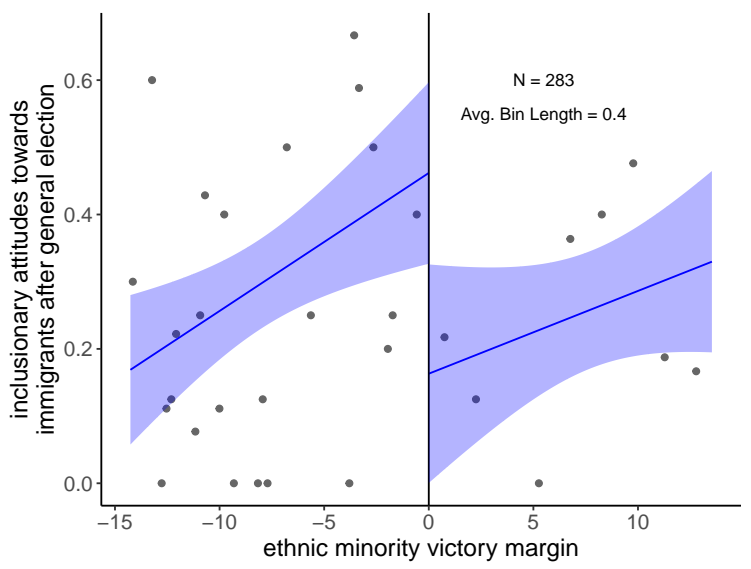

Notes: Lines indicate the average proportion of respondents who do not think that "too many immigrants have been let into the country" (with 95\% confidence intervals) from local linear regression with covariate adjustment fitted to the sample of units within the MSE-optimal bandwidth of $+/-$ 14.3 percentage points around the victory cutoff. Points denote the average proportion of respondents who do not think that "too many immigrants have been let into the country" for equally spaced mimicking-variance bins.

Validity tests and robustness checks Table I.2 (rows 4-6) present the effect estimates and all other relevant statistics for model specifications with and without covariates. The RD estimates are consistent and statistically significant across specifications. Appendix I reports an extensive series of further tests (including RD validity, falsification and placebo checks) that ensure the validity of our public opinion results. 
Table 2: Ethnic minority victory effects on attitudes towards immigrants

\begin{tabular}{lccc}
\hline & \multicolumn{3}{c}{ Outcome: } \\
& $\begin{array}{c}\text { Inclusionary attitudes } \\
\text { towards immigrants }\end{array}$ \\
\cline { 2 - 4 } & $(1)$ & $(2)$ & $(3)$ \\
\hline I(VictoryMargin $>0)=1$ & -0.295 & -0.238 & -0.242 \\
& $(0.056)$ & $(0.066)$ & $(0.083)$ \\
\hline Mean DV control & 0.445 & 0.338 & 0.408 \\
\hline $\mathrm{R}^{2}$ & 0.117 & 0.229 & 0.150 \\
Num. eff. obs. & 283 & 104 & 174 \\
Num. obs. & 1876 & 1876 & 1876 \\
N Clusters & 275 & 275 & 275 \\
Using bandwidth & 14.331 & 7.166 & 10.000 \\
MSE-optimal bandwidth & 14.331 & 14.331 & 14.331 \\
\hline
\end{tabular}

Notes: The dependent variable indicates whether survey respondent do not thinks that "too many immigrants have been let into the country". Average treatment effect at cutoff estimated with local linear regression with triangular kernel and MSE-optimal bandwidth in (1), half MSE-optimal in (2) and fixed at 10pp in (3). In parenthesis standard errors robust bias-corrected and clustered by constituency-election. Models control for predetermined covariates.

\subsection{Media tone toward migrant groups}

In this section we test whether minority victories affect media reporting. There are two reasons to explore the media response. First, unlike hate crimes for which we do not know the victim's ethnic and racial background, and public opinion data where questions are broadly about immigrants and minorities, the newspaper data allows us to measure responses targeting a candidate's ethnic group. Second, the media possibly profits from the public's engagement with elections contested and won by ethnic minority candidates. A growing body of work has demonstrated that social identity cues, especially cues espousing out-group animosity (Rathje, Van Bavel and Van Der Linden, 2021) and a negative tone (Robertson et al., 2023), are increasingly driving heightened engagement with media content. Moreover, media elites are acutely aware of this trend (Klein, 2020). Therefore, given increasing pressure to intensify consumer engagement (Munger, 2020), editors and media executives are likely to pander to consumers by covering stories related to core social identities (Hopkins, Lelkes 
and Wolken, 2023) with a negative valence. Thus, without ruling out the possibility that media may also shape public opinion (Grossman, Margalit and Mitts, 2022), media content analysis can help corroborate changes in mass attitudes toward minority migrant groups.

Figure $3 a$ illustrates our main finding on the media tone toward migrant groups. The line (with 95\% confidence intervals) to the right of the victory cutoff indicates the average monthly proportion of negative mentions of the winning candidate's ethnic group 3 months after the general election, and to the left the average monthly proportion of negative mentions of the losing candidate's ethnic group. These lines depict a jump in the proportion of negative mentions at the winning threshold. The estimated magnitude of this increase in negative media coverage is 20 percentage points (or 0.67 standard deviations), which is equivalent to a $110 \%$ increase relative to the average proportion of negative mentions of the ethnic groups of narrowly losing candidates. Table 3 presents the point estimate from Figure 3 a with robust bias-corrected inference, as well as estimates using half the MSE-optimal bandwidth, and a fixed bandwidth of 10 percentage points. Such media animosity targets a candidate's ethnic group, rather than the candidate as an individual. Fewer than $1 \%$ of the articles used in this analysis include mentions of the minority candidates.

Figure $3 b$ displays the estimates of minority victory effects on media tone by the number of months since the election. We find suggestive evidence that the effects decay over time. The RD estimates of the effects of a minority win decrease in size around the seventh month after the election, but the monthly effects are not statistically distinguishable from each other.

Validity tests and robustness checks Table J.1 presents the effect estimates and other relevant quantities for various model specifications. Across specifications, the effects are in the same direction and have a similar magnitude and are statistically significant when we control for covariates. Appendix J reports the findings of an extensive series of tests (e.g. RD validity, falsification, and placebo checks ${ }^{12}$ ) that further confirm the validity of our media results.

\footnotetext{
${ }^{12}$ We do not compute difference-in-differences estimates as in the hate crime analysis because our media tone measure (specific to the minority candidates' ethnicity) is unspecified for constituencies without minority candidates.
} 
Figure 3: Ethnic minority victory effects on media tone

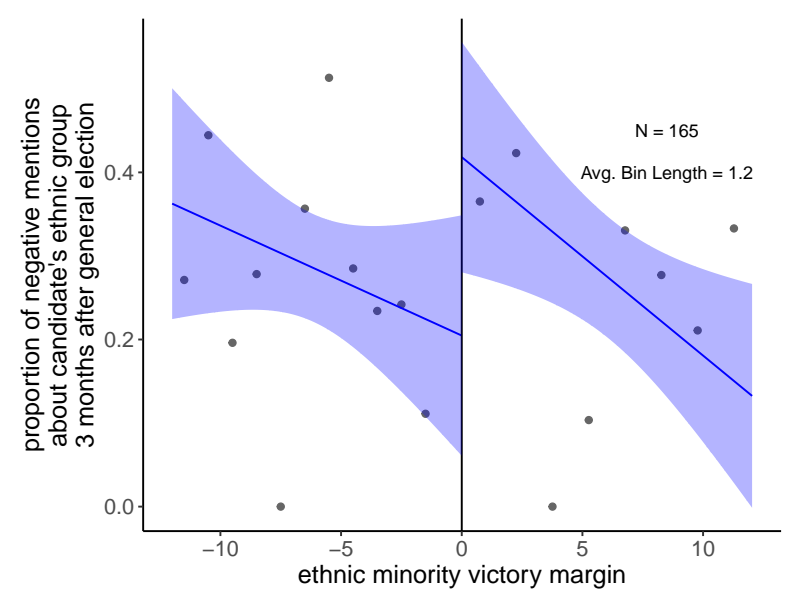

(a) 3 months after general election

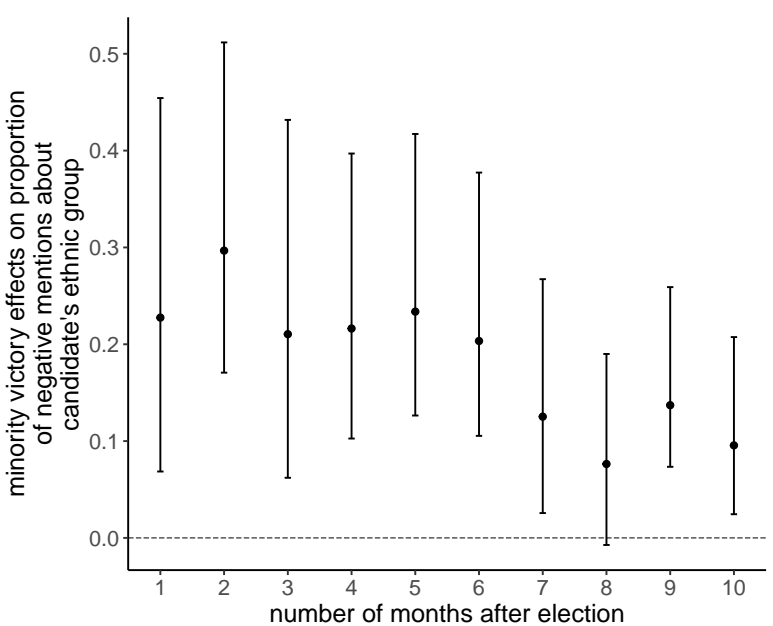

(b) 1-10 months after general election

Notes: In (a) lines indicate the average monthly proportion of negative mentions of a candidate's ethnic group (with 95\% confidence intervals) from local linear regression with covariate adjustment fitted to the sample of units within the MSE-optimal bandwidth of $+/-12$ percentage points around the victory threshold. Points denote the average monthly proportion of negative mentions of a candidate's ethnic group for equally spaced mimicking-variance bins. In (b) points are conventional RD estimates of the effect of an ethnic minority victory and lines $95 \%$ robust bias-corrected confidence intervals.

\subsection{Additional analysis of media tone and salience}

We showed above that media coverage of a winning minority candidate's ethnic group is increasingly negative. Negative valence is recognized to increase the public's news engagement (e.g. Robertson et al., 2023), but also, regardless of valence, coverage of stories about social identities attracts the public's interest (e.g. Hopkins, Lelkes and Wolken, 2023). If editors and media executives are leveraging the public's response to the election context, then we would expect increased coverage of a winning candidate's migrant ethnic group. Here we assess such a possibility. Based on threat concerns that arise from a minority win (related to economic considerations and social status), we then assess whether the resulting negative rhetoric is stronger among segments of society that are predisposed to react to such concerns. We focus on right-wing media, since it is more responsive to those threatened by minorities' electoral victory.

Figure 4a illustrates that there are more media mentions about the ethnic communities of narrow winners than narrow losers: 3 months after the election, there are 20 more mentions of 
Table 3: Ethnic minority victory effects on media tone about migrant groups

\begin{tabular}{lccc}
\hline & \multicolumn{3}{c}{$\begin{array}{c}\text { Outcome: } \\
\text { News articles' negative } \\
\text { mentions (share) }\end{array}$} \\
\cline { 2 - 4 } & $(1)$ & $(2)$ & $(3)$ \\
\hline I(VictoryMargin $>0)=1$ & 0.210 & 0.706 & 0.296 \\
& $(0.094)$ & $(0.218)$ & $(0.167)$ \\
\hline Mean DV control & 0.193 & 0.025 & 0.129 \\
\hline $\mathrm{R}^{2}$ & 0.229 & 0.401 & 0.266 \\
Num. eff. obs. & 165 & 90 & 138 \\
Num. obs. & 1314 & 1314 & 1314 \\
N Clusters & 438 & 438 & 438 \\
Using bandwidth & 12.134 & 6.067 & 10 \\
MSE-optimal bandwidth & 12.134 & 12.134 & 12.134 \\
\hline
\end{tabular}

Notes: The dependent variable is monthly share of negative mentions in news articles about a candidate's ethnic group 3 months after election. Average treatment effect at cutoff estimated with local linear regression with triangular kernel and MSE-optimal bandwidth in (1), half MSE-optimal in (2) and fixed at 10pp in (3). In parenthesis standard errors robust bias-corrected and clustered by constituency-election. Models control for predetermined covariates.

narrow winners (significant at the $10 \%$ level). This increase in media attention is concentrated on speech with a specific valence. We find statistically significant increases in the proportion of negative and positive mentions (equivalent to 0.66 and 0.47 standard deviations, respectively, 3 months postelection), but not neutral mentions (of 0.09 standard deviations, Figure 4b). Furthermore, at least during the first 4 months after the election, the increase in attention is predominantly negative, when we compare the share of negative to neutral mentions (Table K.1).

Overall, we find that minority wins increase hostility from the news media. This is mostly driven by right-wing newspapers and papers with circulation under 25,000 (Appendix K), suggesting that the negative response comes from media whose readership favors less redistribution, compensatory policies, and pluralistic values. 
Figure 4: Ethnic minority victory effects on media attention and tone

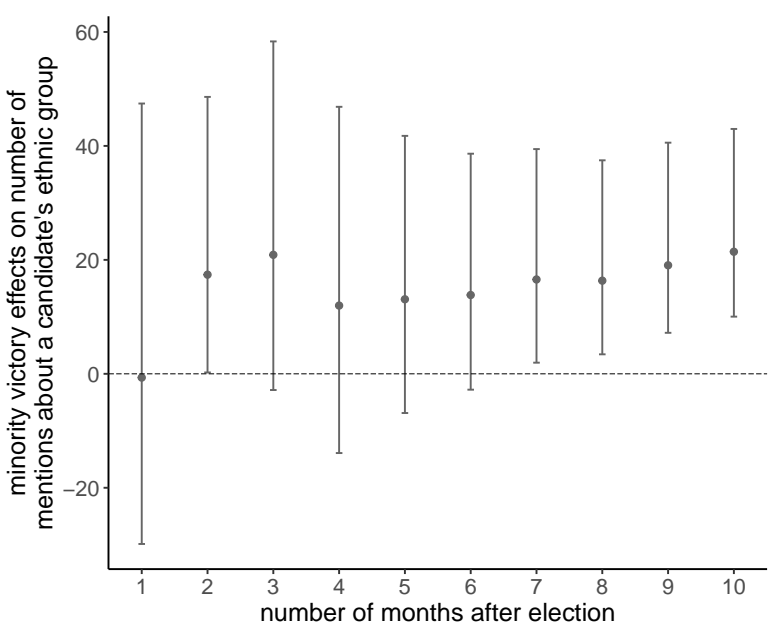

(a) Effects on media attention

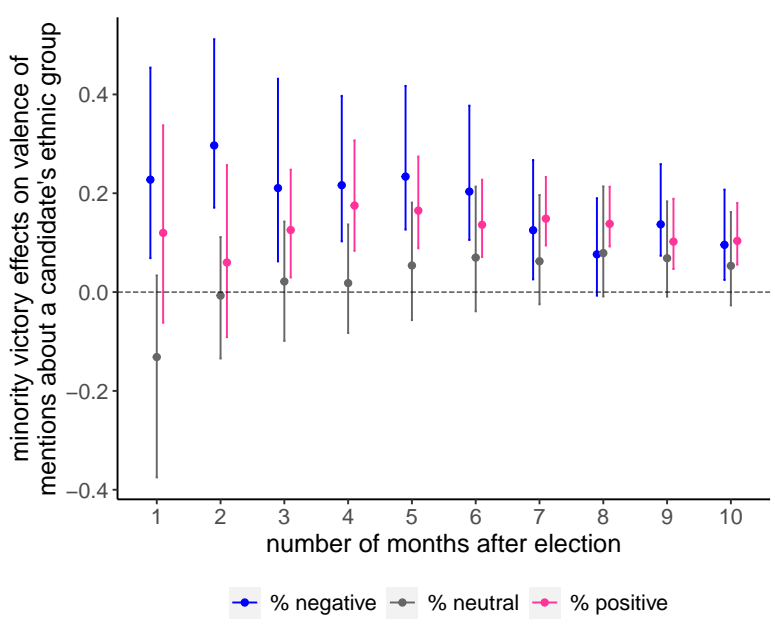

(b) Effects on media tone

Notes: Points are conventional RD estimates of the effect of an ethnic minority victory. Lines denote $95 \%$ robust bias-corrected confidence intervals.

\section{Discussion}

We argue that dominant-group natives respond with hostility to threats triggered by ethnic minority electoral victories, and that this response is stronger when (predetermined) local conditions or candidate characteristics reinforce such threats. It is only observed in constituencies with a large migrant arrival (right side of Figure G.10a) and left-affiliated candidates (Figure G.12a), both of which threaten access to material resources and (national or cultural) identity. The response is also stronger when candidates' Muslim background (Figure G.11a) or gender (Figure G.11b) threatens voters' identity, and among right-wing media (Figure K.1b), whose readership likely has more concerns about material and identity threats.

Our study sharpens the debate about why electoral victories by ethnic minorities trigger a hostile response. We find support for the argument that minority victories produce an information shock that reminds members of the dominant group of their changing ethnic demographic landscape (Craig, Rucker and Richeson, 2018), but that other sources of information exacerbate the hostility of the reaction. The reaction is stronger where the information confirms changes that people observe in their environment (e.g. a large migrant arrival, right side of Figure G.10a), when the information is novel (e.g. when a minority wins a constituency for the first time, Figure G.10b), and if the 
information is recent (soon after the election, Figures $1 \mathrm{~b}$ and 3b). Moreover, the effect of a minority victory on threat concerns changes as more information becomes available. We find that the effects weakly decay over time (Figures $1 \mathrm{~b}$ and $3 \mathrm{~b}$ ) and are concentrated in constituencies with no prior experience of a minority victory (Figure G.10b). Once members of the dominant group realize that minority office holding does not involve high levels of ingroup favoritism, as documented in previous work (e.g Bhalotra et al., 2014), the hostility subsides.

These results - together with the finding that local economic conditions do not moderate the victory effects (left side of Figure G.10a) - suggest that hostile responses are caused by threats based on group categorization and differentiation (i.e. status threats) as well as possible social-structural sources of group difference (i.e. objective material threats), even though these are notoriously hard to separate (Manekin, Grossman and Mitts, 2019). Future work should help clarify which dimension of group threat - threat to group status or material threat - has the greatest impact in this and other settings.

Consistent with theories which suggest that elite mobilization fuels communal grievances for their political benefit, our results point to a hostile response from both media elites and the mass public. The news media can shape the public's political attitudes and electoral behavior (Grossman, Margalit and Mitts, 2022), but market pressures also incentivize media outlets to cover issues that resonate with their audiences' priorities (Gentzkow and Shapiro, 2010), and public sentiment is often reflected by newsworthy political events in themselves, like election results. While our study is not designed to determine the direction of influence, there are good reasons to expect media elites to respond to consumers' growing interest - in the context of a minority victory - in social identity and intergroup relations content. ${ }^{13}$

\section{Conclusion}

Using an RD design of close parliamentary elections in the UK, we identify the effects of immigrantorigin ethnic minority candidates winning political office on the attitudes and behavior of dominant

\footnotetext{
${ }^{13}$ Appendix J.8 discusses and establishes independence between our measures of hate crime and media tone.
} 
group members. We find that such victories result in an increase in hate crimes, in exclusionary attitudes toward immigrants as captured by mass public opinion, and in negative tone in the coverage of a winning candidate's ethnic group in local and national newspapers.

An ethnic minority candidate winning a seat in Parliament triggers a hostile reaction because it threatens the position of dominant group members. The animosity we identify in response to election outcomes is especially troubling because it is so widespread, encompassing not only a violence-prone fringe, but also the mass public. This finding contributes to the intergroup conflict literature, which has not yet specified which members of the majority group are most likely to respond with hostility to a heightened outgroup threat. Our study's findings also raise important questions regarding the role of elections in intergroup conflict and the nature of the threat that causes a hostile response. While the structure of our data prevents us from addressing all of these questions conclusively, they suggest important avenues for future work.

From a normative perspective, it is somewhat reassuring that the hostility to minority communities we identify is temporal. Thus perhaps on balance, the positive outcomes associated with the election of immigrant-origin minorities outweigh the negative effects of such animosity. Future research should address this question and identify policies that can counteract the hostile response to immigrants' integration.

The RD effects we estimate are representative of constituencies where ethnic minority candidates stand for Parliament, which are distinct from the average constituency in dimensions related to immigrant demographics and their settlement choices (Table F.1). Moreover, the RD effects are identified at the victory threshold, where elections between dominant-group and ethnic minority candidates are the most competitive. Future work should use a different research design to investigate the magnitude of effects in non-competitive elections. Finally, it is reasonable to predict that the hostile dynamics we document may generalize to other multicultural rich democracies with firstpast-the-post electoral systems, and where the majority ethnic group is also the dominant group. We hope our single-country study motivates future research in other contexts. 


\section{References}

Alba, Richard, Ruben G Rumbaut and Karen Marotz. 2005. "A distorted nation: Perceptions of racial/ethnic group sizes and attitudes toward immigrants and other minorities." Social forces 84(2):901-919.

Bhalotra, Sonia, Irma Clots-Figueras, Guilhem Cassan and Lakshmi Iyer. 2014. "Religion, politician identity and development outcomes: Evidence from India." Journal of Economic Behavior \&3 Organization 104:4-17.

Blalock, Hubert M. 1967. Toward a theory of minority-group relations. Vol. 325 New York: Wiley.

Blau, Peter Michael. 1977. Inequality and Heterogeneity: A Primitive Theory of Social Structure. Vol. 7 Free Press New York.

Bleich, Erik, Hasher Nisar and Rana Abdelhamid. 2016. "The effect of terrorist events on media portrayals of Islam and Muslims: evidence from New York Times headlines, 1985-2013." Ethnic and Racial Studies 39(7):1109-1127.

Bloemraad, Irene. 2006. Becoming a citizen: Incorporating immigrants and refugees in the United States and Canada. University of California Press.

Blumer, Herbert. 1958. "Race prejudice as a sense of group position." Pacific sociological review $1(1): 3-7$.

Bobo, Lawrence. 1983. "Whites' opposition to busing: Symbolic racism or realistic group conflict?" journal of personality and social psychology 45(6):1196.

Byrne, Bridget, Claire Alexander, Omar Khan, James Nazroo and William Shankley. 2020. Ethnicity, Race and Inequality in the UK: State of the Nation.

Calonico, Sebastian, Matias D Cattaneo and Rocio Titiunik. 2014. "Robust nonparametric confidence intervals for regression-discontinuity designs." Econometrica 82(6):2295-2326.

Catalano, Ana. 2009. "Women acting for women? An analysis of gender and debate participation in the British House of Commons 2005-2007." Politics \& Gender 5(1):45-68.

Cattaneo, Matias D, Nicolás Idrobo and Rocío Titiunik. 2019. A practical introduction to regression discontinuity designs: Foundations. Cambridge University Press.

Cikara, Mina, Vasiliki Fouka and Marco Tabellini. 2021. "Hate crime increases with minoritized 
group rank.".

Clark, Terry Nichols. 1994. "Race and class versus the new political culture." Urban innovation pp. 21-78.

Craig, Maureen A, Julian M Rucker and Jennifer A Richeson. 2018. "Racial and political dynamics of an approaching "majority-minority" United States." The ANNALS of the American Academy of Political and Social Science 677(1):204-214.

Crewe, Emma. 2015. The House of Commons: An anthropology of MPs at work. Bloomsbury Publishing.

D'Alessio, Stewart J, Lisa Stolzenberg and David Eitle. 2002. "The effect of racial threat on interracial and intraracial crimes." Social Science Research 31(3):392-408.

Dancygier, Rafaela M. 2010. Immigration and Conflict in Europe. Cambridge University Press.

Dancygier, Rafaela M. 2017. Dilemmas of Inclusion: Muslims in European Politics. Princeton University Press.

Deloughery, Kathleen, Ryan D King and Victor Asal. 2012. "Close cousins or distant relatives? The relationship between terrorism and hate crime." Crime $\&$ Delinquency 58(5):663-688.

Dipoppa, Gemma, Guy Grossman and Stephanie Zonszein. 2022. "Locked Down, Lashing Out: Situational Triggers and Hateful Behavior Towards Minority Ethnic Immigrants." Journal of Politics .

Dugan, Laura and Erica Chenoweth. 2020. "Threat, emboldenment, or both? The effects of political power on violent hate crimes." Criminology 58(4):714-746.

Eifert, Benn, Edward Miguel and Daniel N Posner. 2010. "Political competition and ethnic identification in Africa." American Journal of Political Science 54(2):494-510.

Gelman, Andrew and Guido Imbens. 2019. "Why high-order polynomials should not be used in regression discontinuity designs." Journal of Business 63 Economic Statistics 37(3):447-456.

Gentzkow, Matthew and Jesse M Shapiro. 2010. "What drives media slant? Evidence from US daily newspapers." Econometrica 78(1):35-71.

Green, Donald P, Dara Z Strolovitch and Janelle S Wong. 1998. "Defended Neighborhoods, Integration, and Racially Motivated Crime." American Journal of Sociology 104(2):372-403.

Grossman, Guy, Yotam Margalit and Tamar Mitts. 2022. "How the Ultra-Rich Use Media Ownership 
as a Political Investment." Journal of Politics .

Hainmueller, Jens and Daniel J Hopkins. 2014. "Public attitudes toward immigration." Annual review of political science 17:225-249.

Hangartner, Dominik, Elias Dinas, Moritz Marbach, Konstantinos Matakos and Dimitrios Xefteris. 2019. "Does exposure to the refugee crisis make natives more hostile?" American political science review 113(2):442-455.

Hardin, Russell. 1995. One for All: The Logic of Group Conflict. Princeton University Press.

Hopkins, Daniel J. 2010. "Politicized places: Explaining where and when immigrants provoke local opposition." American political science review 104(1):40-60.

Hopkins, Daniel J., Yphtach Lelkes and Samuel Wolken. 2023. "The Rise of and Demand for Identity-Oriented Media Coverage." Unpublished manuscript .

Horrowitz, Donald L. 1985. Ethnic groups in conflict. University of California Press.

Hovland, Carl Iver and Robert R Sears. 1940. "Minor Studies of Aggression: VI. Correlation of Lynchings with Economic Indices." The Journal of Psychology 9(2):301-310.

Huddy, Leonie, Lilliana Mason and Lene Aarøe. 2015. "Expressive partisanship: Campaign involvement, political emotion, and partisan identity." American Political Science Review 109(1):1-17.

Jäckle, Sebastian and Pascal D König. 2018. "Threatening events and anti-refugee violence: An empirical analysis in the wake of the refugee crisis during the years 2015 and 2016 in Germany." European Sociological Review 34(6):728-743.

Jackson, Pamela Irving. 1989. Minority group threat, crime, and policing: Social context and social control. Greenwood Publishing Group.

Jacobs, David and Katherine Wood. 1999. "Interracial conflict and interracial homicide: Do political and economic rivalries explain white killings of blacks or black killings of whites?" American Journal of Sociology 105(1):157-190.

Karpowitz, Christopher F, Tyson King-Meadows, J Quin Monson and Jeremy C Pope. 2021. "What Leads Racially Resentful Voters to Choose Black Candidates?" The Journal of Politics 83(1):103121.

King, Ryan D and William I Brustein. 2006. "A Political Threat Model of Intergroup Violence: Jews in Pre-World War II Germany." Criminology 44(4):867-891. 
Klein, Ezra. 2020. Why we're polarized. Simon and Schuster.

Leighley, Jan E. 2001. Strength in numbers?: The political mobilization of racial and ethnic minorities. Princeton University Press.

Manekin, Devorah, Guy Grossman and Tamar Mitts. 2019. "Contested ground: Disentangling material and symbolic attachment to disputed territory." Political Science Research and Methods $7(4): 679-697$.

Marshall, John. 2022. "Can close election regression discontinuity designs identify effects of winning politician characteristics?" American Journal of Political Science .

Maxwell, Rahsaan. 2012. Ethnic minority migrants in Britain and France: Integration trade-offs. Cambridge University Press.

Mayda, Anna Maria. 2006. "Who is against immigration? A cross-country investigation of individual attitudes toward immigrants." The Review of Economics and Statistics 88(3):510-530.

McKay, Lawrence. 2020. "Does constituency focus improve attitudes to MPs? A test for the UK." The Journal of Legislative Studies 26(1):1-26.

Munger, Kevin. 2020. "All the news that's fit to click: The economics of clickbait media." Political Communication 37(3):376-397.

Quillian, Lincoln. 1995. "Prejudice as a response to perceived group threat: Population composition and anti-immigrant and racial prejudice in Europe." American sociological review pp. 586-611.

Quillian, Lincoln. 1996. "Group threat and regional change in attitudes toward African-Americans." American Journal of Sociology 102(3):816-860.

Rathje, Steve, Jay J Van Bavel and Sander Van Der Linden. 2021. "Out-group animosity drives engagement on social media." Proceedings of the National Academy of Sciences 118(26):e2024292118.

Riek, Blake M, Eric W Mania and Samuel L Gaertner. 2006. "Intergroup threat and outgroup attitudes: A meta-analytic review." Personality and social psychology review 10(4):336-353.

Roberts, Colin, Martin Innes, Matthew L. Williams, Jasmin Tregidga and David Gadd. 2013. "Understanding who commits hate crimes and why they do it.".

Robertson, Claire E, Nicolas Pröllochs, Kaoru Schwarzenegger, Philip Pärnamets, Jay J Van Bavel and Stefan Feuerriegel. 2023. "Negativity drives online news consumption." Nature Human Behaviour pp. 1-11. 
Scheve, Kenneth F and Matthew J Slaughter. 2001. "Labor market competition and individual preferences over immigration policy." Review of Economics and Statistics 83(1):133-145.

Schlueter, Elmar and Peer Scheepers. 2010. "The relationship between outgroup size and antioutgroup attitudes: A theoretical synthesis and empirical test of group threat-and intergroup contact theory." Social Science Research 39(2):285-295.

Schwartz, Cassilde, Miranda Simon, David Hudson and Jennifer van Heerde-Hudson. 2021. "A populist paradox? How Brexit softened anti-immigrant attitudes." British Journal of Political Science 51(3):1160-1180.

Sekhon, Jasjeet S and Rocio Titiunik. 2012. "When natural experiments are neither natural nor experiments." American Political Science Review 106(1):35-57.

Sharma, Smriti. 2015. "Caste-based crimes and economic status: Evidence from India." Journal of Comparative Economics 43(1):204-226.

Sniderman, Paul M, Louk Hagendoorn and Markus Prior. 2004. "Predisposing factors and situational triggers: Exclusionary reactions to immigrant minorities." American political science review 98(1):35-49.

Sobolewska, Maria, Rebecca McKee and Rosie Campbell. 2018. "Explaining motivation to represent: how does descriptive representation lead to substantive representation of racial and ethnic minorities?" West European Politics 41(6):1237-1261.

Tajfel, Henri and John Turner. 1979. An integrative theory of intergroup conflict.

Uberoi, Elise and Richard Tunnicliffe. 2021. "Ethnic diversity in politics and public life." House of Commons Library. Available from: https://commonslibrary.parliament.uk/ research-briefings/sn01156/.

Van Dyke, Nella and Sarah A Soule. 2002. "Structural social change and the mobilizing effect of threat: Explaining levels of patriot and militia organizing in the United States." Social Problems 49(4):497-520.

Young, Lori and Stuart Soroka. 2012. "Affective news: The automated coding of sentiment in political texts." Political Communication 29(2):205-231. 


\section{Part}

\section{Online Supplementary Information}

\section{Table of Contents}

A Table of summary statistics

B Assignment of hate crimes from LADs into parliamentary constituencies

B.1 Validation of assignment of hate crimes from LADs . . . . . . . . . . . 1

C Survey items used in measurement of public opinion $\quad 3$

D Newspaper data, computation of media tone measures and validation of key elements

E Data collection on candidates' ethnic minority background

F Selection of constituencies into the sample

G Minority victory effects on hate crimes: validity of the RD design, robustness checks and supporting results

G.1 Continuity of placebo outcomes . . . . . . . . . . . . . . . . . . . 11

G.2 Continuity of main outcome before general election . . . . . . . . . . . . 12

G.3 Continuity of predetermined variables . . . . . . . . . . . . . . . 12

G.4 Density of the running variable . . . . . . . . . . . . . . . . . 12

G.5 Sensitivity to the choice of bandwidth and order of polynomials . . . . . 13

G.6 Controlling for candidate's political party . . . . . . . . . . . . . . . . . 14

G.7 Main RD results in tabular form . . . . . . . . . . . . . . . . . . . . 14

G.8 Assessing a hate crime decay in minority barely lost constituencies . . . . 14

G.9 Difference-in-differences . . . . . . . . . . . . . . . . . . . . 15

G.10 Testing for possible hate crime reporting bias . . . . . . . . . . . . . 19

G.11 Brief discussion of hate crime spillover . . . . . . . . . . . . . . . 19

G.12 Subgroup effects on hate crime . . . . . . . . . . . . . . . 20

H Analysis of political campaign issues $\quad 21$

H.1 UKIP/Brexit Party electoral participation . . . . . . . . . . . . . 23

I Minority victory effects on mass public attitudes: validity of the RD design, robustness checks and supporting results 
I.1 Continuity of placebo outcomes . . . . . . . . . . . . . . . . 24

I.2 Density of the running variable . . . . . . . . . . . . . . 25

I.3 Continuity of outcome before general election . . . . . . . . . . . 26

I.4 Continuity of predetermined variables . . . . . . . . . . . 26

I.5 Sensitivity to the choice of bandwidth and polynomials . . . . . . . . 26

I.6 Controlling for candidate's political party . . . . . . . . . . . . 26

I.7 Additional attitudinal outcomes . . . . . . . . . . . . . . . . . 28

I.8 Including Scotland . . . . . . . . . . . . . . . . . . . . . . . . . . . 29

$\mathrm{J}$ Media tone towards migrant groups: validity of the RD design, robustness checks and supporting results $\quad \mathbf{3 0}$

J.1 Continuity of placebo outcomes . . . . . . . . . . . . . . . . . 30

J.2 Density of the running variable . . . . . . . . . . . . . . . 31

J.3 Continuity of predetermined variables . . . . . . . . . . . . . . . 31

J.4 Continuity of main outcome before general election . . . . . . . . . . . 32

J.5 Sensitivity to the choice of bandwidth and order of polynomial . . . . . 33

J.6 Main RD results in tabular form . . . . . . . . . . . . . . . . . . 33

J.7 Controlling for candidate's political party . . . . . . . . . . . . . 33

J.8 Is the media tone measure independent from the hate crimes measure? . . 33

K Explaining effects on media attention and tone $\quad 34$ 


\section{A Table of summary statistics}

In Table A.1 we present summary statistics for our main outcomes, treatment, and predetermined covariates, including characteristics of the candidates and constituencies.

\section{B Assignment of hate crimes from LADs into parliamen- tary constituencies}

Local Authority Districts are a level of subnational division used for the purposes of local government. As such, district boundaries may include more than one parliamentary constituency, and constituencies may cross district boundaries. On average, districts contain 2 constituencies $(78 \%$ include more than one) and about 30\% of the constituencies cross district boundaries.

In order to compute hate crime rates at the constituency level we assign the LAD crime rate per 1,000 population to each constituency within a LAD, and for constituencies which cross LAD borders, we assign the average LAD crime rate weighted by population overlap, using the wards' population within a constituency and district to compute the weight. When a ward crosses constituency boundaries (251 wards out of 8297 ), we split the ward's population proportionally by the constituency size.

\section{B.1 Validation of assignment of hate crimes from LADs}

To validate the measure of hate crime at the constituency level, we use the assignment rule described above to infer the share of the ethnic minority population at the constituency level and we compare it with the observed share. Figure B.1 shows that the inferred and observed shares are strongly correlated, rendering validity to the assignment rule of hate crimes from districts into constituencies.

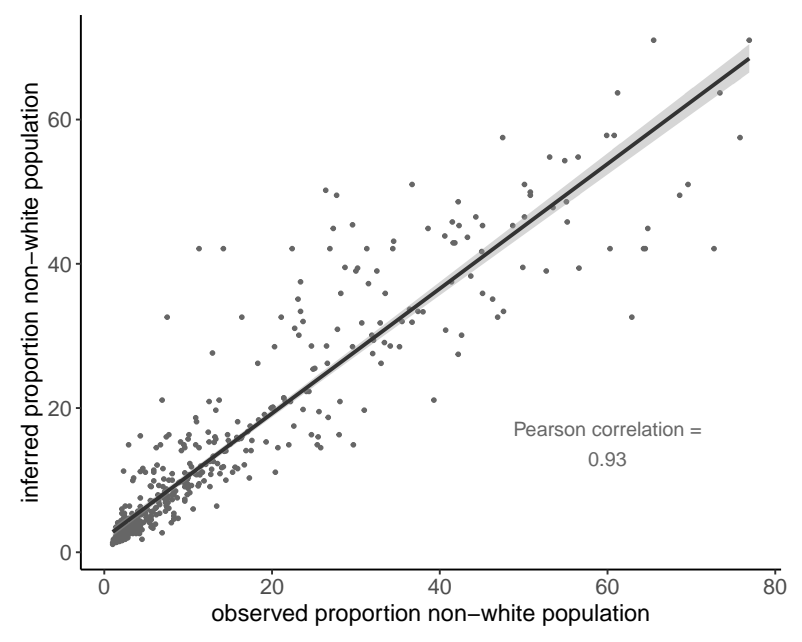

(a) Ethnic minority population

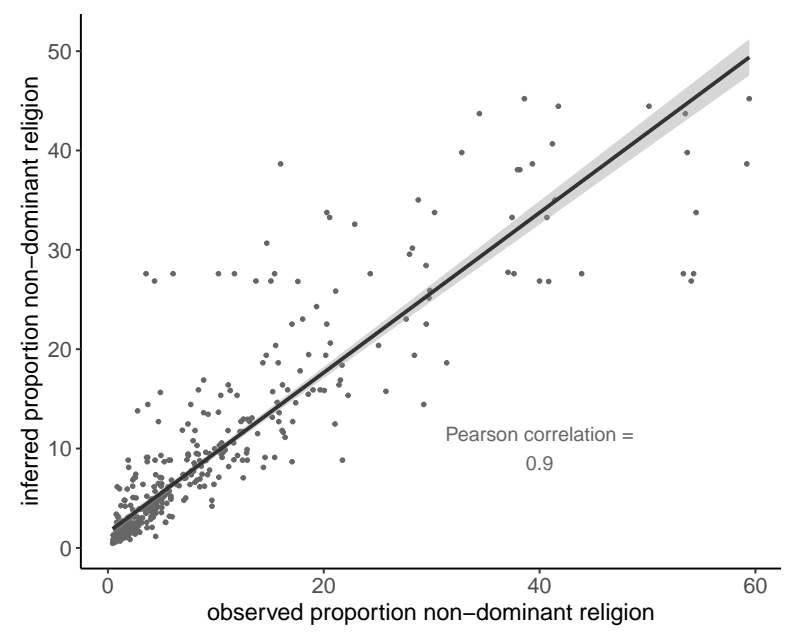

(b) Population with a non-dominant religion

Figure B.1: Validity of hate crime assignment from LAD to constituency 
Table A.1: Summary statistics

\begin{tabular}{|c|c|c|c|c|}
\hline variable & mean & $\mathrm{sd}$ & $\min$ & $\max$ \\
\hline$\%$ negative mentions & 0.30 & 0.31 & 0.00 & 1.00 \\
\hline$\%$ neutral mentions & 0.19 & 0.22 & 0.00 & 1.00 \\
\hline$\%$ positive mentions & 0.21 & 0.26 & 0.00 & 1.00 \\
\hline inclusionary attitudes & 0.35 & 0.48 & 0.00 & 1.00 \\
\hline hate crime rate & 0.10 & 0.08 & 0.00 & 0.90 \\
\hline victory margin & -20.04 & 37.91 & -82.05 & 70.17 \\
\hline winner & 0.29 & 0.45 & 0.00 & 1.00 \\
\hline incumbent candidate & 0.21 & 0.41 & 0.00 & 1.00 \\
\hline female candidate & 0.37 & 0.48 & 0.00 & 1.00 \\
\hline left party candidate & 0.57 & 0.50 & 0.00 & 1.00 \\
\hline$\%$ ethnic minority & 23.66 & 20.18 & 1.00 & 76.90 \\
\hline$\%$ non-dominant religion & 0.16 & 0.17 & 0.00 & 0.91 \\
\hline population density & 35.51 & 34.09 & 0.30 & 146.40 \\
\hline$\%$ young & 0.22 & 0.06 & 0.13 & 0.46 \\
\hline$\%$ single & 37.66 & 9.68 & 23.10 & 65.10 \\
\hline$\%$ deprivation level 1 & 0.33 & 0.02 & 0.28 & 0.38 \\
\hline$\%$ deprivation level 2 & 0.20 & 0.04 & 0.10 & 0.31 \\
\hline$\%$ deprivation & 0.06 & 0.02 & 0.02 & 0.13 \\
\hline$\%$ deprivation level 4 & 0.01 & 0.00 & 0.00 & 0.02 \\
\hline$\%$ social grade ab & 0.24 & 0.09 & 0.08 & 0.50 \\
\hline$\%$ social g & 0.31 & 0.03 & 0.22 & 0.43 \\
\hline$\% \mathrm{sc}$ & 0.19 & 0.05 & 0.06 & 0.32 \\
\hline$\%$ social gr & 0.26 & 0.08 & 0.09 & 0.51 \\
\hline$\%$ level 1 qualifications & 12.76 & 2.72 & 5.70 & 19.20 \\
\hline$\%$ level 2 qualifications & 14.22 & 2.73 & 7.30 & 18.40 \\
\hline$\%$ level 3 qualifications & 12.02 & 2.65 & 8.30 & 27.70 \\
\hline$\%$ level $4+$ qualifications & 29.30 & 9.91 & 12.10 & 57.40 \\
\hline$\%$ economically inactive & 30.05 & 4.33 & 19.20 & 43.00 \\
\hline$\%$ economically acti & 3.79 & 1.73 & 1.90 & 12.50 \\
\hline \% economically active: employed & 61.37 & 6.30 & 42.00 & 74.60 \\
\hline$\%$ economically active: unemployed & 4.79 & 1.55 & 2.20 & 9.50 \\
\hline$\%$ tenure: rent free & 1.35 & 0.42 & 0.60 & 4.00 \\
\hline$\%$ tenure: owned & 58.84 & 14.26 & 20.50 & 85.50 \\
\hline$\%$ tenure: private rented & 19.10 & 7.77 & 7.30 & 42.10 \\
\hline$\%$ tenure: social rented & 19.81 & 8.83 & 5.30 & 50.60 \\
\hline$\%$ English main language: $\mathrm{n}$ & 7.20 & 6.52 & 0.30 & 26.40 \\
\hline$\%$ English main language: one $>16$ & 6.15 & 4.97 & 0.50 & 20.90 \\
\hline$\%$ English main language: one $<16$ & 1.39 & 1.36 & 0.00 & 6.10 \\
\hline$\%$ immigrants: $\mathrm{EU}$ & 4.90 & 3.55 & 0.60 & 16.90 \\
\hline \% immigrants: non-EU & 14.39 & 11.55 & 1.00 & 47.40 \\
\hline$\%$ immigrant arrival $<1960$ & 0.01 & 0.01 & 0.00 & 0.04 \\
\hline \% immigrant arrival 1960-1990 & 0.05 & 0.04 & 0.01 & 0.19 \\
\hline$\%$ immigrant arrival 1990-2011 & 0.14 & 0.11 & 0.01 & 0.42 \\
\hline$\%$ vote far-right & 0.05 & 0.03 & 0.00 & 0.18 \\
\hline
\end{tabular}




\section{Survey items used in measurement of public opinion}

Main outcome: Inclusionary attitudes towards immigrants. Measured with the item Do you think that too many immigrants have been let into this country, or not? on a binary scale with categories Yes, too many, and No, not too many. This item is available and with a fixed wording in the last three post-election surveys.

Additional outcomes:

Attitudes towards immigrants/immigration regarding the economy. Measured in 2010 with the item Immigrants generally are good for Britain's economy. on a 5-point Likert scale ranging from Strongly disagree to Strongly agree. In the other three election years, the framing of this question is about immigration as opposed to immigrants. The wording of the answers and their range is also different. Nevertheless, we pool the answers to these two questions, as we consider that they are close enough in meaning. We do so to have at least one attitudinal item about immigrants spanning the four election years. The question is: Do you think immigration is good or bad for Britain's economy? on a 7-point Likert scale ranging from Bad for economy to Good for economy. To have all answers on a 5-point scale, we collapse the answer categories 2, 3 and 5, 6 .

Index of stereotypical beliefs about migrants and attitudes towards diversity accommodation. Computed by summing the responses to the following items: Now thinking about minorities in Britain. To what extent do you agree or disagree with each of the following statements?

1 Minorities should adapt to customs and traditions of Britain

2 Will of the majority should prevail, even over the rights of minorities

3 Immigrants are generally good for Britain's economy

4 Britain's culture is generally harmed by immigrants

5 Immigrants increase crime rates in Britain

Responses are on a 5-point Likert scale ranging from Strongly agree to Strongly disagree. The order of item 3 is reversed to compute the index. All items are positively correlated with a Cronbach's alpha of 0.83 . These items are only available for the 2017, 2019 post-election surveys, and only for respondents who self-completed an additional module (about $60 \%$ of all respondents).

Placebo outcomes:

Index of left-right views. Computed via simple sum of these 8 items: How much do you agree or disagree with the following statements?

1 Ordinary working people get their fair share of the nation's wealth.

2 There is one law for the rich and one for the poor.

3 There is no need for strong trade unions to protect employees' working conditions and wages.

4 Private enterprise is the best way to solve Britain's economic problems.

5 Major public services and industries ought to be in state ownership.

6 It is the government's responsibility to provide a job for everyone who wants one.

7 People should be allowed to organise public meetings to protest against the government.

8 People in Britain should be more tolerant of those who lead unconventional lives.

Responses are on a 5-point Likert scale ranging from Strongly disagree to Strongly agree. The order of items 2, 5, 6, 7 and 8 are reversed to compute the left-right index. This index has a Cronbach's alpha of 0.62 , and all items are positively correlated. 


\section{Newspaper data, computation of media tone measures and validation of key elements}

Newspaper data We construct the dataset of newspaper articles using the following steps. To determine a comprehensive list of UK newspapers, we first identified a list of seed categories on Wikipedia (WP) (e.g. 'Category:Newspapers_published_in_England'), we took the recursive items of those categories (e.g. 'Category:Newspapers_published_in_England' > 'Category:Newspapers published_in_London'), we used WP article properties to filter out articles about non-newspapers (e.g. people, books), and we extracted the newspaper URLs from the WP Infobox using the Python package wptools. With this process we identified a list of URLS for 337 UK newspapers.

Then, to obtain the articles published by each of these newspapers, we looked up the URLs in Common Crawl (an open repository of web crawl data containing a snapshot of every web page at the moment of the crawl). Particularly in the Index for 2020-16 crawl, the most recent crawl at that moment. We retrieved the WARC (Web ARChive format) records for each crawled page from the newspaper, and extracted the pages' HTML. From the HTML, we extracted the text, title, and byline using the Python package readabiliPy; the publication date using the Python library htmldate; the location by tokenizing the article with CoreNLP, and looking for tokens which match place names in the Index of Place Names in Great Britain, and mapping to the corresponding constituency. Figure D.1 presents the geographical coverage of all extracted articles across constituencies.

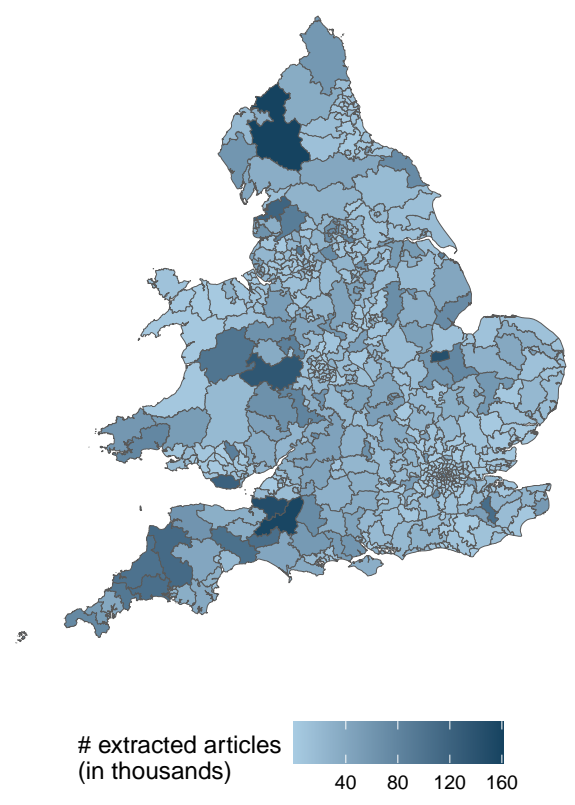

Figure D.1: Geographical coverage of all extracted articles

To select the subset of articles that reference a candidate's ethnic group, we extracted mentions of terms referring to nationalities and countries using the CoreNLP named entity annotator, as well as the sentiment of the sentences mentioning those terms, using CoreNLP's five-category sentiment classifier, in order to define the tone of speech about a candidate's ethnic group. This sentiment classifier improves upon bag of words sentiment classifiers that ignore the order of words and assign positive points for positive words and negative points for negative words and then sum up these 
points (e.g. Young and Soroka, 2012). Instead, it addresses compositionality in semantic vector spaces allowing to detect intricacies of sentiment and to capture complex linguistic phenomena, like sentiment change and scope of negation (Socher et al., 2013). The classifier provides highly accurate sentiment predictions at the sentence level, which is the task at hand. We focus on the sentiment of each sentence containing a mention of relevant country or nationality terms. Therefore, an article may provide more than one instance of speech (or mention) about a candidate's ethnic group. The median article contains 2 mentions of the same term. We focus on the collection of all of these instances of speech for each candidate.

Our sample of articles includes for the most part references to a candidate's ethnic group, as opposed to references to a candidate. The share of articles with mentions of a candidate is low, of only $0.53 \%$, and this share is possibly an overestimate. To compute the share of articles with mentions of a candidate, we extract a candidate's surname from the sample of news articles used in the analysis. Because names can be written differently in different outlets, we use approximate string matching with a similarity score greater than 0.5 to extract mentions of a candidate. Given that we are only extracting a candidate's surname as opposed to their full name, it is possible that we are overestimating the share of articles referencing a candidate, and yet this share is low, suggesting that our analysis captures mostly responses against a candidate's ethnic group.

To provide a sense of coverage by the subset of articles used in our main outcome variable, we present the 160 most frequent words in Table D.1. Naturally, coverage of the COVID-19 pandemic is prevalent (e.g. mentions of coronavirus, health, staff), among other topics such as sports and local politics (e.g. mentions of schools, students, police, government, workers, businesses, local council).

Validation of named entities and their sentiment classification A human judge annotated a sample of 102 articles containing 563 mentions of country/nationality terms in order to validate them and their sentiment classification. Specifically, the human judge first annotated whether the terms refer to a country/nationality or not for each mention in the article. Only $7 \%$ of the mentions refer to something else (e.g. the name of a person, a telephone pole as opposed to a Polish person, or were used in URLs referred in the articles). In other words, for this task the named entity annotator of CoreNLP had $93 \%$ accuracy.

Second, the human judge annotated the sentiment of each article's sentence mentioning a country/nationality term in the five-category classification scale. Comparing the human annotations to the classification of the model for the positive (including 'very positive' and 'positive') and negative ('very negative' and 'negative') categories, and defining the positive class as the negative sentiment category, we have that the CoreNLP's sentiment annotator has an accuracy of $78 \%$, precision of $63 \%$, recall (or true positive rate) of $89 \%$, specificity (or true negative rate) of $72 \%$, and F1-score (or harmonic mean of precision and recall) of $74 \%$. These are reasonable statistics for sentiment classification (Socher et al., 2013). Although the model overpredicts the negative mentions as compared to the human annotations (the precision is $63 \%$ ), it gives us a reasonable, if imperfect, measure of negative speech about a candidate's ethnic group in the newspaper articles. Moreover, the effect estimates are not expected to be affected by the imprecision of the sentiment classification model (although the variance estimates may be affected), given that the model overpredicts negative mentions equally across articles speaking about the ethnic group of a narrowly winner and articles speaking of the ethnic group of a narrowly loser.

Measure of media tone about migrant groups We match the country/nationality mentions' sentiment to candidates based on date, location, and country/nationality. Specifically, we follow this process: 1) we map the candidate's origin characteristics (their country/nationality of 
Table D.1: Top 160 words in relevant articles subset

\begin{tabular}{|c|c|c|c|c|c|c|c|}
\hline word & frequency & word & frequency & word & frequency & word & frequency \\
\hline coronavirus & 290911 & court & 78820 & food & 57489 & war & 45354 \\
\hline people & 238666 & service & 76675 & going & 56524 & local & 45147 \\
\hline said & 238024 & university & 74724 & high & 56135 & council & 44787 \\
\hline year & 230400 & place & 74134 & team & 55430 & season & 44709 \\
\hline new & 209639 & house & 72897 & west & 55208 & don & 44271 \\
\hline children & 198152 & leicester & 72152 & hospital & 54240 & care & 44127 \\
\hline years & 170559 & support & 69967 & information & 54093 & bristol & 44078 \\
\hline $\mathrm{uk}$ & 167058 & away & 69602 & group & 53670 & confirmed & 43993 \\
\hline city & 164893 & pay & 69041 & months & 53295 & john & 43908 \\
\hline home & 144300 & business & 68589 & aged & 52895 & took & 43855 \\
\hline staff & 143187 & way & 68086 & ve & 52678 & open & 43766 \\
\hline time & 142772 & covid & 68054 & women & 52575 & right & 43659 \\
\hline world & 135368 & number & 67629 & park & 52069 & area & 43496 \\
\hline day & 119681 & south & 67255 & play & 51929 & times & 43183 \\
\hline just & 116498 & cases & 67210 & east & 50953 & learning & 43183 \\
\hline family & 113189 & students & 67034 & night & 50908 & want & 42692 \\
\hline old & 109395 & workers & 66969 & north & 50841 & got & 42686 \\
\hline road & 104790 & data & 66363 & read & 50606 & self & 42163 \\
\hline life & 102007 & left & 65938 & jailed & 50585 & big & 42044 \\
\hline like & 101473 & told & 65808 & address & 50340 & close & 41996 \\
\hline image & 96191 & country & 65794 & free & 50322 & come & 41967 \\
\hline use & 95686 & england & 65739 & email & 50030 & lockdown & 41945 \\
\hline week & 95588 & including & 65679 & today & 49435 & say & 41870 \\
\hline police & 95176 & centre & 65481 & national & 49318 & town & 41563 \\
\hline work & 94866 & public & 64495 & death & 49276 & travel & 41529 \\
\hline health & 91352 & february & 63624 & funeral & 48949 & event & 41257 \\
\hline street & 91160 & january & 63237 & working & 48934 & sports & 41185 \\
\hline make & 89190 & latest & 62903 & $\mathrm{mr}$ & 48736 & second & 41170 \\
\hline march & 88325 & great & 62114 & nhs & 48561 & crown & 40980 \\
\hline london & 86030 & days & 61933 & long & 48332 & company & 40686 \\
\hline good & 85488 & live & 61473 & know & 48259 & million & 40601 \\
\hline plymouth & 83783 & student & 61024 & continue & 48007 & guilty & 40354 \\
\hline government & 83491 & club & 60804 & following & 47756 & young & 40257 \\
\hline says & 82081 & league & 60478 & international & 47120 & went & 39950 \\
\hline news & 82037 & set & 59725 & crisis & 47064 & community & 39903 \\
\hline british & 81802 & st & 59446 & social & 46710 & positive & 39855 \\
\hline help & 81497 & virus & 59362 & china & 46477 & pandemic & 39533 \\
\hline man & 80788 & royal & 59141 & end & 46014 & april & 39403 \\
\hline school & 79330 & need & 58468 & think & 45609 & meet & 39284 \\
\hline best & 79065 & love & 58198 & died & 45545 & money & 39119 \\
\hline
\end{tabular}


origin, and their parents' and grandparents' countries/nationalities) to a sub-region, 2) we map the articles' country/nationality mentions to a sub-region and 3) we match candidates and articles based on sub-region, constituency and date of publication (using only the subset of articles published on election day and up to 10 months after the election, which corresponds with the maximum number of months between the 2019 election and the most recent news article. This mapping process implies that for say a candidate of Indian origin, the measure of speech about her ethnic group accounts for mentions in her constituency of all countries/nationalities within Southern Asia. In general, we account for all known countries/nationalities of origin of a candidate. For instance, for a Ugandan-Indian candidate, we include all articles which mention the terms Uganda/Ugandans and India/Indians. In this case, given our mapping process the measure of speech about her ethnic group includes all mentions of Southern Asia and Eastern African. Overall, only 11 candidates are assigned to more than one sub-region, but not to more than two. Furthermore, this process excludes a) candidates for whom we do not have origin information below their continent of origin for example, Asia, Africa, Caribbean and b) articles with mentions of terms like 'asian', 'african'. The proportion of excluded candidates represents $30 \%$ of all strongest minority candidates (winners and first minority losers). While it is a large proportion, their exclusion may be positive in two ways: 1) the salience or online presence of included candidates is kept constant across candidates, given that we are excluding candidates for whom we cannot find information online about their background and 2) the mapping process treats every candidate the same without making assumptions about their origin. Out of all the strongest minority candidates across the four general elections for whom we have specific information about their background, we have at least one mention during the first ten months after election for 438 candidates in England and Wales. The median candidate has 71 mentions.

Following this matching process, we then compute the ratio between the number of negative mentions (adding together the 'very negative' and 'negative' sentiment categories) and the total number of mentions about the candidates' sub-region of origin in their constituency, at every month after the general election. We compute the analogous ratios for positive (summing the 'very positive and 'positive' categories) and neutral mentions. Figure D.2 presents the frequency of sub-region mentions for all matched candidates across the last four general elections (left panel) and the distribution of mentions about the candidate's sub-region by sentiment categories (right panel).

\section{E Data collection on candidates' ethnic minority back- ground}

Collecting data on candidates is a difficult task as there is no single source of candidate data, either from the Electoral Commission, or from the political parties themselves. We rely on a range of sources including the 2010 British General Election Constituency Results, which contains the ethnicity of candidates running with the biggest three political parties: Conservative, Labour and Liberal Democrat. Based on data from the 2015 general election (which is the next closest election for which we have data on every candidate) we know that $76 \%$ of ethnic minority candidates stand in elections with one of these three parties. For the 2015 and 2017 general elections we rely on the Parliamentary Candidates UK project, which collected the ethnicity of every candidate standing in these elections with an established party (Labour, Conservative, Liberal Democrat, Scottish National, Plaid Cymru, UKIP, Green and Northern Ireland parties) and on independent candidates if they are one of the top two finishers in a constituency. For the 2019 election we labelled whether a candidate is BAME by searching the profile of the more than 3,300 candidates and using information 


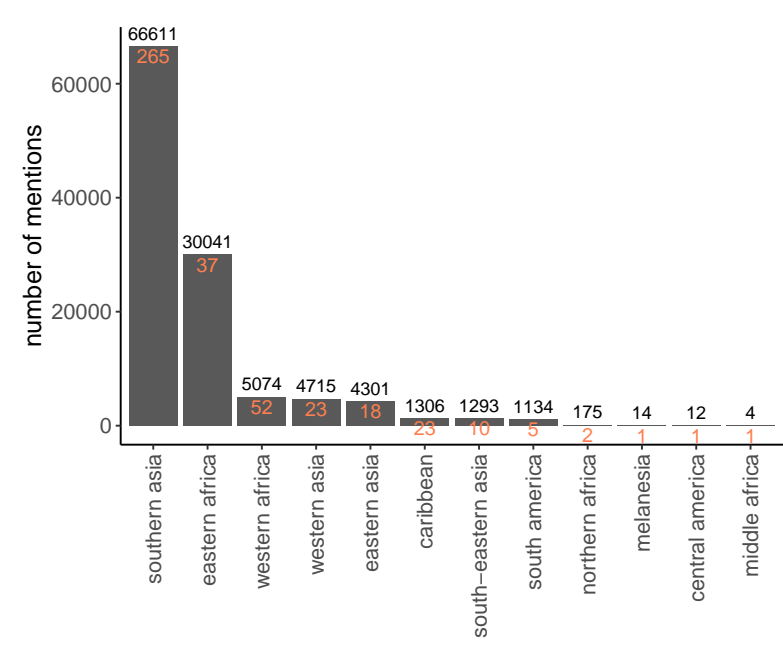

(a) Distribution of all mentions by sub-region

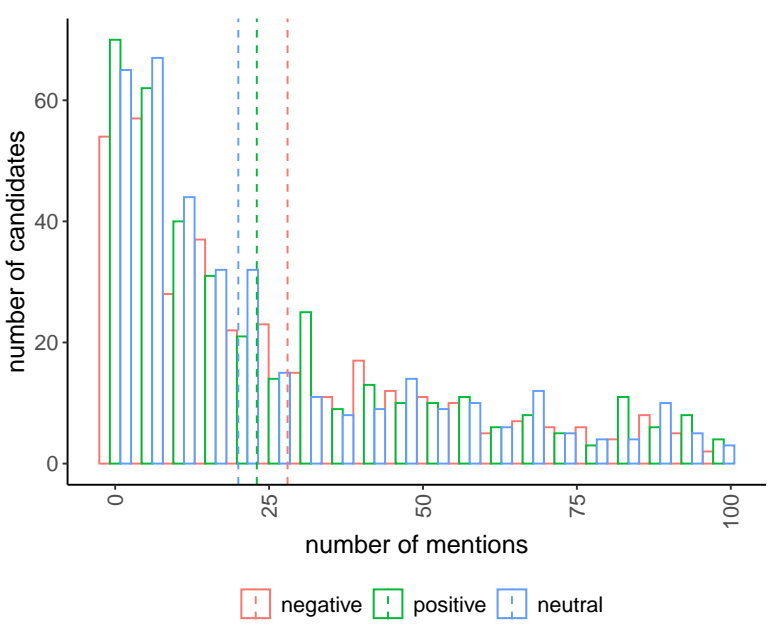

(b) Distribution of candidate mentions by sentiment category

Notes: In (a) the orange numbers indicate the number of candidates from each sub-region. In (b) the dashed vertical lines indicate the median candidate's number of mentions. The histogram excludes the top quartile of candidates with the most mentions for visualization purposes.

Figure D.2: Distribution of mentions

of candidates who have run before for Parliament or who are sitting MPs. For candidates in this election, and to identify a candidate's country of origin for all election years, we rely on various sources including crowdsourced information by the Democracy Club, which collects candidates social media accounts (Facebook, Twitter, LinkedIn), campaign websites and their pictures.

We also cull information from party websites, regional and local newspapers, and especially from ethnic newspapers (e.g. Asian Voice), which usually include a list of co-ethnic candidates in an election special issue. We classify a candidate's ethnic origin only when the candidate selfidentifies as ethnic minority on their social media profile, personal website, their party's website, or if more than one information source confirms the candidate's origin. We do not include national and ethno-linguistic minorities (e.g, Welsh), as these communities are not classified as minorities in the data we are relying on. Figure E.1 describes minority candidates across time, parties and geography. 


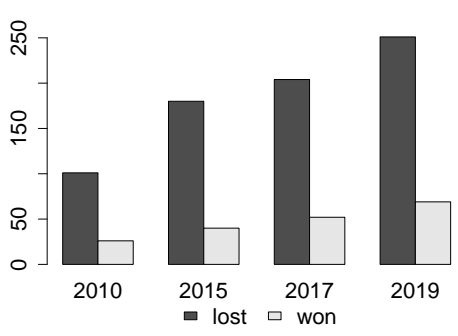

(a) Number of ethnic minority candidates contesting a seat in Parliament

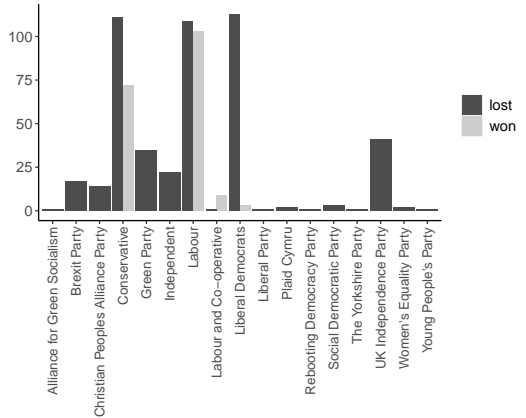

(b) Strongest ethnic minority candidates by political party

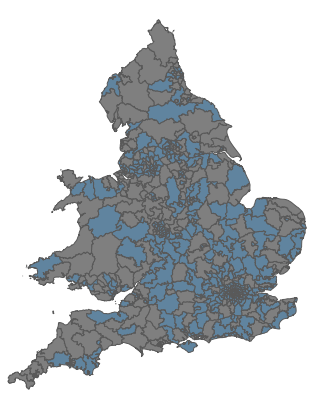

(c) Geographical coverage of ethnic minority candidates

Figure E.1: Description of ethnic minority candidates 


\section{F Selection of constituencies into the sample}

Table F.1: Selection of constituencies into the sample

\begin{tabular}{|c|c|c|c|c|}
\hline \multirow[b]{2}{*}{ variable } & \multicolumn{2}{|c|}{ All constituencies } & \multicolumn{2}{|c|}{ Sample constituencies } \\
\hline & mean & sd & mean & sd \\
\hline share ethnic minority & 12.786 & 15.390 & 23.361 & 20.174 \\
\hline share non-dominant religion & 0.081 & 0.123 & 0.158 & 0.174 \\
\hline population density & 21.280 & 26.334 & 34.301 & 33.481 \\
\hline share young & 0.197 & 0.050 & 0.215 & 0.055 \\
\hline share single & 34.098 & 8.242 & 37.276 & 9.528 \\
\hline share deprivation level 1 & 0.326 & 0.018 & 0.330 & 0.020 \\
\hline share deprivation level 2 & 0.194 & 0.041 & 0.197 & 0.043 \\
\hline share deprivation level 3 & 0.052 & 0.022 & 0.057 & 0.023 \\
\hline share deprivation level 4 & 0.005 & 0.003 & 0.006 & 0.004 \\
\hline share social grade ab & 0.224 & 0.083 & 0.233 & 0.092 \\
\hline share social grade c1 & 0.307 & 0.032 & 0.311 & 0.032 \\
\hline share social grade c2 & 0.212 & 0.044 & 0.195 & 0.047 \\
\hline share social grade de & 0.257 & 0.077 & 0.261 & 0.084 \\
\hline share level 1 qualifications & 13.388 & 2.267 & 12.919 & 2.692 \\
\hline share level 2 qualifications & 15.390 & 2.203 & 14.387 & 2.715 \\
\hline share level 3 qualifications & 12.321 & 2.411 & 12.001 & 2.514 \\
\hline share level $4+$ qualifications & 26.824 & 8.355 & 28.657 & 9.783 \\
\hline share economically inactive & 30.419 & 3.950 & 30.169 & 4.312 \\
\hline share economically active: students & 3.334 & 1.525 & 3.739 & 1.683 \\
\hline share economically active: employed & 61.912 & 5.443 & 61.296 & 6.261 \\
\hline share economically active: unemployed & 4.336 & 1.428 & 4.795 & 1.526 \\
\hline share tenure: rent free & 1.352 & 0.398 & 1.352 & 0.412 \\
\hline share tenure: owned & 64.278 & 11.563 & 59.347 & 14.133 \\
\hline share tenure: private rented & 16.281 & 6.354 & 18.785 & 7.575 \\
\hline share tenure: social rented & 17.354 & 7.489 & 19.626 & 8.807 \\
\hline share English main language: none & 4.034 & 4.871 & 7.050 & 6.453 \\
\hline share English main language: one $>16$ & 3.553 & 3.759 & 6.066 & 4.970 \\
\hline share English main language: one $<16$ & 0.736 & 0.989 & 1.370 & 1.343 \\
\hline share immigrants: EU & 3.404 & 2.771 & 4.737 & 3.506 \\
\hline share immigrants: non-EU & 8.258 & 8.878 & 14.074 & 11.473 \\
\hline share immigrant arrival $<1960$ & 0.009 & 0.005 & 0.012 & 0.006 \\
\hline share immigrant arrival 1960-1990 & 0.032 & 0.031 & 0.053 & 0.041 \\
\hline share immigrant arrival 1990-2011 & 0.082 & 0.084 & 0.133 & 0.107 \\
\hline share vote far-right 2010 & 0.056 & 0.029 & 0.050 & 0.032 \\
\hline $\mathrm{N}$ constituency-election & & 92 & & 2 \\
\hline
\end{tabular}

Notes: shows descriptive statistics for all constituencies, and constituencies in our sample. Our sample is selected by dropping constituencies where ethnic minority candidates do not stand for Parliament. The unit of observation is a constituency-election year. 


\section{G Minority victory effects on hate crimes: validity of the $\mathrm{RD}$ design, robustness checks and supporting results}

In this section we report a set of placebo and falsification tests that establish the validity of the $\mathrm{RD}$ design (sections G.1-G.5), the main RD results in tabular form (section G.7), a comparison between the main RD results and the results when we control for party dummies (section G.6), a descriptive test confirming that the minority victory effects are not driven by a crime decay in constituencies with minority close defeats (section G.8), and robustness of the RD estimates to an alternative difference-in-differences specification (section G.9).

\section{G.1 Continuity of placebo outcomes}

We use as a placebo outcome the constituency crime rate for equivalent crimes that are not motivated by racial or religious animus. We test whether this placebo outcome is discontinuous at the margin of victory cutoff. The rationale for this test is the same as the rationale for a test assessing discontinuities in predetermined covariates: when a placebo outcome that correlates strongly with the outcome of interest is discontinuous at the cutoff, then the continuity of the potential outcome functions is unlikely to hold, questioning the validity of the $\mathrm{RD}$ design under the continuity-based approach.

Figure G.1 shows that this placebo outcome is not discontinuous at the threshold where an ethnic minority candidate wins a seat in Parliament. The effects are not statistically significant, have the opposite direction to the effects on hate crime and are comparably smaller (Figure G.1c). This increases our confidence that the validity of the design holds, and that the estimates of the minority victory effects on hate crime are not explained by a generalized higher level of crime in constituencies where minorities win.

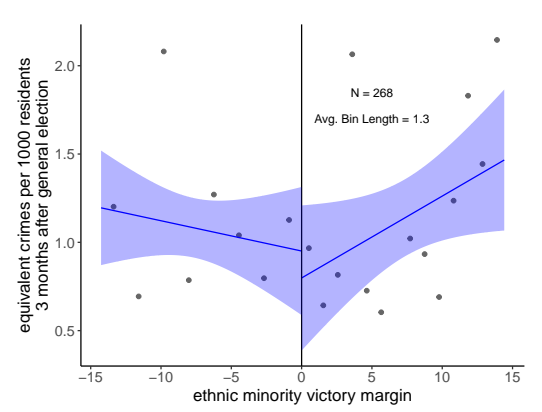

(a) 3 months after general election

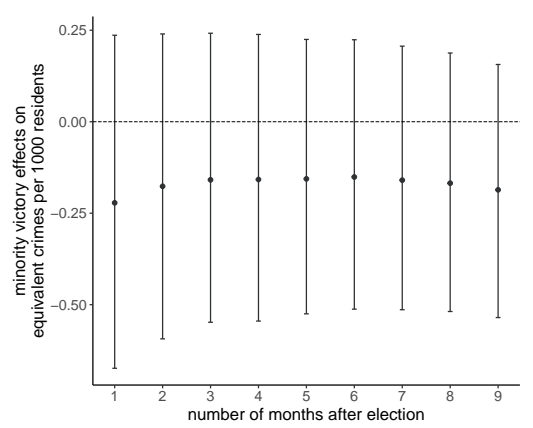

(b) 1-9 months after general election

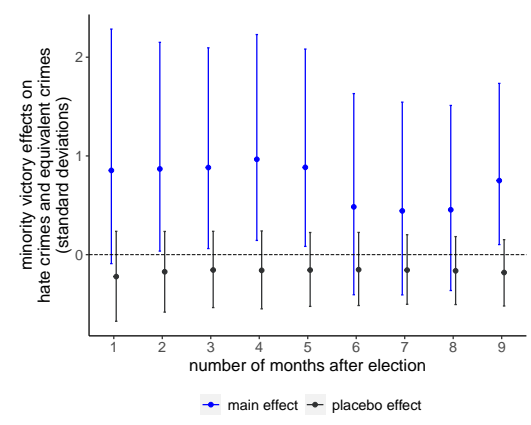

(c) Comparison of main and placebo effects

Notes: In (a) lines represent the average monthly crime rate (with $95 \%$ confidence intervals) from local linear regression with covariate adjustment fitted to the sample of units whose vote-share winning margin is within the MSE-optimal bandwidth of $+/-14.5$ percentage points around the victory threshold. Points are the average monthly crime rate for equally spaced mimicking-variance bins. In (b) and (c) points are RD estimates of the effect of an ethnic minority victory and lines 95\% robust bias-corrected confidence intervals.

Figure G.1: Ethnic minority victory effects on equivalent crimes 


\section{G.2 Continuity of main outcome before general election}

We test whether the hate crime rate is discontinuous at the margin of victory cutoff before the general election. Figure G.2a shows that the hate crime rate is not discontinuous at the threshold where an ethnic minority candidate wins a seat in Parliament. The effects are not statistically significant and are comparably smaller to the effects after the election. This increases our confidence about the robustness of our results, as it suggests that the estimates of the minority victory effects on hate crime are not explained by other dynamics in constituencies where minorities win.

\section{G.3 Continuity of predetermined variables}

Following (Calonico, Cattaneo and Titiunik, 2014), we also test (using the rdrobust package in R) the continuity assumption for predetermined variables with local linear regression within an MSEoptimal bandwidth. Given that we have a large number of covariates, we show in Figure G.2b the threshold for the p-values of the tests of discontinuity (the dashed vertical line), when controlling the false discovery rate with the Benjamini-Hochberg procedure. (See De la Cuesta and Imai (2016) for an example of controlling the false discovery rate with the Benjamini-Hochberg procedure when testing for multiple discontinuities in predetermined variables in RD contexts of close elections). In this case, 3 of a total of 37 covariates show statistically significant discontinuities after controlling the FDR.

However, some of the covariates we include are not independent of each other (as BH correction would assume); in particular some of the covariates (such as the proportions of immigrant arrivals in different decades) are linear combinations of an underlying variable. To account for this dependence, we test the continuity assumption with a permutation test for continuity in the distribution of observations around the cutoff (which is a stronger requirement than continuity of means) as described in (Canay and Kamat, 2018) and as implemented by the RATest R package. Here we find that only 4 of the 37 predetermined variables are discontinuous at the cutoff (Figure G.2c). This number of discontinuous covariates is equivalent to two more than the average number of false rejections (which is 2). Furthermore, when controlling for the FDR with the Benjamini-Hochberg procedure, we do not find any discontinuous variables.

Given the results from both the permutation test for continuity of distribution around the cutoff and the FDR-corrected local linear regression test, the distribution of p-values is consistent with the uniform distribution that we would expect for balance checks in a randomized experiment. This indicates that there were no systematic discontinuities at the threshold where minorities become MPs, and that therefore the continuity assumption of the potential outcome functions is likely to hold.

\section{G.4 Density of the running variable}

Following (Cattaneo, Jansson and Ma, 2020), we test (using the rddensity R package) the continuity assumption of the density functions of the running variable with local polynomial density estimators. Figure G.3 reveals no evidence of sorting around the cutoff. Even though there is a jump in the density functions for losing and winning candidates at the cutoff, the confidence intervals of these functions completely overlap and the p-value of the continuity test indicates that we cannot reject the null of continuity of the density functions. The results of this test indicate no manipulation of the election results. 


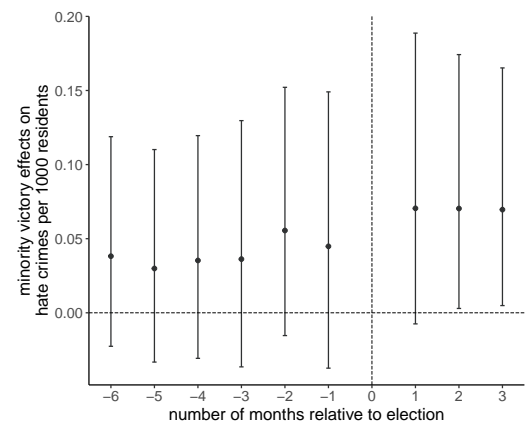

(a) Ethnic minority victory effects on hate crimes before and after the election

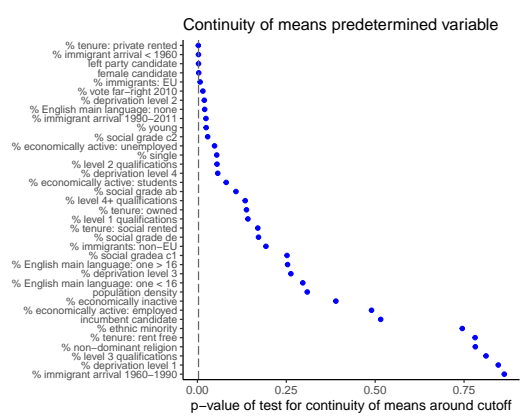

(b) Continuity of means using local linear regression

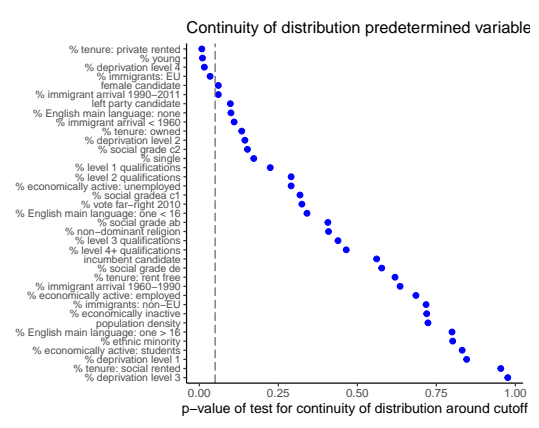

(c) Continuity of distribution using asymptotic permutation test

Notes: In (a) points are RD estimates of the effect of an ethnic minority victory and lines $95 \%$ robust bias-corrected confidence intervals. (b), (c) test for continuity of candidate and constituency predetermined background characteristics in (b) using a local linear regression with a symmetric MSE-optimal bandwidth as implemented by the rdrobust $R$ package and in (c) using an asymptotic permutation test comparing the distribution of observation near the cutoff as implemented by the RATest $\mathrm{R}$ package. The vertical line in $(\mathrm{b})$ indicates a $p$-value $=0.004$, which is the threshold for the p-values when controlling the false discovery rate with the Benjamini-Hochberg procedure, and in (c) a $p$-value $=0.05$. Here the threshold for p-values when controlling the FDR with BH procedure is approximately 0 .

Figure G.2: Continuity of predetermined variables around the victory threshold
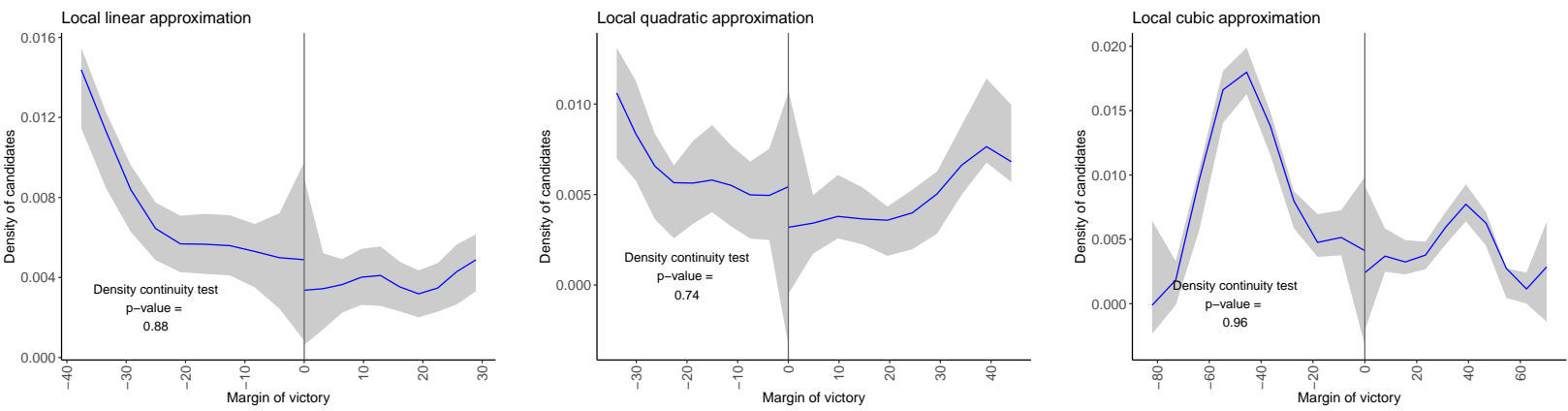

Notes: Tests for manipulation of the election results by assessing continuity of the candidate density functions at the cutoff with local polynomial density estimators and robust bias-corrected inference.

Figure G.3: Continuity in the density of candidates around the cutoff

\section{G.5 Sensitivity to the choice of bandwidth and order of polynomials}

In Figure G.4 we test for sensitivity of the results to the choice of bandwidth, using CER- and MSEoptimal bandwidths, half, three fourths, five fourths and one and a half times their size. We find that the results are broadly consistent with the findings obtained with the optimal MSE bandwidth.

In our main estimation method we compute the RD estimates by fitting local-linear polynomials to avoid noisy estimates with poor coverage of confidence intervals (Gelman and Imbens, 2019). We show nevertheless, in Figure G.5a, that the results are robust to fitting quadratic polynomials. 


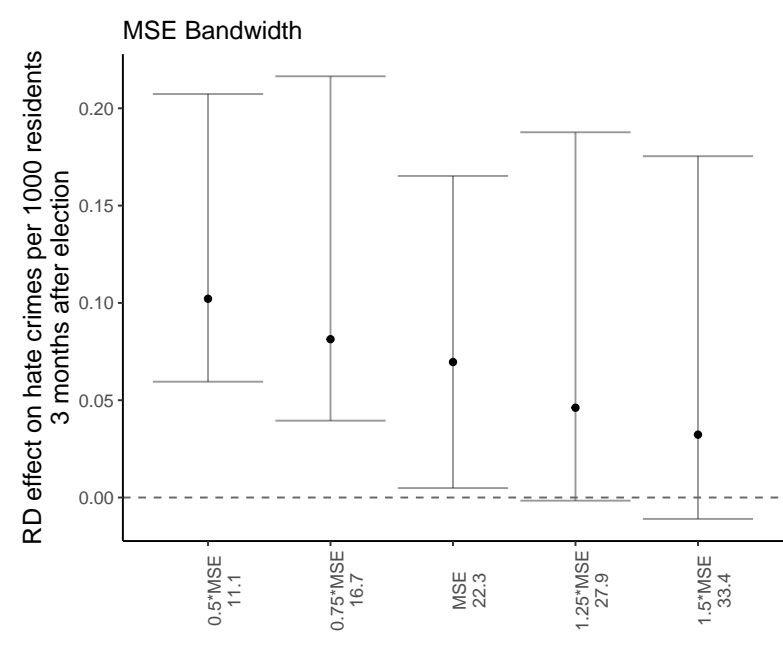

(a)

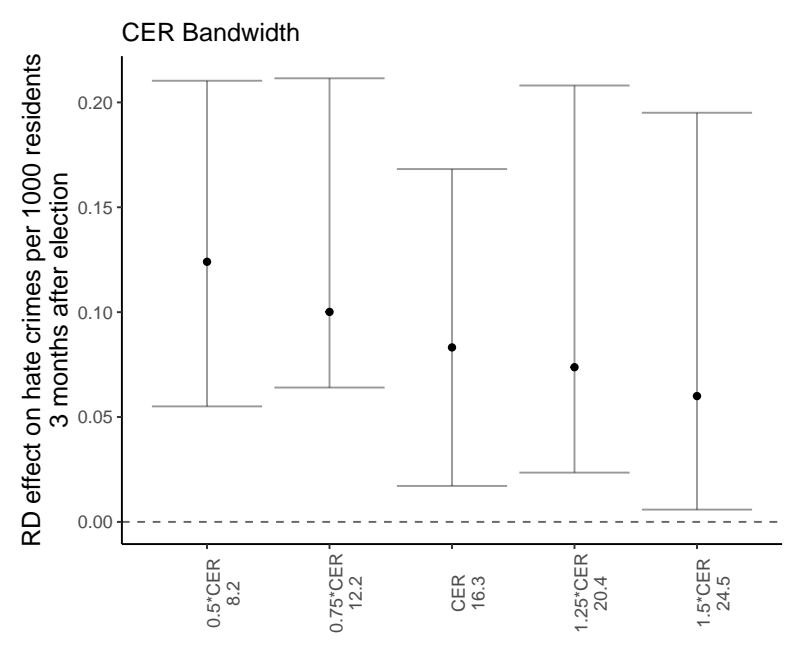

(b)

Notes: tests for sensitivity to the choice of bandwidth. In (a) MSE stands for mean squared error optimal bandwidth and in (b) CER refers to a bandwidth that minimizes the coverage error from the robust biased corrected confidence intervals obtained with the MSE-optimal bandwidth. The values next to the 'MSE', 'CER', labels indicate the bandwidth size.

Figure G.4: Sensitivity to bandwidth size

\section{G.6 Controlling for candidate's political party}

We isolate the ethnic identity of candidates from their political party affiliation from the hate crime response by controlling for party dummies. In Figure G.5b we compare the RD estimates of our main specification to the estimates from a specification controlling for party dummies. The coefficients are very close in magnitude, suggesting that the violent response is not explained only by the political affiliation of the candidates.

\section{G.7 Main RD results in tabular form}

Table G.1 presents estimates of RD effects on hate crime for model specifications with/out covariates.

\section{G.8 Assessing a hate crime decay in minority barely lost constituen- cies}

In Figure G.6 we descriptively show that the minority victory effects on hate crime are not driven by a crime decay in constituencies with close minority defeats. The average hate crime rate in these constituencies after the election is very close to the average hate crime rate before the election. If anything, hate crimes are on average slightly increasing in these constituencies after the election rather than decreasing. This suggests that the documented effect on hate crime is a backlash to minority victories, rather than sympathy towards minorities in constituencies narrowly won by dominant-group candidates. 


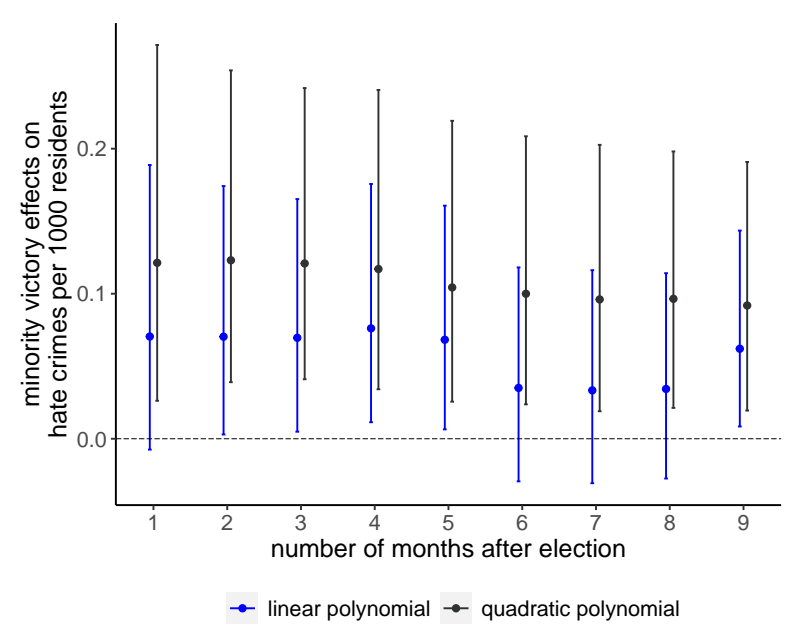

(a) Sensitivity to polynomial choice

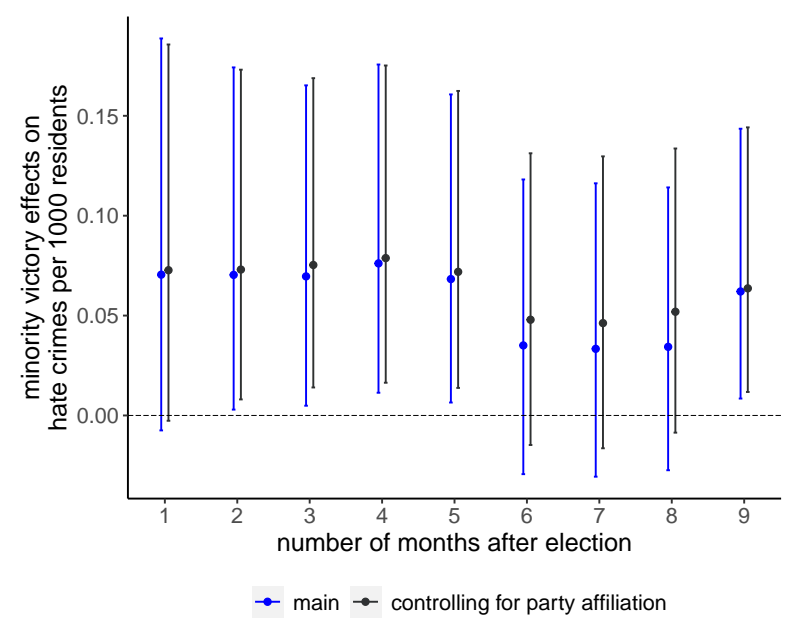

(b) Isolating the ethnic identity of candidates from their political party

Notes: (a) tests for sensitivity to the choice of polynomial order by comparing estimates with locallinear and quadratic polynomials, and (b) adds controls for candidates' political parties.

Figure G.5: Sensitivity to polynomial choice and control variables

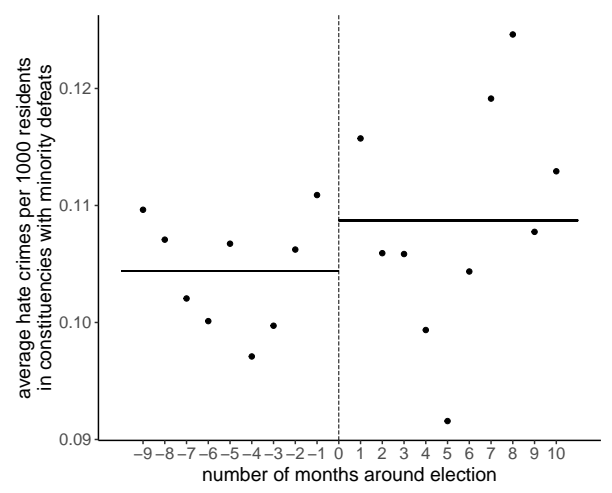

Figure G.6: No hate crime decay in minority barely lost constituencies

Notes: Points are monthly average hate crimes per 1000 residents in constituencies barely lost by ethnic minority candidates, and horizontal lines pre- and post-election hate crime averages in those constituencies.

\section{G.9 Difference-in-differences}

As an additional check for the estimated effects on hate crime, we use a difference-in-differences (DiD) approach that compares the hate crime rate across constituencies that elect ethnic minority candidates and constituencies that do not, before and up to nine months after the election when a minority candidate is elected for the first time in a constituency.

With this estimation design, a constituency is in the treatment condition during the months following a general election in which an ethnic minority candidate is elected, and in the control condition, otherwise. 69 out of 520 constituencies have an ethnic minority MP during at least 
Table G.1: Ethnic minority victory effects on hate crimes

\begin{tabular}{ccccccccccc}
\hline $\begin{array}{c}\text { RD } \\
\text { estimate }\end{array}$ & se & $\begin{array}{c}\text { p- } \\
\text { value }\end{array}$ & $\begin{array}{c}95 \% \\
\text { CI }\end{array}$ & $\begin{array}{c}\text { mean } \\
\text { control }\end{array}$ & $\begin{array}{c}\text { sd } \\
\text { effect }\end{array}$ & $\begin{array}{c}\text { MSE- } \\
\text { opt bw }\end{array}$ & $\begin{array}{c}\text { eff. } \\
\text { N }\end{array}$ & N & controls & month \\
\hline 0.076 & 0.066 & 0.212 & {$[-0.054,0.244]$} & 0.107 & 0.911 & 20.59 & 192 & 1040 & no & 1 \\
0.070 & 0.045 & 0.070 & {$[-0.007,0.189]$} & 0.107 & 0.853 & 21.23 & 198 & 1040 & yes & 1 \\
0.076 & 0.059 & 0.162 & {$[-0.038,0.228]$} & 0.108 & 1.012 & 18.98 & 273 & 1560 & no & 2 \\
0.070 & 0.039 & 0.043 & {$[0.003,0.174]$} & 0.110 & 0.868 & 20.41 & 285 & 1560 & yes & 2 \\
0.076 & 0.054 & 0.135 & {$[-0.029,0.217]$} & 0.104 & 1.010 & 19.14 & 364 & 2080 & no & 3 \\
0.070 & 0.037 & 0.038 & {$[0.005,0.165]$} & 0.103 & 0.882 & 22.29 & 416 & 2080 & yes & 3 \\
0.083 & 0.057 & 0.122 & {$[-0.027,0.231]$} & 0.098 & 1.135 & 18.69 & 450 & 2600 & no & 4 \\
0.076 & 0.038 & 0.026 & {$[0.011,0.176]$} & 0.100 & 0.966 & 20.73 & 480 & 2600 & yes & 4 \\
0.076 & 0.053 & 0.136 & {$[-0.029,0.214]$} & 0.099 & 1.053 & 18.81 & 546 & 3120 & no & 5 \\
0.068 & 0.035 & 0.034 & {$[0.006,0.161]$} & 0.099 & 0.884 & 21.90 & 618 & 3120 & yes & 5 \\
0.071 & 0.051 & 0.140 & {$[-0.029,0.203]$} & 0.102 & 0.963 & 19.32 & 644 & 3640 & no & 6 \\
0.035 & 0.030 & 0.238 & {$[-0.029,0.118]$} & 0.104 & 0.484 & 31.87 & 1113 & 3640 & yes & 6 \\
0.068 & 0.050 & 0.151 & {$[-0.031,0.199]$} & 0.105 & 0.878 & 19.26 & 736 & 4160 & no & 7 \\
0.033 & 0.030 & 0.254 & {$[-0.031,0.116]$} & 0.108 & 0.443 & 31.81 & 1272 & 4160 & yes & 7 \\
0.067 & 0.049 & 0.142 & {$[-0.028,0.193]$} & 0.104 & 0.857 & 19.24 & 828 & 4680 & no & 8 \\
0.034 & 0.029 & 0.230 & {$[-0.027,0.114]$} & 0.108 & 0.455 & 31.52 & 1413 & 4680 & yes & 8 \\
0.062 & 0.046 & 0.149 & {$[-0.028,0.182]$} & 0.105 & 0.801 & 19.79 & 930 & 5200 & no & 9 \\
0.062 & 0.031 & 0.027 & {$[0.008,0.144]$} & 0.104 & 0.750 & 21.21 & 990 & 5200 & yes & 9 \\
\hline
\end{tabular}

Notes: The dependent variable is monthly hate crimes per 1000 residents in a constituency. RD estimate is computed with local-linear regression within a symmetric MSE-optimal bandwidth. se is the conventional standard error, $p$-value and 95\% CI are robust bias-corrected. mean control indicates the average monthly hate crime rate in constituencies where ethnic minorities barely lose, sd effect presents the RD estimate in standard deviations, MSE-opt bw is the MSE-optimal bandwidth of vote-share winning margin around the victory threshold, eff. $N$ is the sample size within the MSE-optimal bandwidth and $N$ is the sample size. controls include an indicator of whether the candidate is the incumbent, constituency vote share for UKIP and BNP in the previous election, constituency share that is ethnic minority, young population, single, with social grade DE, unemployed, population density, and share of households with 3 or more deprivations, and in social tenure. Standard errors are clustered by constituency-election. Hate crime data are from Home Office, ethnic background of candidates is constructed by the authors, and constituency characteristics from 2011 UK Decennial Census.

one month between April 2014 and September 2020, 23 constituencies have a minority MP during this whole period, and 4 constituencies go in and out of the treatment condition. We focus on the first nine months after the election - the maximum number of months which are observable for constituencies electing an ethnic minority candidate for the first time in 2019.

We estimate the DiD estimator with the generalized synthetic control method based on interactive fixed effects models as described in (Xu, 2017) and implemented by the gsynth $\mathrm{R}$ package. We use this approach as opposed to a standard two-way fixed effects regression because even after controlling for relevant predetermined covariates that determine both minority victories and hate crimes, we reject the null hypothesis of common trends for all pre-minority victory periods and all groups of constituencies that elect a minority candidate for the first time at a particular election. The Cramer von Mises test statistic and p-value of (Callaway, Sant'Anna et al., 2018)'s integrated moments test for the conditional parallel trends assumption holding in all pre-treatment time periods for all groups are 0.886 and $0 . \overline{0}$, respectively.

Given this, we instead impute a counterfactual for each treated constituency that resembles 
the pre-minority victory hate crime trends of treated constituencies. Furthermore, we prefer the generalized synthetic control method over the most recently developed approaches for DiD with multiple time periods and variation in treatment timing (e.g. Callaway, Sant'Anna et al. (2018)), given that the number of constituencies electing a minority candidate for the first time at each of the three observed elections is small: 14, 9, 20, respectively. This produces group-time average treatment effects that are rather noisy.

Figure G.7 presents the estimated effects of electing an ethnic minority candidate to Parliament on monthly hate crimes per 1000 residents. It shows a positive and significant effect in the first month after the election that is won by a minority candidate. After that month, each monthly effect is relatively smaller, and is not statistically significant. However, on average the effect remains positive and larger than the average effect before minority candidates win an election. Consistent with parallel trends (and with the method computing an adequate counterfactual), we do not see any pre-minority MP significant effects, and the effects are very close to zero throughout the 12 month period before an ethnic minority candidate wins the election.

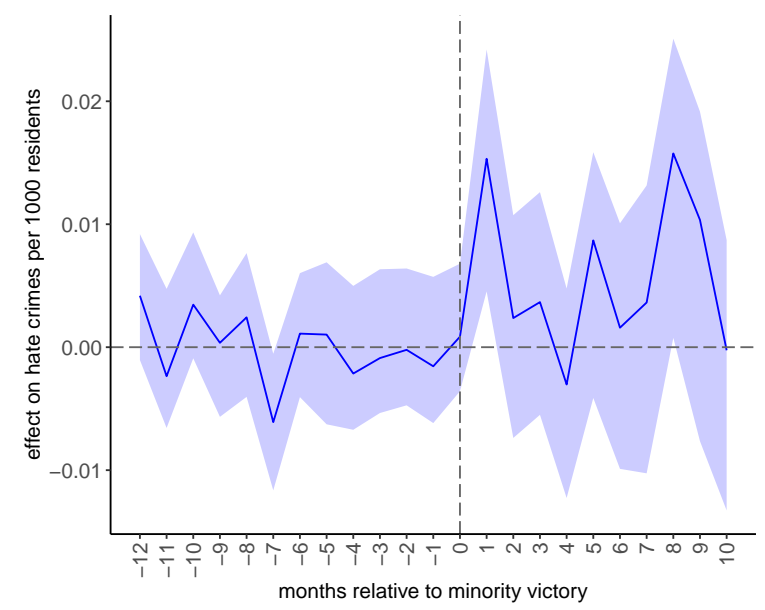

Notes: The line represents the ATT, and the ribbon $95 \%$ confidence intervals.

Figure G.7: First time ethnic minority victory effects on hate crime

Table G.2 presents the average effects across the first nine months after a minority victory. In general, the average effects during this period are positive, statistically significant in the first three months, and decrease with time. Again, these patterns suggest a violent but rather short-lived reaction to ethnic minorities accession to political office.

While the effect at one month after a victory is equivalent to an increase of 1.5 hate crimes per 100,000 residents (and statistically significant at the $1 \%$ level), the average effect after three months of victory almost halves to 0.7 hate crimes per 100,000 residents (statistically significant at the $10 \%$ level). These effect is ten times smaller than the effect estimated with the RD design. On the one hand, because close elections between ethnic minority and dominant-group candidates are more likely to be perceived as posing a threat to the dominant group's status, and therefore to result in conflict, the RD estimates are likely capturing an upper-bound effect of ethnic minority victories on hostility against minority communities. To provide suggestive evidence that the difference between the magnitude of our $\mathrm{RD}$ and $\mathrm{DiD}$ estimates is in part explained by how close the election is, in Figure G.8 we compute DiD estimates for different values of victory margins. We start by including constituencies with elections won by a maximum of 22 percentage points, corresponding to the 


\begin{tabular}{cccccc}
\hline ATT.avg & S.E. & CI.lower & CI.upper & p.value & months \\
\hline 0.0153 & 0.0051 & 0.0045 & 0.0242 & 0.005 & 1 \\
0.0088 & 0.0041 & -0.0003 & 0.0160 & 0.058 & 2 \\
0.0071 & 0.0038 & -0.0010 & 0.0139 & 0.078 & 3 \\
0.0046 & 0.0035 & -0.0029 & 0.0106 & 0.268 & 4 \\
0.0054 & 0.0035 & -0.0025 & 0.0110 & 0.199 & 5 \\
0.0048 & 0.0034 & -0.0032 & 0.0104 & 0.287 & 6 \\
0.0046 & 0.0034 & -0.0035 & 0.0100 & 0.350 & 7 \\
0.0060 & 0.0035 & -0.0026 & 0.0112 & 0.199 & 8 \\
0.0065 & 0.0036 & -0.0026 & 0.0114 & 0.207 & 9 \\
\hline
\end{tabular}

Notes: The dependent variable is monthly hate crimes (racially/religiously aggravated offenses) per 1,000 residents. Inference is conducted via bootstrapping. Standard errors are clustered by constituency.

Table G.2: Average first time ethnic minority victory effects on hate crime (averaging across months after victory)

MSE-optimal bandwidth from the RD estimates. We then increase the sample until we include every constituency (that is, with elections won by a maximum of 100 percentage points, as shown in Table G.2). In general, as we increase the victory margin, the DiD estimates decay, suggesting that the degree to which the election is more or less competitive may explain, in part, the difference in the size of effect estimates across the two estimation methods.

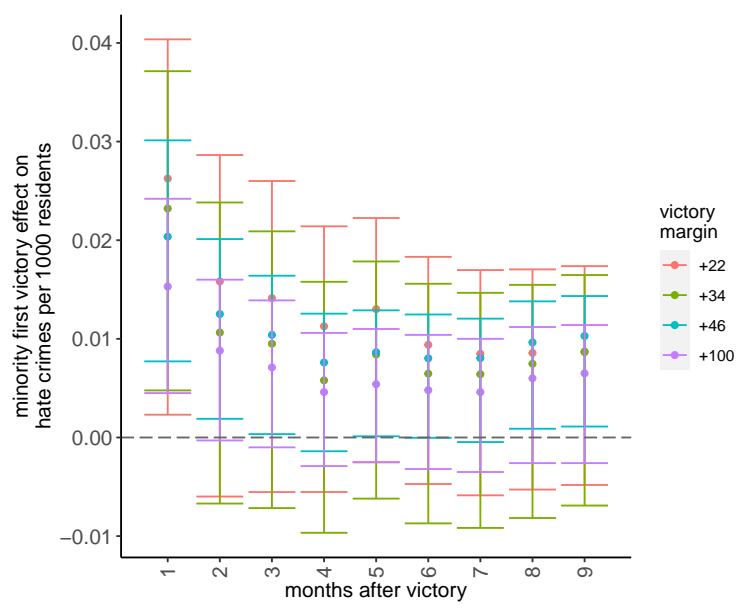

Notes: Points represents the ATT and lines $95 \%$ bootstrapped confidence intervals.

Figure G.8: First time ethnic minority victory effects on hate crime by victory margin

On the other hand, the effects of the two estimation methods are not directly comparable as they are targeting different quantities of interest. The quantity of interest in the RD design is the local average treatment effect (LATE), while in the DiD approach is the average treatment effect on the treated (ATT). Moreover, the effective samples across the two different approaches are different: the DiD ATT includes the group of constituencies won by large margins and that on average have 
a smaller post-minority victory hate crime rate (of 0.10 per 1,000 people in constituencies won by more than $15 \mathrm{pp}$ compared to 0.14 in constituencies won by less than $15 \mathrm{pp}$ ), while the RD LATE does not include such group of constituencies. Relatedly, the comparison group in the DiD includes constituencies where minority candidates lose by large margins or do not even run for Parliament, and that have on average higher post-election hate crime rates than constituencies where minority candidates run and lose by small margins. These differences in the composition of the samples can explain, in part, the difference in the size of effect estimates across the two estimation methods.

\section{G.10 Testing for possible hate crime reporting bias}

It is possible that the observed increase in hate crime is not only explained by the reaction of the dominant group to ethnic minorities winning elections, but also by an increase in the reporting of hate crime: members of the winning candidate's ethnic group may be empowered to report crime. While this is feasible, we contend that it is unlikely, as the definition of hate crime and the process to report it in the UK is designed to prevent under-reporting. Crimes are identified and flagged as a hate crime by the police and the Crown Prosecution Service when the criminal offense is perceived by the victim or any other person to be motivated by hostility or prejudice towards someone based on a personal characteristic like race (defined as race, color, nationality or ethnic or national origin), religion or beliefs, without further prove.

To further assess such a concern we estimate victory effects on hate crime categorized as 'violence against the person', specifically 'violence with injury'. Because of the seriousness of this offense, such type of hate crime is expected to be consistently reported regardless of whether people are empowered or discouraged to report crime. Accordingly, the RD estimates of the effects of a minority win should not suffer from such a reporting bias. Despite the small number of crimes within this category ( $5 \%$ of total hate crimes), the estimates presented in Table G.3 are broadly consistent with our main findings on total hate crime: crimes jump at the minority victory threshold.

\section{G.11 Brief discussion of hate crime spillover}

It is possible that hate crime spills over across constituencies. Two types of spillover could be going on. First, constituencies with minority losers are in the neighborhood of constituencies with minority winners and hate crime spills over within neighborhoods. This scenario suggests our RD estimate is downward biased. Second, constituencies with minority winners are in the neighborhood of constituencies with minority winners and hate crime spills over within neighborhoods. This scenario suggests that our RD estimate accounts for a constituency's treatment and their neighbor's treatment (that is, a direct and an indirect effect of minority victory on crime).

Now, assuming that a neighborhood is characterized by a constituency's first-degree neighbors (that is, constituencies that are adjacent) and that spillover happens only via first-degree neighbors, the probability of the first spillover scenario described above is 0.21 and of the second scenario 0.18. These probabilities are even lower, 0.11 and 0.07 ; respectively, when we account only for constituencies with narrow elections (a margin of victory of $+/-22$ percentage points), suggesting that it is not very likely there would be spillover, and if there is, it is more likely that our RD estimates are conservative. Figure G.9 presents maps illustrating the contiguity between constituencies with ethnic minority candidate winners and ethnic minority candidate losers in close elections $(+/-22$ pp. around the cutoff). 
Table G.3: Ethnic minority victory effects on violent hate crimes

\begin{tabular}{cccccccccc}
\hline $\begin{array}{c}\text { RD } \\
\text { estimate }\end{array}$ & se & $\begin{array}{c}\text { p- } \\
\text { value }\end{array}$ & $\begin{array}{c}95 \% \\
\text { CI }\end{array}$ & $\begin{array}{c}\text { mean } \\
\text { control }\end{array}$ & $\begin{array}{c}\text { sd } \\
\text { effect }\end{array}$ & $\begin{array}{c}\text { MSE- } \\
\text { opt bw }\end{array}$ & eff. & N & month \\
\hline-0.0003 & 0.001 & 0.909 & {$[-0.002,0.003]$} & 0.006 & -0.045 & 20.56 & 192 & 1040 & 1 \\
0.0010 & 0.001 & 0.160 & {$[-0.001,0.004]$} & 0.005 & 0.154 & 21.76 & 303 & 1560 & 2 \\
0.0026 & 0.001 & 0.000 & {$[0.001,0.005]$} & 0.004 & 0.439 & 18.66 & 360 & 2080 & 3 \\
0.0011 & 0.001 & 0.105 & {$[-0.000,0.003]$} & 0.005 & 0.185 & 23.95 & 540 & 2600 & 4 \\
0.0009 & 0.001 & 0.128 & {$[-0.000,0.003]$} & 0.005 & 0.141 & 18.62 & 540 & 3120 & 5 \\
0.0017 & 0.001 & 0.023 & {$[0.000,0.005]$} & 0.004 & 0.242 & 15.10 & 490 & 3640 & 6 \\
0.0020 & 0.001 & 0.010 & {$[0.001,0.005]$} & 0.004 & 0.280 & 14.58 & 544 & 4160 & 7 \\
0.0027 & 0.001 & 0.000 & {$[0.001,0.005]$} & 0.004 & 0.376 & 13.63 & 558 & 4680 & 8 \\
0.0026 & 0.001 & 0.000 & {$[0.001,0.005]$} & 0.004 & 0.349 & 13.04 & 580 & 5200 & 9 \\
\hline
\end{tabular}

Notes: The dependent variable is monthly hate crimes within the category of 'violence against the person with injury' per 1000 residents in a constituency. $R D$ estimate is computed with local-linear regression within a symmetric MSE-optimal bandwidth. se is the conventional standard error, $p$-value and $95 \% C I$ are robust bias-corrected. mean control indicates the average monthly hate crime rate in constituencies where ethnic minorities barely lose, sd effect presents the RD estimate in standard deviations, MSE-opt bw is the MSE-optimal bandwidth of vote-share winning margin around the victory threshold, eff. $N$ is the sample size within the MSE-optimal bandwidth and $N$ is the sample size. The model specification includes controls. Standard errors are clustered by constituency-election. Hate crime data are from Home Office, ethnic background of candidates is constructed by the authors, and constituency characteristics from 2011 UK Decennial Census.
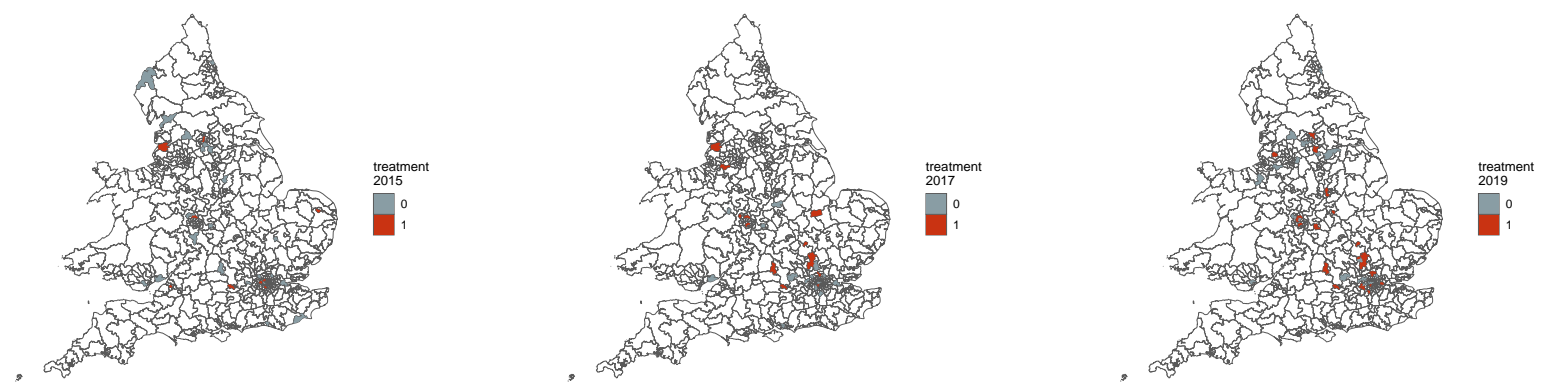

Figure G.9: Constituencies with ethnic minority candidate winners and losers in close elections

\section{G.12 Subgroup effects on hate crime}

We conduct five subgroup analyses. First, in Figure G.10a (right side) we show that the effect of a minority candidate victory in close parliamentary elections on hate crime is concentrated in constituencies that experience a larger than median increase in the number of migrants in the decade preceding the elections. In contrast, while we find that the effect on hate crimes is larger in constituencies that have experience larger than median increase in their unemployment rate in the decade preceding the election versus those experiencing relatively low unemployment rate, the difference between those two coefficients is not statistically significant (Figure G.10a, left side).

Second, we assess whether candidates with a Muslim background trigger a stronger hate crime response. Because we are able to code religion only for $23 \%$ of the candidates-contituency-election years, for this analysis, we impute a candidate's religion based on their region of origin by assigning 


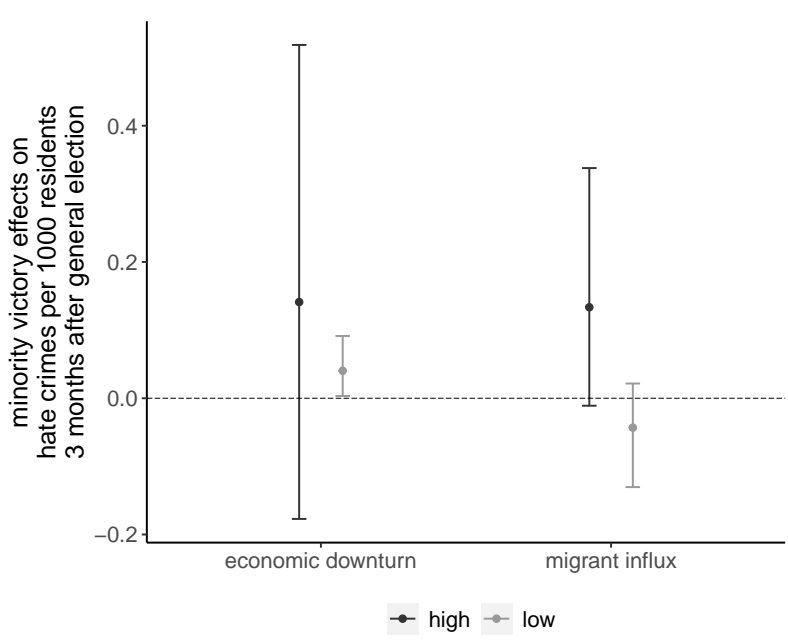

(a) By local conditions

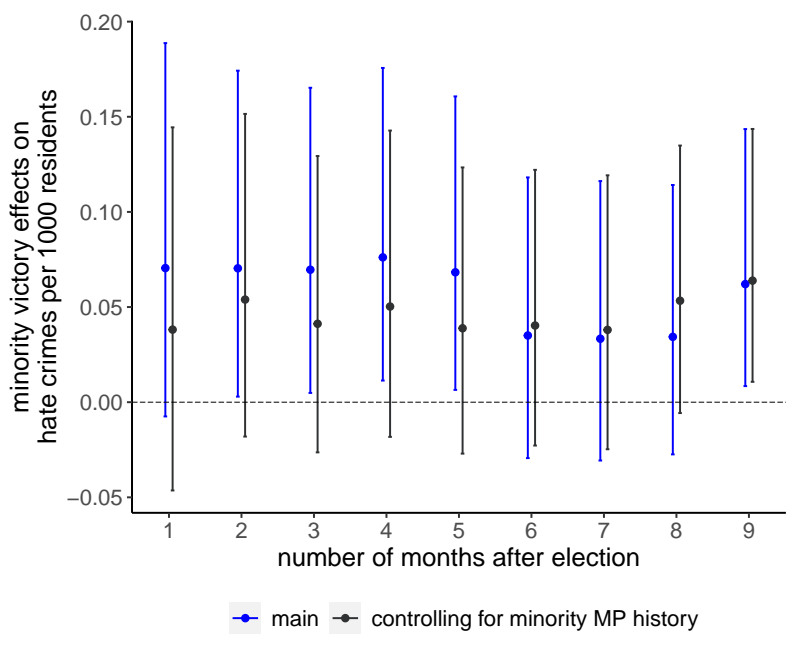

(b) Controlling for history of an ethnic minority MP

Notes: Points are RD estimates of the effect of an ethnic minority victory on hate crimes per 1000 residents and lines $95 \%$ robust bias-corrected confidence intervals.

Figure G.10: Subgroup effects on hate crime: local conditions and novelty

to each candidate the main religion in their region. 19\% of candidates-contituency-election years (from 2010-2019) are classified as Muslim, and the rest are Christian, Buddhist, or Hindu. The results in Figure G.11a suggest that the minority victory effects on hate crime are concentrated in constituencies with candidates from regions where the main religion is Islam (the difference in coefficients is statistically significant at the 0.1 level; $\mathrm{t}=1.76$ ). Third, the results in Figure G.11b suggest that consistent with threat, hate crime perpetrators (who are mostly White males) may be reacting not only to the symbolic and substantive representational threat posed by the political accession of ethnic minorities, but also to women entering historically men-dominated institutions, and their capacity to strengthen the position of women's interests.

Fourth, in Figure G.12a we show that minority migrant victory only has a positive effect on hate crime incidence when the candidate hails from a left- but not a right-wing party. We further show in Figure G.12b that these effects are not driven by a candidate's political affiliation only, but by the interaction between party affiliation and minority background. Particularly, we repeat the RD analysis but using races in which only White candidates stand for Parliament. Here, the running variable is the difference between the vote share of a White Labour candidate against the strongest White contestant. We do not find that a White Labour close victory increases hate crimes after the election; the coefficients are close to zero and not statistically significant. Fifth, in Figure G.10b we demonstrate that when controlling for whether the constituency was represented in the past by a minority candidate, the size of the effect shrinks quite a bit in the first 5 post-election months.

\section{H Analysis of political campaign issues}

We argue that compared to non-competitive races, election loss in close races between ethnic minority and dominant-group candidates are more likely to provoke hostility, in part because political elites have stronger incentives to stoke communal grievances to mobilize voters. In this section we 


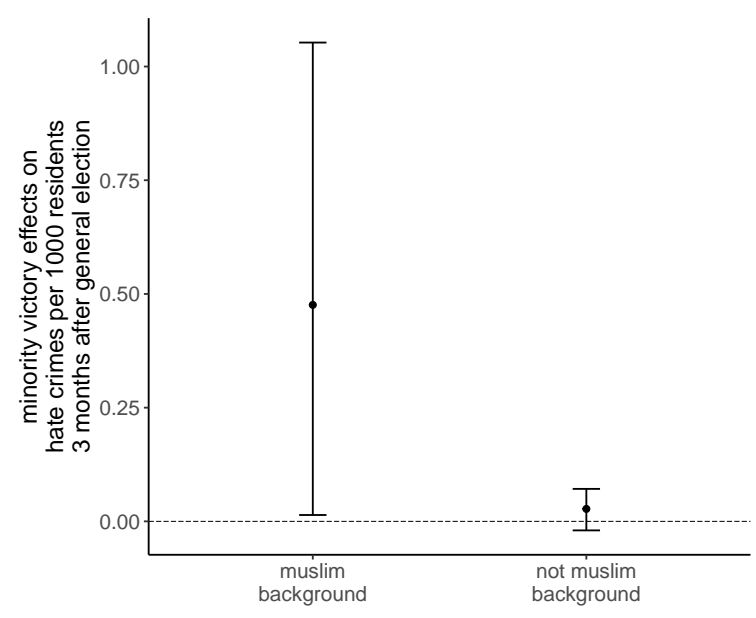

(a) By candidate's Muslim background

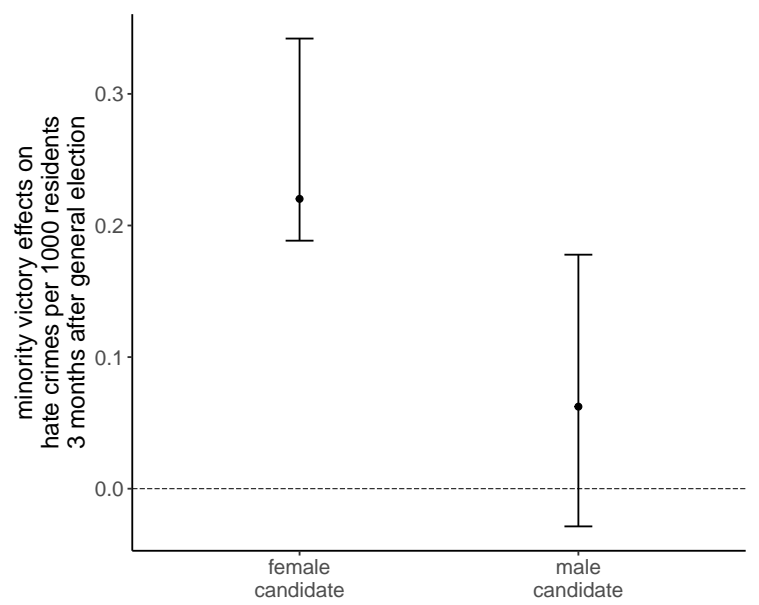

(b) By candidate's gender

Notes: Points are RD estimates of the effect of an ethnic minority victory and lines $95 \%$ robust bias-corrected confidence intervals.

Figure G.11: Subgroup effects on hate crime: religion and gender

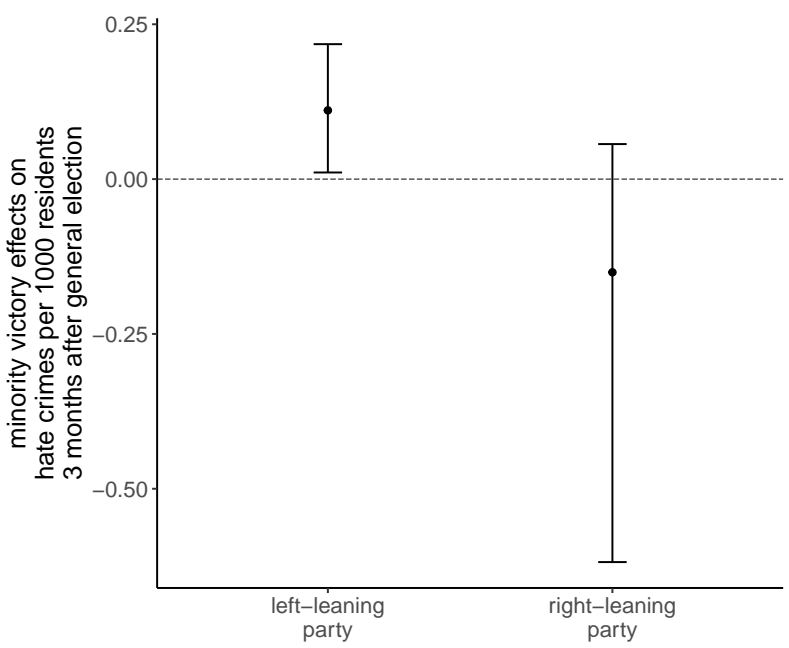

(a) By political ideology of candidate's party

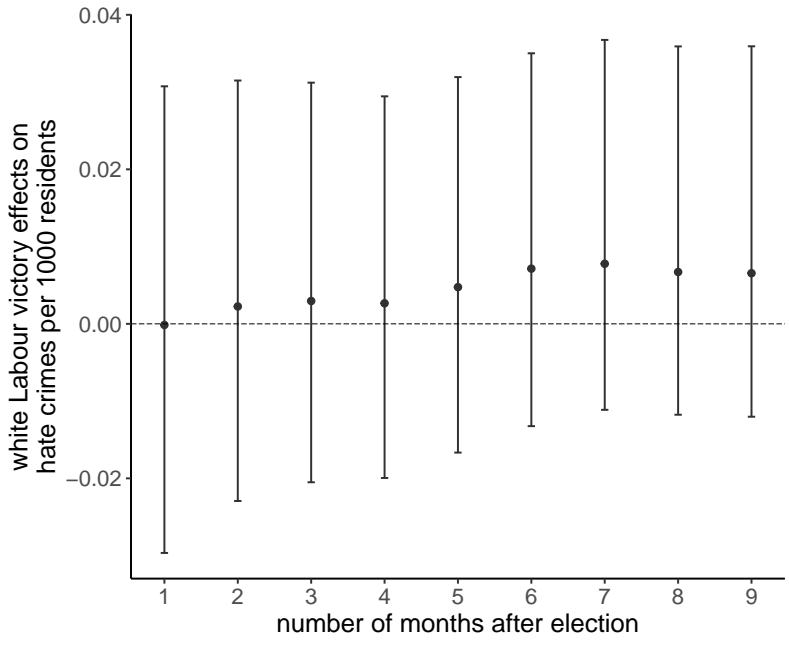

(b) White Labour victory effects on hate crime

Notes: Points are RD estimates of the effect of a victory of a White Labour candidate and lines $95 \%$ robust bias-corrected confidence intervals.

Figure G.12: Subgroup effects on hate crime: party ideology

show that while the role of political elites in close elections may enhance hostility, the political campaigns themselves and the issues covered in the campaigns (e.g. immigration, Brexit) do not seem to be the mechanism connecting an ethnic minority victory to hostility against ethnic minority immigrants.

To provide data on the issues covered by the political campaigns in our sample and to inform our mechanism, we collected data of candidate's campaign leaflets for the 2010, 2015, 2017 and 2019 general elections. This data is made available by Open Elections. In addition to hosting an online 
archive of the leaflets, Open Elections evaluates the leaflets on whether they include references to policies related to the economy, immigration, health, social welfare, education, environment, Europe/Brexit, or matters related to governance. We rely on this categorization to first, show that the issue coverage of political campaigns in close elections is no different to the coverage in all elections in our sample. This is presented in Figure H.1a which compares across constituencies with close elections and all constituencies in our sample, the share of constituencies in which at least one candidate covers an issue. Constituencies with close elections (defined as constituencies with a minority victory margin of $+/-22$ percentage points, according to the MSE-optimal bandwidth from the hate crime analysis) campaign on immigration (or Europe/Brexit) at similar rates than all constituencies. Secondly, in Figure H.1b and Figure H.1c, we show that the political campaign issues are not discontinuously covered at the victory cutoff, that is, the topic of immigration or Europe/Brexit, for example, is similarly covered across constituencies narrowly won by an ethnic minority candidate and constituencies narrowly won by a dominant-group candidate: the RD estimates are close to zero (Figure H.1b) and the p-values of the estimates testing for a discontinuity are above the 0.05 significance threshold (Figure H.1c).

This analysis suggest that the discussion of immigration or Brexit during the political campaigns is not driving the exclusionary response to an ethnic minority victory, reinforcing the possibility that dominant-group members respond to status threat as advanced by our main argument.

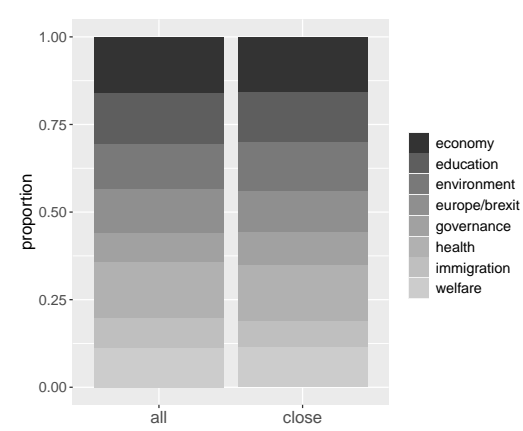

(a) Campaign issue coverage

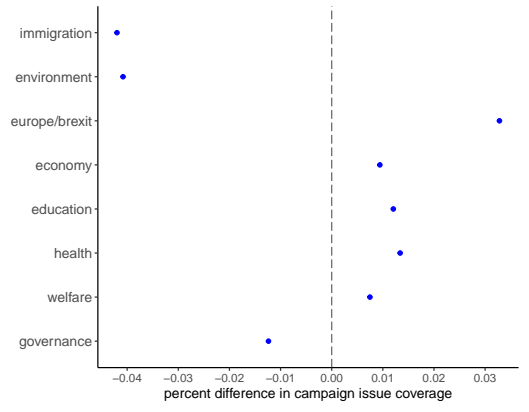

(b) RD estimates of campaign issues

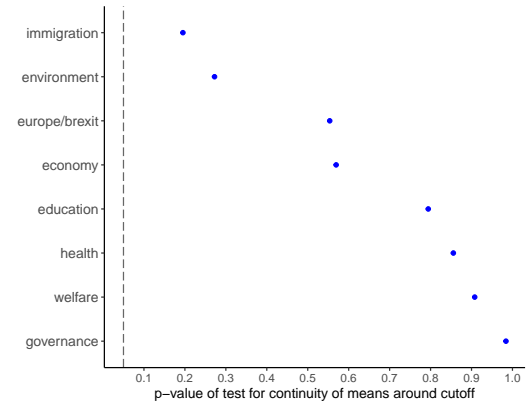

(c) p-values of campaign issues RD estimates

Notes: (b), (c) test for continuity of campaign issues using a local linear regression with a symmetric MSE-optimal bandwidth as implemented by the rdrobust $\mathrm{R}$ package. (b) shows RD estimates and (c) p-values of estimates.

Figure H.1: Continuity of campaign issues around the victory threshold

\section{H.1 UKIP/Brexit Party electoral participation}

We have shown above that campaign issues are equally covered in constituencies narrowly won and lost by ethnic minority candidates. However, it is still possible that in constituencies narrowly won by ethnic minority candidates UKIP/Brexit participates at higher rates than in constituencies narrowly lost by ethnic minority candidates. If so, our RD estimates would measure the bundled treatment of a minority victory and the role of UKIP in stoking an anti-immigrant sentiment during the campaigns. We assess such a possibility by looking at whether the probability of UKIP running in the elections and UKIP's vote share is discontinuous at the victory cutoff. The results presented in Figure H.2a suggest that there is no discontinuity in the probability of UKIP participating in 
the elections: the RD-estimate is positive and not statistically significant. Furthermore, the RDestimate on UKIP's vote share is negative and not statistically significant (Figure H.2a).

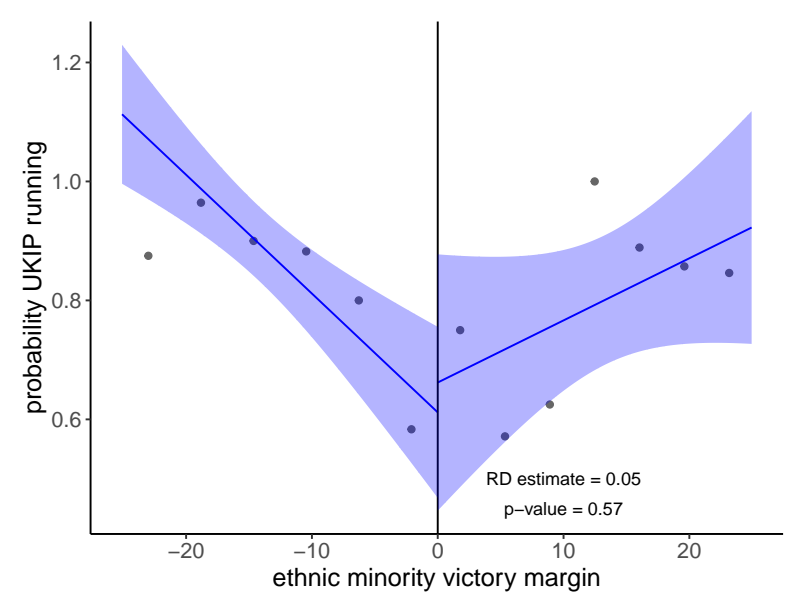

(a) Probability of running

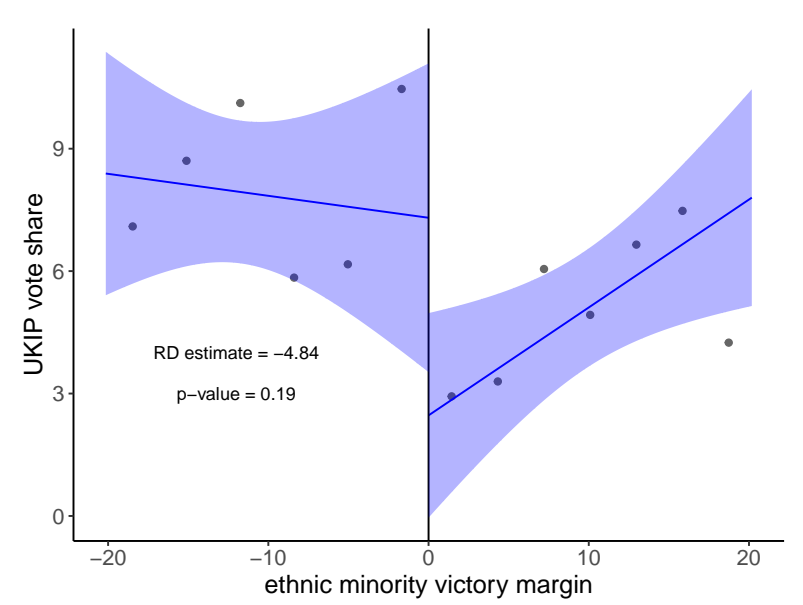

(b) Vote share

Notes: In (a) lines are average UKIP's participation rate (with 95\% confidence intervals) from local linear regression. Points are average UKIP's participation rates for equally spaced mimickingvariance bins. In (b) lines are average vote share (with $95 \%$ confidence intervals) from local linear regression. Points are average UKIP's vote share for equally spaced mimicking-variance bins.

Figure H.2: Continuity of UKIP/Brexit Party electoral participation

These results reassure us that the exclusionary responses we document here are responses to the election of a minority candidate clean and orthogonal to UKIP's political activism.

\section{Minority victory effects on mass public attitudes: valid- ity of the RD design, robustness checks and supporting results}

Moving to mass public opinion, we report below a set of placebo and falsification tests that establish the validity of the $\mathrm{RD}$ design (sections I.1-I.5), and the results' robustness to alternative specifications (section I.6). We further report the main RD results in tabular form and the robustness of those results to alternative survey questions in section I.7.

\section{I.1 Continuity of placebo outcomes}

We test whether an index of left-right views is discontinuous at the threshold where constituencies go from electing a dominant group candidate to electing a minority candidate. The rationale for using ideology as a placebo outcome is that it is expected to be strongly correlated with attitudes towards immigrants and ethnic minorities, but as ideology is sticky is not expected to be affected by the ethnic identity of the winning candidate. Figure I.1 reveals no discontinuity in ideology at the threshold where minority candidates win a seat in Parliament. These tests suggest that the validity of the design holds. 


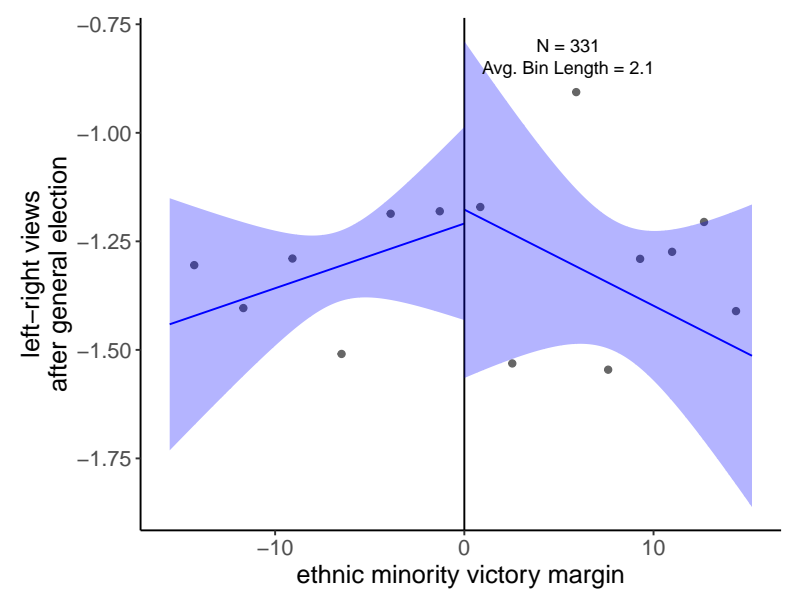

(a) Effects on ideology (placebo outcome)

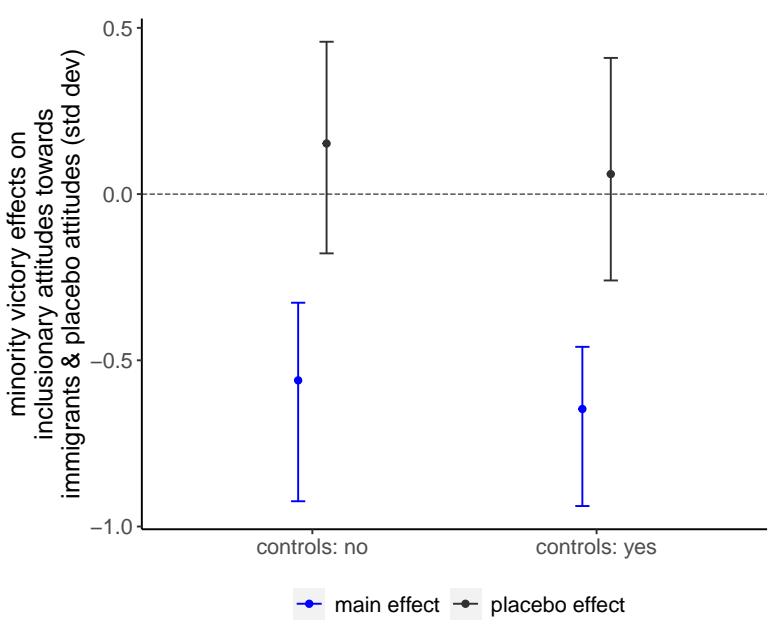

(b) Comparison of main and placebo effects

Notes: In (a) lines represent respondents' average left-right view (with 95\% confidence intervals) from local linear regression with covariate adjustment fitted to the sample of units whose vote-share winning margin is within the MSE-optimal bandwidth of $+/-15.7 \mathrm{pp}$ around the victory threshold. Points are the average left-right view for equally spaced mimicking-variance bins. In (b) points are RD estimates of the effect of an ethnic minority victory and lines $95 \%$ robust bias-corrected confidence intervals.

Figure I.1: Ethnic minority victory effects on ideology (placebo outcome)

\section{I.2 Density of the running variable}

Figure I.2 reveals no evidence of sorting around the cutoff. Even though there appears to be a jump in the density functions of respondents at the threshold in which constituencies go from electing a dominant group candidate to electing a minority candidate, the confidence intervals of these density functions completely overlap and the p-value of the continuity test indicates that we cannot reject the null of continuity of the density functions. The results of these tests indicate no manipulation of the election results.
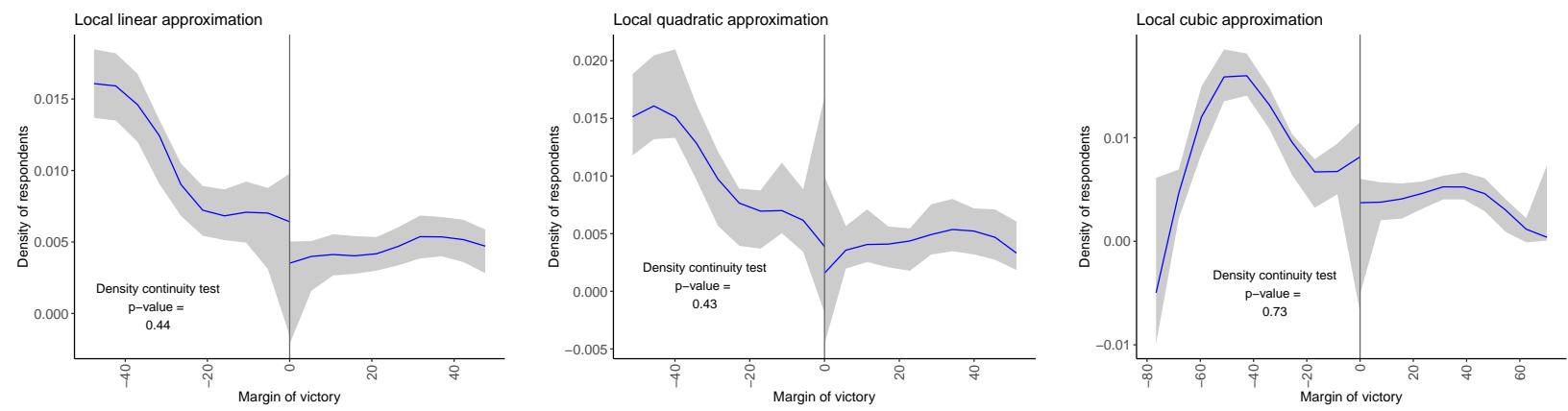

Notes: Tests for manipulation of the election results by assessing continuity of the density functions at the cutoff with local polynomial density estimators and robust bias-corrected inference.

Figure I.2: Continuity in the density of survey respondents around the cutoff 


\section{I.3 Continuity of outcome before general election}

We test whether attitudes toward immigrants are discontinuous at the margin of victory cutoff before the general election. To do so, we would ideally use our main outcome measure on attitudes toward immigration entry policy. However, the face-to-face British Election Study (the data we use in the main analysis) does not include pre-election observations. Instead, we use the British Election Study Internet Panel, which includes pre-election waves. The only question on attitudes toward immigration/immigrants available in pre-election waves in 2015 (wave 3), 2017 (wave 11), and 2019 (wave 16) is: "Do you think immigration is good or bad for Britain's economy?" on a 7-point scale from bad to good. Consistent with our 5 -point scale post-election outcome measure we collapse the answer categories 2, 3 and 5, 6, to be able to compare the RD estimates before/after election.

Figure I.3a shows that pre-election attitudes toward immigrants are not discontinuous at the threshold where an ethnic minority candidate wins a seat in Parliament. The effect is not statistically significant and is comparably smaller to the post-election effect. (The pre- and post-election coefficients have opposite signs). This increases our confidence about the robustness of our results, as it suggests that the estimates of the minority victory effects on attitudes toward immigrants are not explained by other dynamics in constituencies where minorities win.

\section{I.4 Continuity of predetermined variables}

In Figure I.3 we present results for the tests on the continuity of predetermined variables around the threshold where minority candidates win a seat in Parliament. We find that 2 of a total of 36 covariates show statistically significant discontinuities in means with the test employing local linear regression within an MSE-optimal bandwidth controlling for the FDR with the Benjamini-Hochberg procedure (Figure I.3b). This number of discontinuous covariates is equivalent to the average number of false rejections (which is 1.8). Furthermore, with the permutation test for continuity in the distribution of observations around the cutoff, we find that only 1 of the 35 predetermined variables are discontinuous at the cutoff (Figure I.3c). The results from both tests suggest that there were no systematic discontinuities in the covariates at the threshold were minorities win political office, and that therefore the continuity assumption of the potential outcome functions is likely to hold.

\section{I.5 Sensitivity to the choice of bandwidth and polynomials}

The results on mass public opinion are not sensitive to the choice of bandwidth. In Figure I.4 we present the minority victory effects on the main attitudinal outcome for different values of the bandwidth. We fit our lineal model to the sample of observations within the CER- and MSE-optimal bandwidths, half, three fourths, five fourths, and one half their size. We find that the results are broadly consistent with the findings obtained with the MSE-optimal bandwidth.

In Table I.1, we show that the results are robust to fitting quadratic polynomials.

\section{I.6 Controlling for candidate's political party}

We isolate the ethnic identity of candidates from their political party affiliation from the attitudinal response by controlling for party dummies. In Figure I.5 we present the ethnic minority victory effects from a specification that controls for party dummies. The coefficient is very close in magnitude (somewhat bigger) to that obtained with our main specification shown in Figure 2, suggesting that the exclusionary attitudinal response is not driven by the political affiliation of the candidates. 


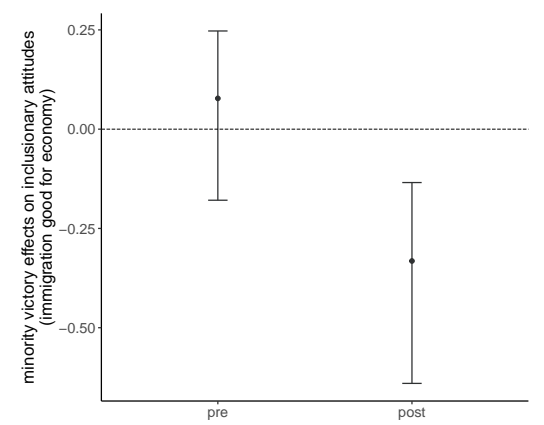

(a) Ethnic minority victory effects on inclusionary attitudes before and after election

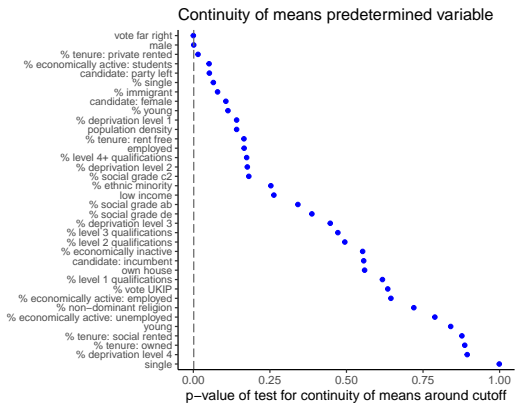

(b) Continuity of means using local linear regression

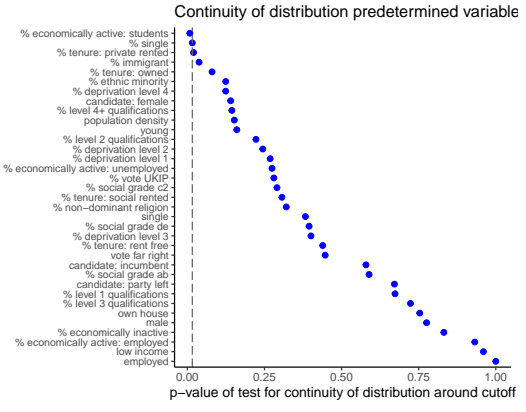

(c) Continuity of distribution using asymptotic permutation test

Notes: In (a) points are RD estimates of the effect of an ethnic minority victory before and after the election and lines $95 \%$ robust bias-corrected confidence intervals. (b), (c) test for continuity of candidate and constituency predetermined background characteristics in (b) using a local linear regression with a symmetric MSE-optimal bandwidth as implemented by the rdrobust $R$ package and in (c) using an asymptotic permutation test comparing the distribution of observation near the cutoff as implemented by the RATest $\mathrm{R}$ package. The vertical line in (b) indicates a $p$-value $=$ 0.0012, which is the threshold for the p-values when controlling the false discovery rate with the Benjamini-Hochberg procedure, and in (c) $p$-value $=0.008$.

Figure I.3: Continuity of predetermined variables around the cutoff

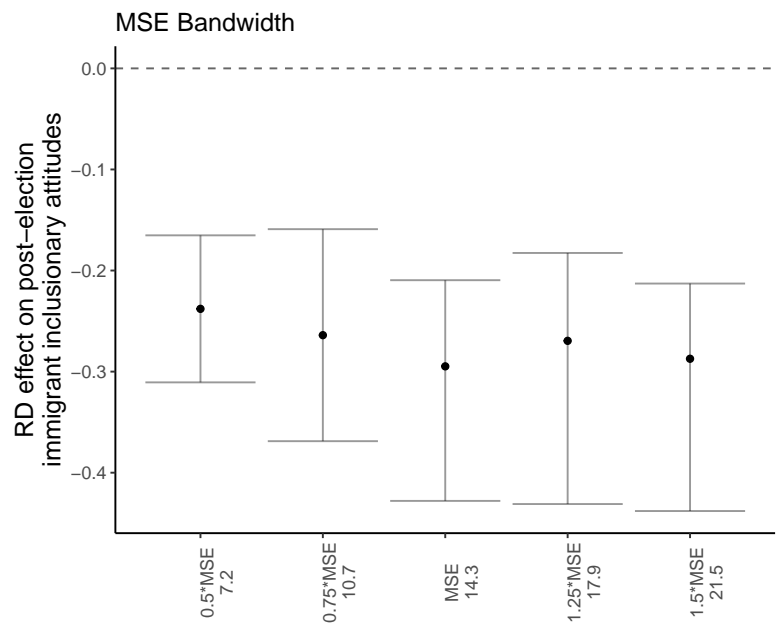

(a)

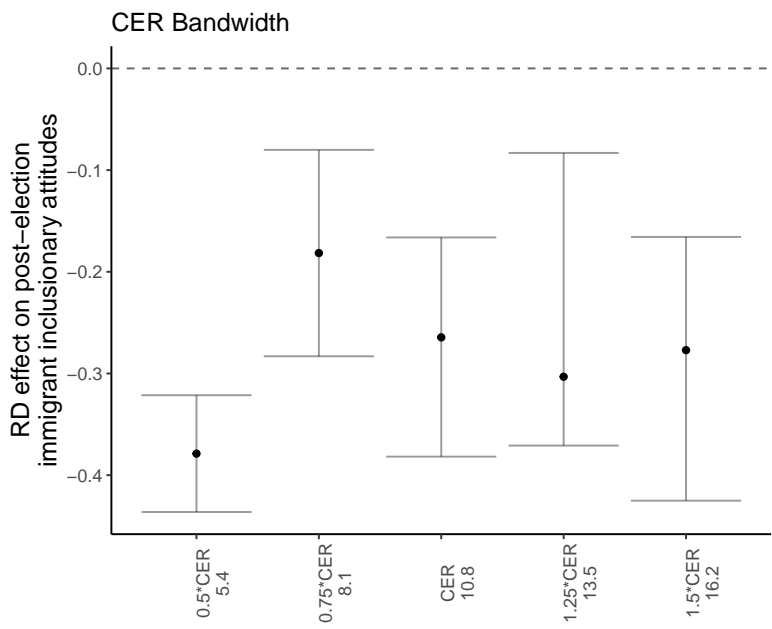

(b)

Notes: tests for sensitivity to the choice of bandwidth. In (a) MSE stands for mean squared error optimal bandwidth and in (b) CER refers to a bandwidth that minimizes the coverage error from the robust biased corrected confidence intervals obtained with the MSE-optimal bandwidth. The values next to the 'MSE', 'CER', labels indicate the bandwidth size.

Figure I.4: Sensitivity to bandwidth size 
Table I.1: Ethnic minority victory effects on mass inclusionary attitudes towards immigrants

\begin{tabular}{cccccccccccc}
\hline $\begin{array}{c}\text { RD } \\
\text { estimate }\end{array}$ & se & $\begin{array}{c}\text { p- } \\
\text { value }\end{array}$ & $\begin{array}{c}95 \% \\
\text { CI }\end{array}$ & $\begin{array}{c}\text { mean } \\
\text { control }\end{array}$ & $\begin{array}{c}\text { sd } \\
\text { effect }\end{array}$ & $\begin{array}{c}\text { MSE- } \\
\text { opt bw }\end{array}$ & $\begin{array}{c}\text { eff. } \\
\text { N }\end{array}$ & N & cov & smpl & pol \\
\hline-0.255 & 0.065 & 0.000 & {$[-0.426,-0.150]$} & 0.434 & -0.562 & 14.42 & 291 & 1924 & no & f & l \\
-0.258 & 0.065 & 0.000 & {$[-0.425,-0.150]$} & 0.440 & -0.560 & 15.14 & 288 & 1876 & no & c & l \\
-0.295 & 0.052 & 0.000 & {$[-0.428,-0.210]$} & 0.445 & -0.646 & 14.33 & 283 & 1876 & yes & c & l \\
-0.270 & 0.073 & 0.001 & {$[-0.454,-0.127]$} & 0.461 & -0.589 & 21.99 & 403 & 1924 & no & f & q \\
-0.277 & 0.071 & 0.000 & {$[-0.460,-0.129]$} & 0.469 & -0.605 & 22.89 & 399 & 1876 & no & c & q \\
-0.313 & 0.063 & 0.000 & {$[-0.433,-0.137]$} & 0.446 & -0.687 & 17.61 & 345 & 1876 & yes & c & q \\
\hline
\end{tabular}

Notes: The dependent variable is a dummy indicating whether a survey respondent do not thinks that "too many immigrants have been let into the country". RD estimate is computed with local-linear regression within a symmetric MSE-optimal bandwidth when $p o l$ is $l$, and with a quadratic polynomial when pol is $q$. se is the conventional standard error, $p$-value and $95 \% C I$ are robust bias-corrected. mean control indicates the average dependent variable value in constituencies where ethnic minorities barely lose. sd effect presents the RD estimate in standard deviations, MSE-opt bw is the MSE-optimal bandwidth of vote-share winning margin around the victory threshold, eff. $N$ is the sample size within the MSE-optimal bandwidth and $N$ is the sample size. cov includes predetermined covariates in the model specification. smpl is the used sample: $f$ stands for full sample and $c$ for a complete cases sample with no missing values for respondent's predetermined variables. Standard errors are clustered by constituency-election. Survey data are from the British Election Study, ethnic background of candidates is constructed by the authors, and constituency characteristics from 2001 and 2011 UK Decennial Census.

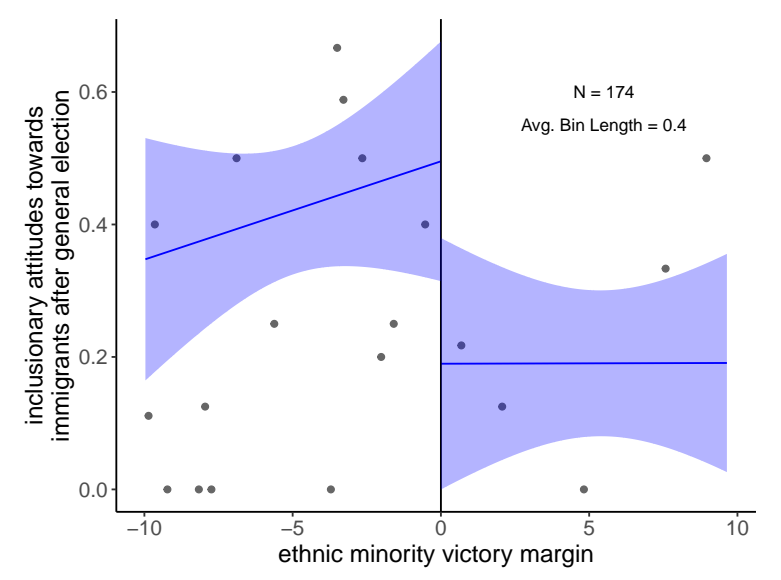

Figure I.5: Isolating candidates' ethnic identity from their political party

Notes: Lines represent the average proportion of respondents who do not think that "too many immigrants have been let into the country" (with 95\% confidence intervals) from local linear regression with covariate adjustment, including party dummies, fitted to units whose vote-share winning margin is within the MSE-optimal bandwidth of +/- $10.3 \mathrm{pp}$.

\section{I.7 Additional attitudinal outcomes}

To validate the robustness of our results beyond our main attitudinal outcome we compute two additional outcomes that use all other available survey items on attitudes towards immigration and ethnic minorities. The first outcome, economy, is an item that asks survey respondents whether immigrants are good for Britain's economy. This item is included in all survey years, but the wording of questions and answers (and their range) changes across time. The second outcome is an 
index that includes stereotypical beliefs about immigrants and attitudes towards accommodating diversity. However, this items are only included for a subsample of $60 \%$ of those who answered the 2017, 2019 surveys, more than halving the sample size compared to the sample size of the main outcome entry, and almost reducing the sample to a third compared to the sample of the economy outcome. Such a reduction in sample size, reduces the continuity test's statistical power.

In Table I.2 we present the effect estimates on these two additional attitudinal outcomes discussed further in Appendix C. We include as well the estimates on our main outcome as benchmark. The effect estimate is negative across the main outcome and the two additional measures, and across model specifications. The magnitude of the effect on the two additional outcomes, economy and index, is similar: a decrease in inclusionary attitudes of $9.5 \%$ and $6.5 \%$; respectively, relative to the average attitude in constituencies narrowly lost by ethnic minority candidates. However, given the limitations in sample size, the effect estimate on the index is not statistically significant.

The consistency in sign and magnitude across outcome measures and model specifications increases our confidence in the attitudinal results.

Table I.2: Ethnic minority victory effects on mass attitudes towards immigrants

\begin{tabular}{cccccccccccc}
\hline $\begin{array}{c}\text { RD } \\
\text { estimate }\end{array}$ & se & $\begin{array}{c}\mathrm{p}- \\
\text { value }\end{array}$ & $\begin{array}{c}95 \% \\
\text { CI }\end{array}$ & $\begin{array}{c}\text { mean } \\
\text { control }\end{array}$ & $\begin{array}{c}\text { sd } \\
\text { effect }\end{array}$ & $\begin{array}{c}\text { MSE- } \\
\text { opt bw }\end{array}$ & $\begin{array}{c}\text { eff. } \\
\text { N }\end{array}$ & N & out & cov & smpl \\
\hline-0.332 & 0.118 & 0.003 & {$[-0.640,-0.134]$} & 3.438 & -0.252 & 11.69 & 239 & 2111 & economy & no & $\mathrm{f}$ \\
-0.371 & 0.120 & 0.001 & {$[-0.678,-0.167]$} & 3.468 & -0.284 & 11.39 & 233 & 2058 & economy & no & c \\
-0.479 & 0.063 & 0.000 & {$[-0.645,-0.380]$} & 3.336 & -0.367 & 8.05 & 133 & 2058 & economy & yes & $\mathrm{c}$ \\
-0.255 & 0.065 & 0.000 & {$[-0.426,-0.150]$} & 0.434 & -0.562 & 14.42 & 291 & 1924 & entry & no & $\mathrm{f}$ \\
-0.258 & 0.065 & 0.000 & {$[-0.425,-0.150]$} & 0.440 & -0.560 & 15.14 & 288 & 1876 & entry & no & $\mathrm{c}$ \\
-0.295 & 0.052 & 0.000 & {$[-0.428,-0.210]$} & 0.445 & -0.646 & 14.33 & 283 & 1876 & entry & yes & $\mathrm{c}$ \\
-0.145 & 0.201 & 0.510 & {$[-0.582,0.289]$} & 2.225 & -0.157 & 18.83 & 170 & 899 & index & no & $\mathrm{f}$ \\
-0.187 & 0.203 & 0.408 & {$[-0.624,0.253]$} & 2.263 & -0.202 & 18.70 & 161 & 865 & index & no & $\mathrm{c}$ \\
-0.092 & 0.186 & 0.754 & {$[-0.453,0.329]$} & 2.274 & -0.099 & 15.66 & 145 & 865 & index & yes & $\mathrm{c}$ \\
\hline
\end{tabular}

Notes: The dependent variable is indicated by out: economy is respondent's agreement with the statement "immigration is good for Britian's economy" on a 5-point Likert scale, entry, which is our main outcome of interest and is included here as benchmark, is a dummy indicating whether a survey respondent do not thinks that "too many immigrants have been let into the country", and index aggregates agreement with five statements about immigrants and ethnic minorities; higher values indicate more inclusionary attitudes. RD estimate is computed with local-linear regression within a symmetric MSE-optimal bandwidth. se is the conventional standard error, p-value and 95\% CI are robust bias-corrected. mean control indicates the average proportion of respondents who do not think that "too many immigrants have been let into the country" in constituencies where ethnic minorities barely lose. sd effect presents the RD estimate in standard deviations, MSE-opt bw is the MSE-optimal bandwidth of vote-share winning margin around the victory threshold, eff. $N$ is the sample size within the MSE-optimal bandwidth and $N$ is the sample size. cov is a vector of controls including an indicator of whether the candidate is the incumbent, whether the survey respondent is male, young, single, employed, owns a house, and the constituency vote share for UKIP and BNP in the previous election, share that is foreign born, and share of households with 3 or more deprivations. smpl is the used sample: $f$ stands for full sample and $c$ for a complete cases sample with no missing values for respondent's predetermined variables. Standard errors are clustered by constituency-election. Survey data are from the British Election Study, ethnic background of candidates is constructed by the authors, and constituency characteristics from 2001 and 2011 UK Decennial Census.

\section{I.8 Including Scotland}

The analysis centers on England and Wales as hate crime data requested to the Home Office via a FOI was only secured for these two countries. Restriction to England and Wales for the analysis on attitudes follows the hate crime sample. However, in this section, we show that the main 
conclusions are robust to including observations from Scotland. ${ }^{14}$ Figure I. 8 presents the estimated effects of a minority victory on the three attitudinal outcomes. Effect estimates are presented in standard deviations for comparison across measures. The estimated coefficients are negative and statistically significant, indicating that a minority victory provokes less inclusionary attitudes toward immigrants. In sum, this evidence suggests that the results are not sensitive to the country composition of the sample.

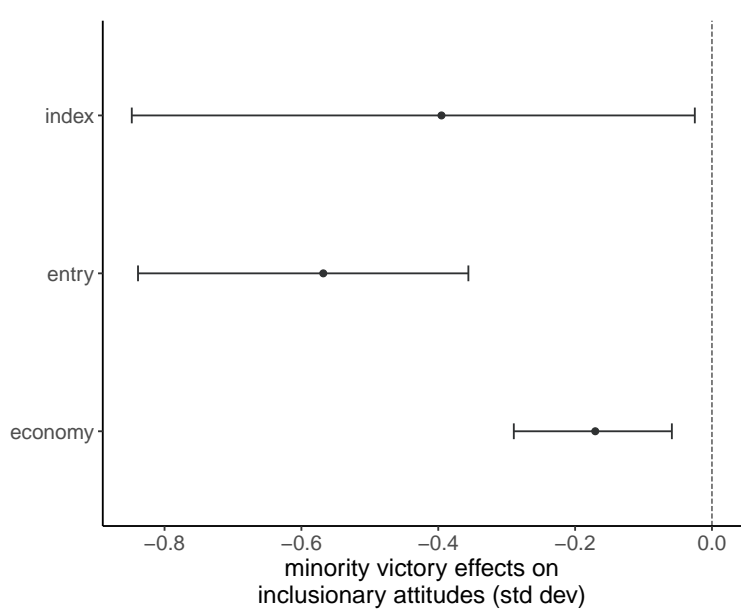

Notes: Points are RD estimates of ethnic minority victory effects and lines $95 \%$ robust bias-corrected confidence intervals from local linear regression with covariate adjustment on the sample of units with vote-share winning margins within the MSE-optimal bandwidth.

Figure I.6: Ethnic minority victory effects on attitudes toward immigrants (in England, Scotland and Wales)

\section{J Media tone towards migrant groups: validity of the RD design, robustness checks and supporting results}

We report placebo and falsification tests that establish the validity of the RD design and the robustness of our results (sections J.1-J.5), an analysis showing that our media tone measure is independent from our hate crime measure, and the main RD results in tabular form (section J.6).

\section{J.1 Continuity of placebo outcomes}

We use as a placebo measure the tone of news article mentions about countries and nationalities from North America, Western Europe, Australia and New Zealand that co-occur with mentions about the candidate's constituency. The placebo outcome is thus the monthly ratio of negative mentions to total mentions about these countries and nationalities in the candidate's constituency. In Figure J.1a we illustrate the RD estimates of the effect of a minority win on this placebo outcome three months from the election, and in Figure J.1b we present the estimates across months after the election, and

\footnotetext{
${ }^{14}$ We exclude Ireland as our candidate data does not include minority candidates from this country.
} 
we compare them to the estimates of the effects on media tone about the candidate's ethnic group (our main outcome variable). Both figures show no discontinuity in the tone of mentions about placebo countries and nationalities at the threshold where minorities win political office, suggesting that the validity of the design holds.

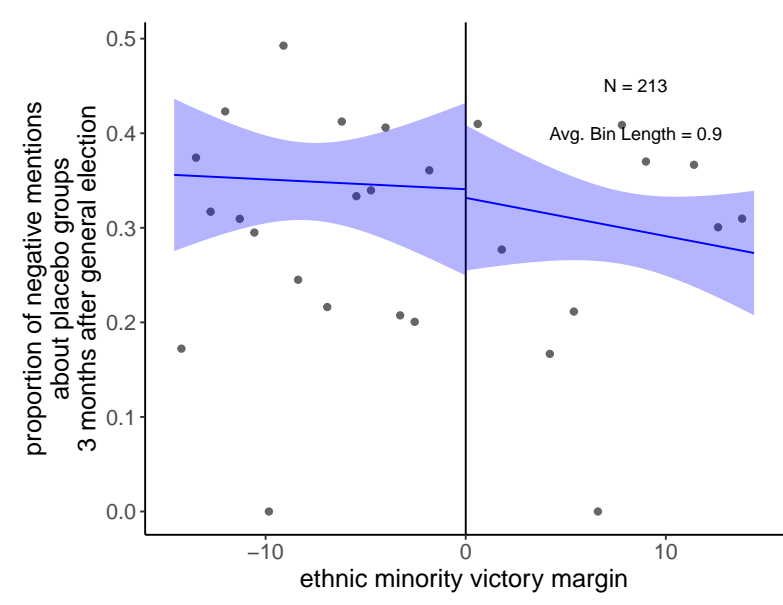

(a) Effect on proportion of negative mentions about placebo groups

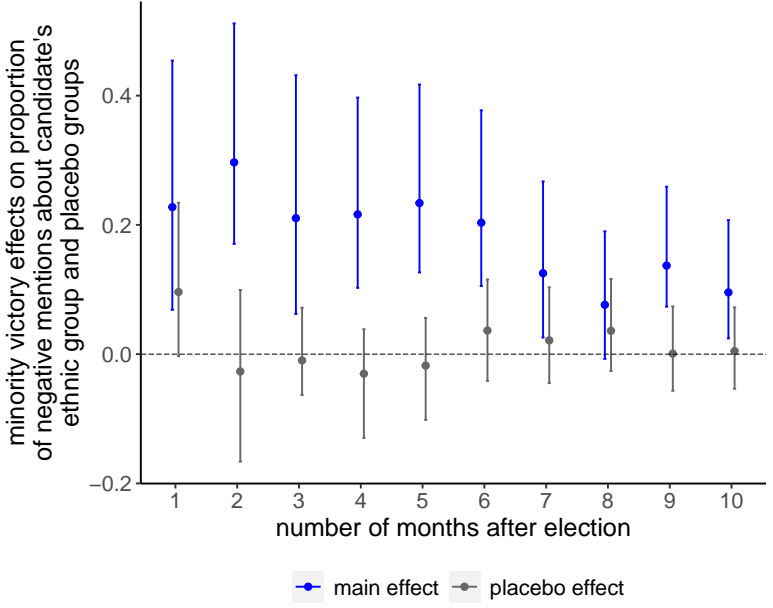

(b) Comparison of main and placebo effects

Notes: In (a) lines represent monthly proportion of negative mentions about countries and nationalities from North America, Western Europe, Australia and New Zealand in a candidate's constituency (with 95\% confidence intervals) from local linear regression with covariate adjustment on the sample of units with vote-share winning margins within the MSE-optimal bandwidth of $+/-12.1 \mathrm{pp}$. In (b) points are RD estimates of ethnic minority victory effects and lines $95 \%$ robust bias-corrected confidence intervals.

Figure J.1: Ethnic minority victory effects on media tone of placebo groups

\section{J.2 Density of the running variable}

Figure J.2 reveals no evidence of sorting around the cutoff. Even though there appears to be a jump in the density functions of candidates at the threshold in which constituencies go from electing a dominant group candidate to electing a minority candidate, the confidence intervals of these density functions completely overlap and the p-value of the continuity test indicates that we cannot reject the null of continuity of the density functions. In addition, the p-value for the (McCrary, 2008) sorting test is 0.82 , indicating that we cannot reject the null hypothesis of continuity of the density of candidates at the threshold. The results of these tests indicate no manipulation of the election results.

\section{J.3 Continuity of predetermined variables}

In Figure J.3 we present results for the tests on the continuity of predetermined variables around the threshold where minority candidates win a seat in Parliament. We find that 2 of a total of 32 covariates show statistically significant discontinuities in means with the test employing local linear 

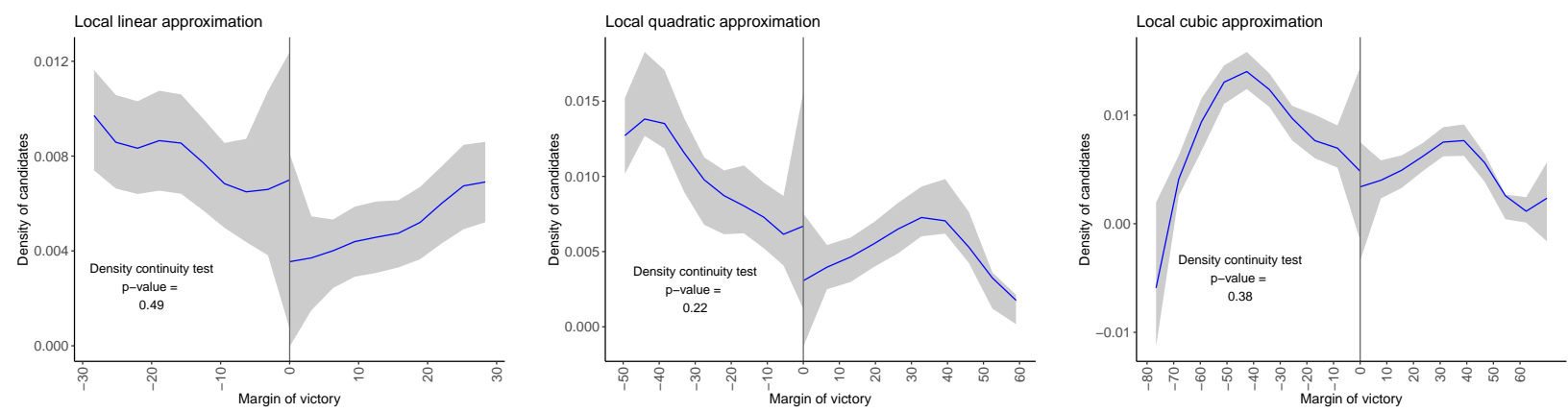

Notes: Manipulation tests for the election results by assessing continuity of the density functions at the cutoff with local polynomial density estimators and robust bias-corrected inference.

Figure J.2: Continuity in the density of candidates around the cutoff

regression within an MSE-optimal bandwidth (Figure J.3a). Furthermore, controlling for the FDR with the Benjamini-Hochberg procedure we do not find discontinuous variables. Moreover, with the permutation test for continuity in the distribution of observations around the cutoff, we find that only 1 of the 31 predetermined variables are discontinuous at the cutoff, and zero when we control the FDR with the Benjamini-Hochberg procedure (Figure J.3b). This number of discontinuous covariates is equivalent to the average number of false rejections (which is 1.55). The results from both tests suggest that there were no systematic discontinuities in the covariates at the threshold were minorities win political office, and that therefore the continuity assumption of the potential outcome functions is likely to hold.

\section{J.4 Continuity of main outcome before general election}

We test whether the proportion of negative mentions about a candidate's ethnic group is discontinuous at the minority victory threshold before the general election. We find no discontinuities at the threshold before the election - the estimates of the effect of a minority win are centered around zero (and are not statistically significant) - except for two months before the election; when there is a jump at the threshold in the proportion of negative mentions about the winner's ethnic group. Such an increase however, is only distinguishable from zero one month prior to the election (Figure J.3c). Campaigns officially begin with the dissolution of Parliament, which is about one month and a half prior to the election. It is possible that there is an anticipatory reaction from the media to minorities winning a seat in Parliament, as the media is more informed than the general public. The media may be also using elections contested by competitive minority candidates to maximize profit from the expected public's increased engagement with negative coverage of out-groups (e.g. Rathje, Van Bavel and Van Der Linden, 2021). It is also possible that the media responds to minority candidacies with a more negative coverage of candidates who are more likely to win, with the objective of affecting the election results. Overall, this placebo test increases our confidence about the robustness of our results. It suggests that the estimates of the minority victory effects on media tone about a candidate's ethnic group are explained by the election and not by other dynamics in constituencies where minorities win. 


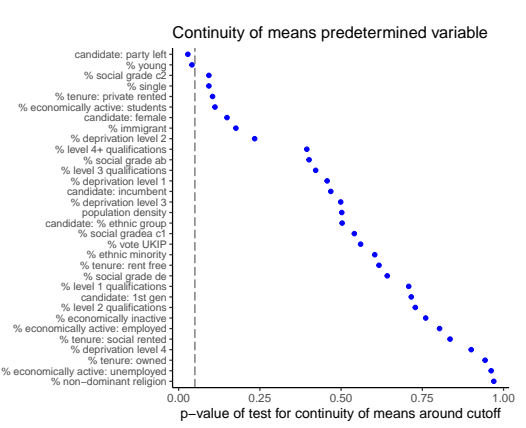

(a) Continuity of means using local linear regression

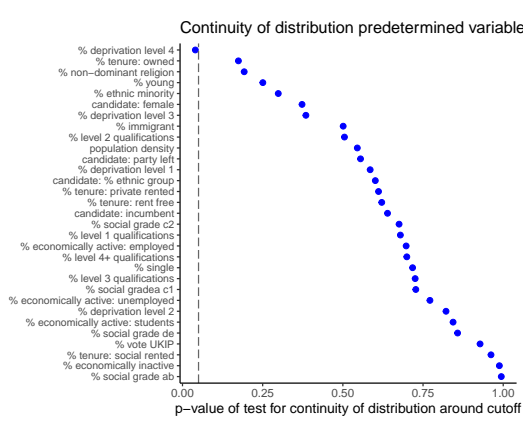

(b) Continuity of distribution using asymptotic permutation test

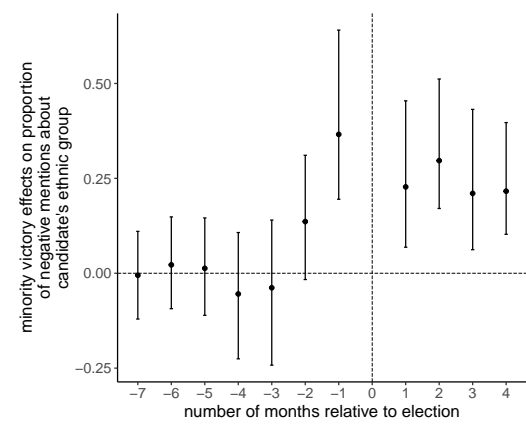

(c) Ethnic minority victory effects on media tone before and after the election

Notes: (a), (b) test for continuity of candidate and constituency predetermined background characteristics in (a) using a local linear regression with a symmetric MSE-optimal bandwidth as implemented by the rdrobust $\mathrm{R}$ package and in (b) using an asymptotic permutation test comparing the distribution of observation near the cutoff as implemented by the RATest $\mathrm{R}$ package. The vertical line indicates $p$-value $=0.05$. In (c) points are $\mathrm{RD}$ estimates of the effect of an ethnic minority victory and lines $95 \%$ robust bias-corrected confidence intervals

Figure J.3: Continuity of predetermined variables around the cutoff

\section{J.5 Sensitivity to the choice of bandwidth and order of polynomial}

In Figures J.4a and J.4b we test for sensitivity of the results to the choice of bandwidth, using CERand MSE-optimal bandwidths, three fourths, half, five fourths, and one half their size. We find that the results are consistent with the findings obtained with the optimal MSE bandwidth - there is an increase in the proportion of negative mentions about a candidate's ethnic group at the victory threshold. In Figure J.4c we show that the results are robust to fitting quadratic polynomials. These two results strengthen the validity of our findings on media tone.

\section{J.6 Main RD results in tabular form}

Table J.1 presents estimates for model specifications with/out covariates.

\section{J.7 Controlling for candidate's political party}

We further isolate the ethnic identity of candidates from their political party affiliation from the media negative coverage response by controlling for party indicator variables. In Figure J.5a we compare the RD estimates of our main specification to the estimates from a specification controlling for party dummies. The coefficients are very close in magnitude, suggesting that the media response is not explained only by the political affiliation of the candidates.

\section{J.8 Is the media tone measure independent from the hate crimes measure?}

To answer this question, we classify the newspaper article sentences which contain mentions of the minority candidates' ethnicity as speaking about hate crime or xenophobia by looking at whether 


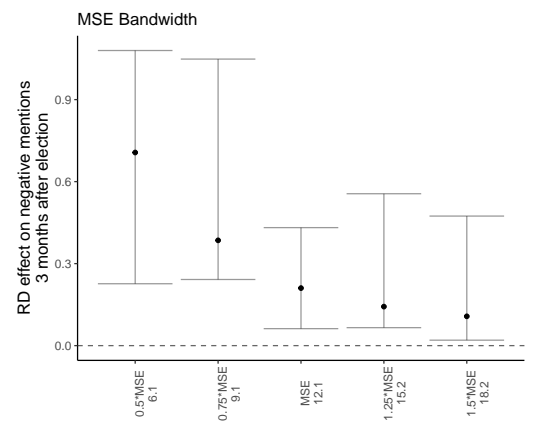

(a) Sensitivity to bandwidth size: MSE

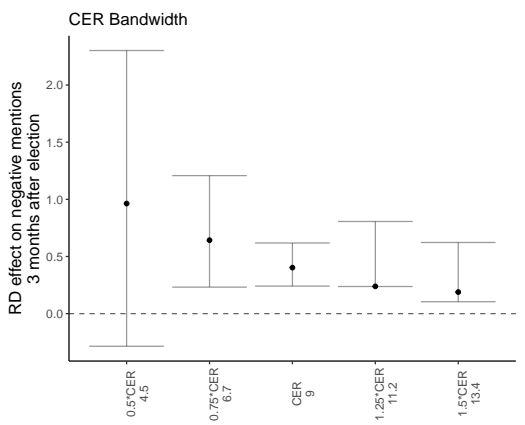

(b) Sensitivity to bandwidth size: CER

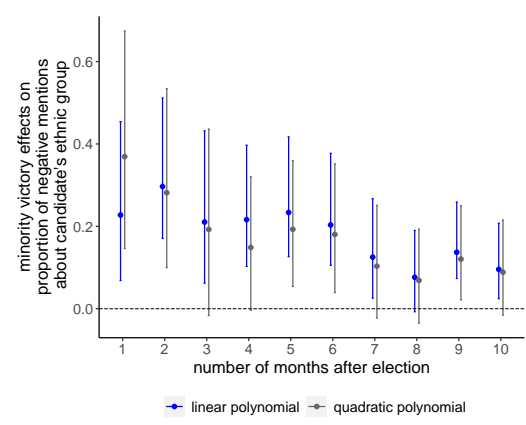

(c) Sensitivity to order of polynomial

Notes: (a), (b) test for sensitivity to the choice of bandwidth. In (a) MSE stands for mean squared error optimal bandwidth and in (b) CER refers to a bandwidth that minimizes the coverage error from the robust biased corrected confidence intervals obtained with the MSE-optimal bandwidth. The values next to the 'MSE', 'CER', labels indicate the bandwidth size. (c) tests for sensitivity to the choice of polynomial order by comparing estimates with local-linear and quadratic polynomials.

Figure J.4: Sensitivity to bandwidth size

the sentence contains keywords (and their derivatives) related to these topics (e.g. offence, attack, hate crime, harassment, violence, victim). Note that article sentences containing such keywords are not necessarily reporting hate crime, but instead discussing other topics related to immigrant and ethnic minority groups (like their background as marginalized groups or ethnic relations in general). Therefore, our classification may be an overcount of hate crime mentions about candidates' ethnic groups. We find that $5.3 \%$ of mentions about the candidates' ethnic groups cover hate crime (or xenophobia). However, we also find that our results are robust to excluding such articles (Figure J.5b), suggesting that our measures of hate crime and negative media coverage are independent.

\section{K Explaining effects on media attention and tone}

We assess whether there is an association between the political alignment of newspapers and the increase in speech about migrant groups with a specific valence (negative and positive). To do so, we classify the newspapers into right-wing or not right-wing using Wordscores (Laver, Benoit and Garry, 2003) (as implemented by the R package quanteda) with 2017 party manifestos as reference texts and expert surveys as exogenous scores. The party manifestos are from Burst et al. (2020) and the expert surveys from Norris (2020). The party scores are the average value of experts' party placements on economic and social issues. We consider that all newspapers with computed scores to the right of the most left-leaning self-identified right-wing newspaper are right-wing. This classification has an accuracy of $73 \%$, measured against newspaper self-identification, which we extract from Wikipedia infoboxes, and is available for 22/156 newspapers.

In Figure K.1a we present the RD estimates of the effects of a minority win on valence of migrant groups for newspapers that support a candidate's party (based on political alignment) and nonsupportive papers. These estimates suggest that the negative mentions are indeed driven by newspapers that do not support the parties - the minority victory effects on the proportion of negative mentions are bigger for mentions from non-supportive newspapers than supportive newspapersbut the coefficients also suggest that non-supportive newspapers contribute with the positive men- 
Table J.1: Ethnic minority victory effects on media tone about migrant groups

\begin{tabular}{ccccccccccc}
\hline $\begin{array}{c}\text { RD } \\
\text { estimate }\end{array}$ & se & $\begin{array}{c}\text { p- } \\
\text { value }\end{array}$ & $\begin{array}{c}95 \% \\
\text { CI }\end{array}$ & $\begin{array}{c}\text { mean } \\
\text { control }\end{array}$ & $\begin{array}{c}\text { sd } \\
\text { effect }\end{array}$ & $\begin{array}{c}\text { MSE- } \\
\text { opt bw }\end{array}$ & $\begin{array}{c}\text { eff. } \\
\text { N }\end{array}$ & N & cov & month \\
\hline 0.080 & 0.106 & 0.331 & {$[-0.104,0.309]$} & 0.189 & 0.269 & 24.77 & 142 & 438 & no & 1 \\
0.228 & 0.098 & 0.008 & {$[0.069,0.454]$} & 0.115 & 0.998 & 14.37 & 70 & 438 & yes & 1 \\
0.123 & 0.097 & 0.078 & {$[-0.019,0.362]$} & 0.135 & 0.417 & 14.34 & 138 & 876 & no & 2 \\
0.297 & 0.087 & 0.000 & {$[0.171,0.512]$} & 0.025 & 1.088 & 10.53 & 92 & 876 & yes & 2 \\
0.102 & 0.101 & 0.165 & {$[-0.058,0.339]$} & 0.217 & 0.321 & 16.44 & 240 & 1314 & no & 3 \\
0.210 & 0.094 & 0.009 & {$[0.062,0.432]$} & 0.193 & 0.674 & 12.13 & 165 & 1314 & yes & 3 \\
0.121 & 0.072 & 0.030 & {$[0.015,0.297]$} & 0.210 & 0.393 & 14.57 & 284 & 1752 & no & 4 \\
0.216 & 0.075 & 0.001 & {$[0.103,0.397]$} & 0.183 & 0.724 & 11.65 & 208 & 1752 & yes & 4 \\
0.144 & 0.075 & 0.016 & {$[0.033,0.329]$} & 0.176 & 0.474 & 13.42 & 320 & 2190 & no & 5 \\
0.234 & 0.074 & 0.000 & {$[0.126,0.417]$} & 0.159 & 0.781 & 10.69 & 235 & 2190 & yes & 5 \\
0.124 & 0.076 & 0.040 & {$[0.007,0.305]$} & 0.169 & 0.419 & 14.59 & 432 & 2628 & no & 6 \\
0.203 & 0.069 & 0.001 & {$[0.105,0.377]$} & 0.163 & 0.699 & 11.89 & 318 & 2628 & yes & 6 \\
0.065 & 0.067 & 0.195 & {$[-0.045,0.219]$} & 0.189 & 0.223 & 16.51 & 567 & 3066 & no & 7 \\
0.125 & 0.062 & 0.017 & {$[0.026,0.267]$} & 0.180 & 0.428 & 14.53 & 497 & 3066 & yes & 7 \\
0.043 & 0.056 & 0.258 & {$[-0.046,0.173]$} & 0.196 & 0.145 & 16.45 & 648 & 3504 & no & 8 \\
0.076 & 0.050 & 0.070 & {$[-0.007,0.190]$} & 0.197 & 0.255 & 16.60 & 656 & 3504 & yes & 8 \\
0.068 & 0.057 & 0.111 & {$[-0.021,0.201]$} & 0.177 & 0.227 & 15.41 & 693 & 3942 & no & 9 \\
0.137 & 0.047 & 0.000 & {$[0.073,0.259]$} & 0.169 & 0.463 & 14.23 & 612 & 3942 & yes & 9 \\
0.042 & 0.054 & 0.267 & {$[-0.046,0.167]$} & 0.193 & 0.140 & 16.79 & 830 & 4380 & no & 10 \\
0.096 & 0.047 & 0.013 & {$[0.024,0.207]$} & 0.186 & 0.318 & 15.61 & 770 & 4380 & yes & 10 \\
\hline
\end{tabular}

Notes: The dependent variable is the monthly proportion of negative mentions in news articles about a candidate's ethnic group. RD estimate is computed with local-linear regression within a symmetric MSE-optimal bandwidth. $s e$ is the conventional standard error, p-value and $95 \% C I$ are robust bias-corrected. mean control indicates the average proportion of negative news article mentions about the barely losing candidate's ethnic group. $s d$ effect presents the RD estimate in standard deviations, MSE-opt bw is the MSE-optimal bandwidth of vote-share winning margin around the victory threshold, eff. $N$ is the sample size within the MSE-optimal bandwidth and $N$ is the sample size. cov is a vector of controls including whether the candidate is the incumbent, from a left-leaning party, a woman, a first-generation immigrant, the constituency vote share for UKIP and BNP in the previous election, constituency share that shares the candidate's ethnic background, shares of foreign born, with a minority religion, young population, single, with level 1 qualifications, with social grade DE, unemployed, and share of households with 4 or more deprivations, and in social tenure. Standard errors are clustered by constituency-election. News articles were extracted from Common Crawl, ethnic background of candidates is constructed by the authors, and constituency characteristics from 2001 and 2011 UK Decennial Census.

tions. Furthermore, when we compute the minority win effects for right- and left-wing newspapers (Figure K.1b), we find evidence that the increase in negative mentions is mostly driven by right-wing newspapers, and that at least for the first quarter after the election, left-wing newspapers contribute the most to the increase in positive mentions about a candidate's ethnic group. Moreover, the estimates of the RD effects of a minority win on the tone of newspapers by their circulation (above or below 25,000 copies), suggest that during the first months after the election the positive mentions about a winning candidate's ethnic group are contributed by papers with a circulation of more than 25,000 copies, while smaller papers drive the negative mentions (Figure K.1c). 


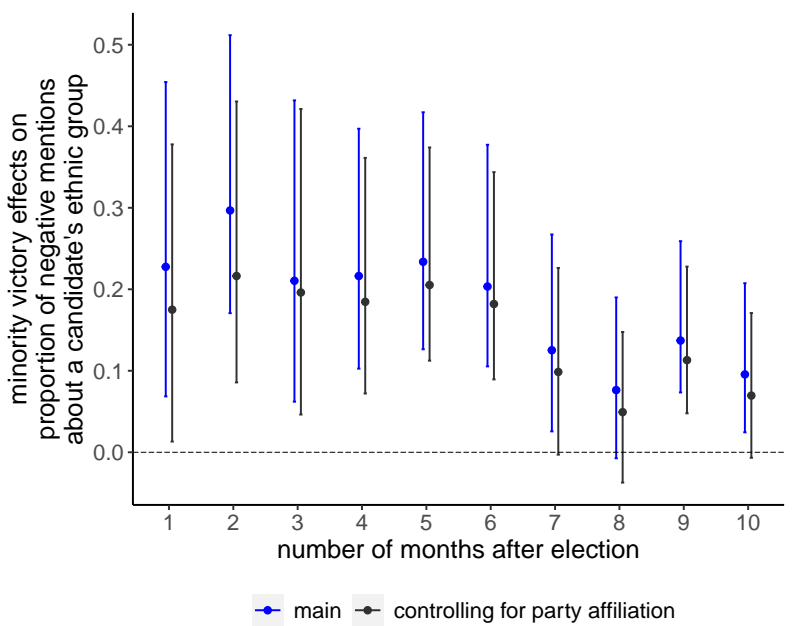

(a) Isolating the ethnic identity of candidates from their political party

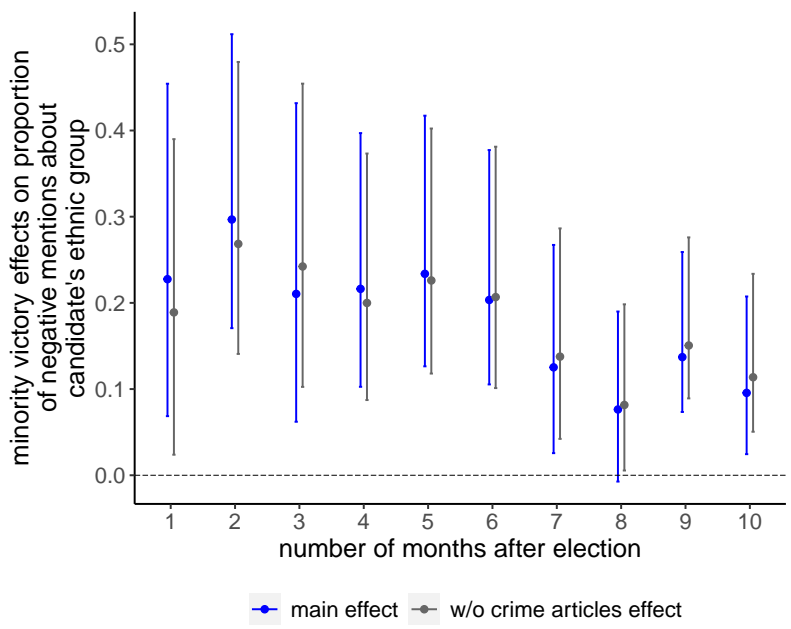

(b) Ethnic minority victory effects on media tone excluding mentions covering hate crime

Notes: Points are RD estimates of the effect of an ethnic minority victory on hate crimes per 1000 residents and lines $95 \%$ robust bias-corrected confidence intervals.

Table K.1: Minority victory effects across media valence categories

\begin{tabular}{cccc}
\hline month & (negative - positive) & (negative - neutral) & (positive - neutral) \\
\hline 1 & 0.76 & 2.50 & 1.72 \\
2 & 1.90 & 2.83 & 0.62 \\
3 & 0.78 & 1.68 & 1.25 \\
4 & 0.44 & 2.11 & 1.96 \\
5 & 0.78 & 1.88 & 1.44 \\
6 & 0.84 & 1.41 & 0.88 \\
7 & -0.33 & 0.75 & 1.29 \\
8 & -1.05 & -0.03 & 0.91 \\
9 & 0.59 & 1.00 & 0.55 \\
10 & -0.14 & 0.63 & 0.87 \\
\hline
\end{tabular}

Notes: Values indicate the $t$-statistic of the difference between the RD estimates of the effects of a minority win on the proportion of negative, positive, and neutral mentions about a candidate's ethnic group in the media. Values larger than the critical value of 1.96 are statistically significant. 


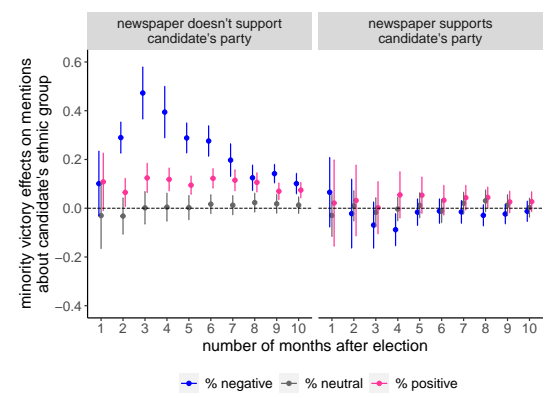

(a) Effects by newspaper-party political alignment
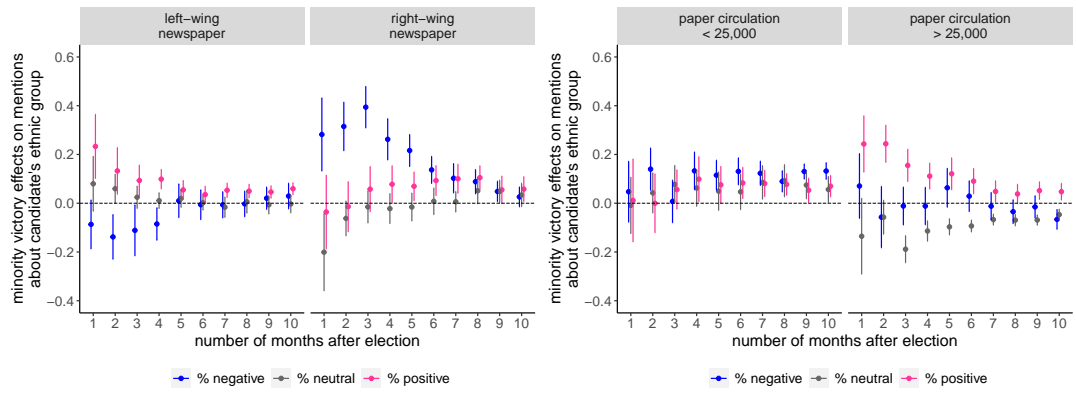

(b) Effects by newspaper ideol-(c) Effects by newspaper circulaogy tion

Notes: Points are RD estimates of the effect of an ethnic minority victory and lines $95 \%$ robust bias-corrected confidence intervals.

Figure K.1: Ethnic minority victory effects on media tone by newspaper-party political alignment, paper ideology, and circulation 


\section{References for Appendix}

Burst, Tobias, Werner Krause, Pola Lehmann, Jirka Lewandowski, Theres Matthieb, Nicolas Merz, Sven Regel and Lisa Zehnter. 2020. "Manifesto Corpus.". Berlin: WZB Berlin Social Science Center.

Callaway, Brantly, Pedro HC Sant'Anna et al. 2018. "Difference-in-differences with multiple time periods and an application on the minimum wage and employment." arXiv preprint arXiv:1803.09015 pp. 1-47.

Calonico, Sebastian, Matias D Cattaneo and Rocio Titiunik. 2014. "Robust nonparametric confidence intervals for regression-discontinuity designs." Econometrica 82(6):2295-2326.

Canay, Ivan A and Vishal Kamat. 2018. "Approximate permutation tests and induced order statistics in the regression discontinuity design." The Review of Economic Studies 85(3):1577-1608.

Cattaneo, Matias D, Michael Jansson and Xinwei Ma. 2020. "Simple local polynomial density estimators." Journal of the American Statistical Association 115(531):1449-1455.

De la Cuesta, Brandon and Kosuke Imai. 2016. "Misunderstandings about the regression discontinuity design in the study of close elections." Annual Review of Political Science 19:375-396.

Laver, Michael, Kenneth Benoit and John Garry. 2003. "Extracting policy positions from political texts using words as data." American political science review 97(2):311-331.

McCrary, Justin. 2008. "Manipulation of the running variable in the regression discontinuity design: A density test." Journal of econometrics 142(2):698-714.

Norris, Pippa. 2020. "Global Party Survey, 2019.".

URL: https://doi.org/10.7910/DVN/WMGTNS

Rathje, Steve, Jay J Van Bavel and Sander Van Der Linden. 2021. "Out-group animosity drives engagement on social media." Proceedings of the National Academy of Sciences 118(26):e2024292118.

Socher, Richard, Alex Perelygin, Jean Wu, Jason Chuang, Christopher D Manning, Andrew Y $\mathrm{Ng}$ and Christopher Potts. 2013. Recursive deep models for semantic compositionality over a sentiment treebank. In Proceedings of the 2013 conference on empirical methods in natural language processing. pp. 1631-1642.

$\mathrm{Xu}$, Yiqing. 2017. "Generalized synthetic control method: Causal inference with interactive fixed effects models." Political Analysis 25(1):57-76. 